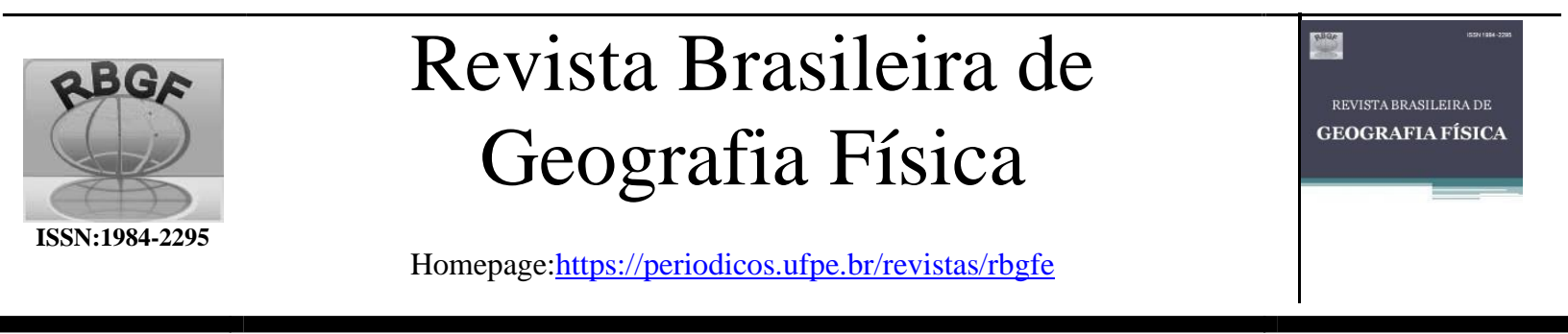

\title{
Variação sazonal das redes de interações planta-artrópodes em Floresta Tropical Sazonalmente Seca
}

\author{
Joanny Kelly Silva dos Santos Martins ${ }^{1}$, Antônio Fernando Morais de Oliveira ${ }^{2}$, Jarcilene \\ Silva de Almeida ${ }^{3}$
}

\begin{abstract}
${ }^{1}$ Universidade Federal de Pernambuco-UFPE, Avenida Prof. Moraes Rego, n. 1235, Cidade Universitária, Recife-PE, Brasil. CEP: 50670-9010. E-mail: joanny.bio@gmail.com. ${ }^{2}$ Universidade Federal de Pernambuco-UFPE, Avenida Prof. Moraes Rego, n. 1235, Cidade Universitária, Recife-PE, Brasil. CEP: 50670-9010. E-mail: afmoliveira@gmail.com. ${ }^{3}$ Universidade Federal de Pernambuco-UFPE, Avenida Prof. Moraes Rego, n. 1235, Cidade Universitária, Recife-PE, Brasil. CEP: 50670-9010.E-mail: jarcilene.almeida@ufpe.br
\end{abstract}

Artigo recebido em 12/06/2020 e aceito em 24/08/2020

\begin{abstract}
R E S U M O
O presente artigo apresenta uma visão ampla das interações entre plantas e artrópodes na Caatinga, destacando o papel da sazonalidade climática na disponibilidade e qualidade dos recursos vegetais, bem como os efeitos destes fatores na produção de defesas químicas vegetais, interações mutualísticas, e interações antagônicas como a herbivoria. Os efeitos indiretos de um nível trófico sobre outro na Caatinga também são relatados. A Caatinga e outras florestas secas compartilham várias características, como a prevalência do sistema de polinização biótico e a dispersão abiótica de sementes. A alta frequência de plantas com nectários extraflorais possibilita uma ampla gama de interações entre plantas e artrópodes, especialmente com formigas. Porém, todas estas interações apresentam custos e benefícios de forma variável, tendo como a principal justificativa a sazonalidade dos fatores abióticos. Além da fragmentação em virtude de ações antrópicas, as mudanças climáticas já se mostram críticas sobre vários aspectos da ecologia da Caatinga. Assim, a quebra ou alterações nas interações tróficas causam efeitos múltiplos em vários níveis biológicos distintos que irão repercutir desde o nível de população ao nível de ecossistemas. Portanto é essencial a compreensão das interações ecológicas em termos de dinâmica florestal para que só assim ocorra de forma apropriada o planejamento para restauração e práticas adequadas de conservação na Caatinga.
\end{abstract}

Palavras-chave: Caatinga, Polinização, Herbivoria, Predação, Fator abiótico.

\section{Seasonal variation of networks of plant-arthropod interactions in Seasonally Dry Tropical Forest}

\begin{abstract}
A B S T R A C T
This article presents a broad view of the interactions between plants and arthropods in the Caatinga, highlighting the role of climatic seasonality in the availability and quality of plant resources, as well as the effects of these factors in the production of plant chemical defenses, mutualistic interactions, and antagonistic interactions as herbivory. The indirect effects of one trophic level on another in the Caatinga ecosystem are also reported. The Caatinga and other dry forests share several characteristics, such as the prevalence of the biotic pollination system and the abiotic dispersion of seeds. The high frequency of plants with extrafloral nectaries allows a wide range of interactions between plants and arthropods, especially with ants. However, all these interactions present their costs and benefits in a variable way, with the main justification for the seasonality of abiotic factors. The Caatinga has been undergoing fragmentation due to anthropic actions and climate change is already showing criticism about various aspects of the ecology of this ecosystem. Thus, the breakdown or changes in the trophic interactions cause multiple effects at several different biological levels that will have repercussions from the population level to the level of ecosystems. It is essential the understanding of the ecological interactions in terms of forest dynamics to planning properly for restoration and best conservation practices in the Caatinga.
\end{abstract}

Keywords: Caatinga, Pollination, Herbivory, Predation, Abiotic factor 


\section{Introdução}

Atualmente os programas para a conservação da biodiversidade têm se preocupado principalmente com levantamentos de espécies e mecanismos intrínsecos ou de funcionamento dos ecossistemas, além da manutenção da variabilidade genética. Porém, as prioridades vêm se modificando recentemente no sentido de promover uma visão mais ampla e integrada da biodiversidade, onde a preocupação deixa de ser apenas frequências e abundâncias relativas de espécies, e passam a ser os conjuntos de interações (Del-Claro e Torezan-Silingardi, 2012).

A esta tentativa de retratar a biodiversidade como conjuntos integrados de organismos se denominou "biodiversidade interativa" (interaction biodiversity, sensu Thompson, 1997), um assunto de muito interesse atual. Assim estudos de ecologia de interações, voltados para a compreensão do impacto das relações entre organismos sobre a biodiversidade das comunidades e ecossistemas que integram, representam um novo e estimulante desafio.

Neste contexto as Florestas Tropicais Sazonalmente Secas (FTSS) ocorrem em áreas fragmentadas que estão espalhadas pela região Neotropical. De acordo com Pennington et al. (2009), foi a persistência desta fragmentação ao longo de muito tempo que influenciou a evolução e a biogeografia de linhagens vegetais e toda a biota a elas associada.

Muito embora, as Florestas Tropicais Úmidas sempre tenham sido consideradas hotspots em termos de interações planta-animal (Bronstein, 2015), estudos recentes demonstraram que as FTSS também exibem altos níveis de dependência nas interações entre os parceiros mutualistas, incluindo produção de recursos alimentares mediando os serviços de polinização (Machado e Lopes, 2004; Quesada et al., 2011; Sànchez-Azofeifa et al., 2014), além de alta complexidade nas interações planta-animal, envolvendo alto grau de especificidade.

Um aspecto crucial inerente as FTSS são as mudanças sazonais que influenciam a dinâmica física e química dos vegetais deste ecossistema, afetando consequentemente diferentes grupos de animais, não apenas em virtude das mudanças nutricionais vegetais como também, em consequência das mudanças fenológicas, que, portanto, constituem um importante processo temporal (Malheiros, 2016).
A principal mudança estrutural desse ecossistema resulta da deciduidade foliar durante a estação seca, que reduz a produtividade das plantas, seguido por um período de maior concentração de chuvas (Sanchez-Azofeifa et al., 2005). Assim, o efeito da sazonalidade em florestas secas tem implicações importantes sobre os padrões fenológicos das plantas, bem como sobre a abundância, riqueza e composição da fauna associada (Cuevas-Reyes et al., 2006; Martins et al., 2018).

No Brasil, a Caatinga representa um mosaico de floresta tropical sazonal seca, onde cerca de $80 \%$ destas áreas passam por processo de regeneração natural (Cabral et al., 2013). Além disso, a Caatinga consiste na maior e mais diversa mancha de floresta seca nos Neotrópicos (Silva et al., 2017), apresentando uma grande diversidade de interações entre plantas e animais. Porém, embora estes fatores tenham importância para a manutenção da biodiversidade, estrutura de comunidades, além de fornecimento de serviços ecossistêmicos e sustentabilidade, estudos básicos de interações planta-animal neste ecossistema ainda são escassos em comparação com outros ecossistemas (Del-Claro, 2004; Leal et al., 2018).

A Caatinga vem sofrendo alterações desde os primeiros séculos de descoberta (Andrade, 2005). É possivelmente o ambiente mais negligenciado, descuidado e degradado, sendo, assim, o menos protegido do país (Santos et al., 2011; Koch et al., 2017). De acordo com Pereira et al. (2004), a exploração consciente e racional de qualquer ecossistema só pode ser delineada a partir do conhecimento de suas dinâmicas biológicas.

Diante do que foi exposto, o presente artigo apresenta uma breve revisão das interações entre plantas e artrópodes no ecossistema Caatinga, elucidando o papel da sazonalidade climática na disponibilidade e qualidade dos recursos vegetais, bem como os efeitos destes fatores na I) produção de defesas químicas vegetais; II) interações mutualísticas de polinização e dispersão de sementes; III) interações antagônicas como herbivoria e IV) os efeitos indiretos de um nível trófico sobre outro mediados pela sazonalidade e temporalidade dos recursos no ecossistema Caatinga. Além das perspectivas futuras para estudos de interações, enfocaremos também a importância de estudos em vegetação de Caatinga em detrimento a outras florestas tropicais secas. 


\section{A Caatinga dentro do cenário de Florestas Tropicais Sazonalmente Secas (FTSS)}

O Neotrópico possui vasta área de Floresta Tropical Sazonalmente Seca (FTSS). Estas Florestas são encontradas em áreas espalhadas, com a maior riqueza de espécies no México, mas níveis similares de diversidade podem ser encontrados no Peru e Bolívia, por exemplo (Lima et al., 2018). Os níveis de similaridade florística entre as áreas são geralmente baixos, e em algumas áreas (e.g. Caatinga, Vales Inter-Andinos peruanos, e a Costa Pacífica do México) são ricas em espécies endêmicas, enquanto outras (e.g. Chiquitano Boliviano) não o são (Spichiger et al., 2004).

Pennington et al. (2006), embasou a definição de FTSS em estudos desenvolvidos por Murphy e Lugo (1986), assumindo uma ampla interpretação com a inclusão de formações que abrangem desde florestas de copa elevada em regiões úmidas, até florestas de cactos nas áreas mais secas.

As FTSS abrangem cerca de $42 \%$ das florestas tropicais no mundo, das quais $51 \%$ estão nas Américas (Pennington et al., 2009; SánchezAzofeifa, 2010; Bastin et al., 2017). Por conta desta grande territorialidade, as médias de precipitação são bastante variadas, indo de 250 a $2000 \mathrm{~mm}$ (Sánchez-Azofeifa, 2010), com períodos de pelo menos 5 a 6 meses recebendo menos que $100 \mathrm{~mm}$ (Pennington et al., 2006). Entretanto, apresenta uma variabilidade temporal e espacial marcante (Reddy, 1983). Por exemplo, 20\% da precipitação total anual pode ocorrer em apenas um dia e $60 \%$ em um único mês (Sampaio, 1995). Tais fatores abióticos são correlacionados com a duração da estação seca, e com os limites de latitude da região (Sanchez-Azofeifa et al., 2005). Estas florestas desenvolvem-se, geralmente, em solos férteis associados a rochas calcárias, com moderado a elevados valores de $\mathrm{pH}$ e nutrientes, e baixos níveis de alumínio, sendo adequados a agricultura e pecuária (Pennington et al., 2006). A sua vegetação tem por característica a deciduidade das plantas, em que praticamente todas as espécies de árvores nativas perdem suas folhas durante a estação seca (Nascimento et al., 2007). Entretanto, é verificado um aumento de espécies suculentas e de árvores que sempre se mantêm verdes (Pennington et al., 2009).
O bioma é considerado um dos mais importantes, visto sua grande diversidade de fauna e flora e alta taxa de endemismo, e diversidade de interações (Leal et al., 2018) e também o mais ameaçado quando se trata de fragmentação e degradação ambiental (Espírito-Santo et al., 2006; Quesada et al., 2009; Portillo-Quintero; SanchezAzofeifa, 2010; Santos et al., 2011).

Prado e Gibbs (1993) e Pennington et al. (2000) compararam a atual distribuição das FTSS na América do Sul, mostrando que mais de 100 espécies não relacionadas filogeneticamente possuem um padrão similar de distribuição, formando quatro núcleos disjuntos de FTSS organizados diagonalmente ao sul da Amazônia. São eles: Andino, Chiquitano, de Misiones, Piedmont Andino, e da Caatinga. A maior área de FTSS ocorre ao sul da floresta tropical Amazônica, formando uma distribuição disjunta, conectadas pelo Cerrado e Chaco, que juntos formam uma "Diagonal Seca" de floresta entre a Caatinga e as FTSS do Piedmont Andino (Mayle, 2006). Assim, o Cerrado, a Caatinga, o Chaco e as FTSS formam a chamada "Diagonal de formações abertas", ou "Diagonal Seca" (Prado e Gibbs, 1993).

Porém, em relação à vegetação seca no Neotrópico, é importante definir e fazer a distinção entre FTSS e savanas, embora a relação entre essas formações seja complexa. As FTSS constituem um ecossistema dominado por árvores com dossel contínuo ou quase contínuo e as gramíneas são elementos pouco presentes, enquanto uma cobertura xeromórfica e tolerante ao fogo é um importante componente das savanas (Pennington et al., 2006; Lima et al., 2018). Com menos características bióticas e abióticas compartilhadas com a FTSS e as savanas, o Chaco apresenta o clima semiárido, fortemente sazonal com verões de temperatura elevada e ocorrência de geadas no inverno (Prado, 1993).

As áreas mais extensas de savana no Neotrópico são encontradas no ecossistema brasileiro, o Cerrado, representando $23 \%$ da área do país com aproximadamente 2 milhões de $\mathrm{km}^{2}$ (Lima et al., 2018). Deste modo, Ratter et al. (1997) definem as savanas, e isto inclui os Cerrados, pela riqueza de gramíneas que cobrem o solo, apresenta características climáticas similares, com áreas um pouco mais úmidas e os solos menos férteis do que o observado para as FTSS. Goodland e Pollard (1973) relacionam essas diferenças na estrutura vegetal ao gradiente de fertilidade do solo, enquanto que Durigan e Ratter (2016) acrescentam ainda a frequência de ocorrência de fogo, que se trata de um fator ecológico e evolutivo importante 
no ecossistema e a flora lenhosa mostra adaptações, tais como: a espessura da casca do tronco; a cortiça; o xilopódio e o crescimento de gemas laterais, quando a gema apical é danificada ou destruída pelas chamas (Lima et al., 2018).

No Brasil, a Caatinga é o maior e mais isolado núcleo de FTSS da América do Sul (Prado, 2003), além de ser a mais diversa área dentre as Florestas Tropicais Sazonalmente secas da região Neotropical (Silva et al., 2017), ocupando cerca de $11 \%\left(912.529 \mathrm{Km}^{2}\right)$ do país (Silva et al., 2017; Santos et al., 2014), sendo predominante no Nordeste do Brasil (Prado, 2003). Ocorre em clima semiárido com um elevado potencial de evapotranspiração (1.500-2.000 mm/ano), baixa precipitação (300-1.000 mm/ano) e estação seca de 6 a 11 meses (Queiroz, 2006; Moro et al., 2016). É caracterizada por uma floresta baixa composta de pequenas árvores e arbustos, frequentemente com troncos retorcidos e espinhos, com folhas muito pequenas que são decíduas na estação seca. As plantas suculentas da família Cactaceae são comuns e há presença de herbáceas no solo na curta estação chuvosa (Queiroz, 2006; Silva et al., 2012; Tavares et al., 2016).

Vários tipos de solos são encontrados na região, formando um mosaico retalhado, com mudanças de um tipo de solo para outro, frequentemente ocorrendo com poucos metros de distância. Verifica-se desde solos rasos e pedregosos, associados à imagem típica do sertão seco coberto por cactáceas, a solos arenosos e profundos que dão lugar às caatingas de areia (Velloso et al., 2002). Em termos geológicos, a Caatinga é separada em dois ambientes: o cristalino - de maior abrangência - e o sedimentar. Há ainda, espalhados pela região, terrenos cárticos, geralmente constituídos de rocha calcária (Moro et al., 2016).

Velloso et al. (2002), propuseram a subdivisão da Caatinga em oito ecorregiões, com base na similaridade da biodiversidade e fatores abióticos, são elas: 1) Complexo de Campo Maior; 2) Complexo Ibiapaba; 3) Depressão Sertaneja Setentrional; 4) Planalto da Borborema; 5) Depressão Sertaneja Meridional; 6) Dunas do São Francisco; 7) Complexo da Chapada Diamantina; e 8) Raso da Catarina.

A Caatinga apresenta uma heterogeneidade marcante com várias fisionomias o que faz dela um ambiente de extrema importância biológica, tornando o cenário atraente para pesquisa, no entanto as espécies neotropicais são pouco estudas, sendo ainda desconhecidas ou pouco compreendidas acerca de seus aspectos ecológicos, origem, história evolutiva e manutenção dessa elevada biodiversidade (Antonelli e San-Martin, 2011; Turchetto-Zolet et al., 2013).

A forte sazonalidade do ecossistema Caatinga e de outras FTSS concentra praticamente toda dinâmica de interações seja com herbívoros (Santos et al., 2011; Paula et al., 2011), dispersores, ou polinizadores durante a estação chuvosa, onde há uma maior concentração de recursos vegetais, ou seja maior emissão de folhas (Sena et al., 2017) e flores (Martins et al., 2018; Martins et al., 2020a), e consequentemente frutos (Silva et al., 2018; Poorter et al., 2019; Schulz et al., 2019)

Apesar da água ser um fator limitante (Sousa et al., 2015), a devastação e a fragmentação da Caatinga podem ser considerados como um dos impactos ambientais e de maior relevância para o semiárido brasileiro (Siegmund-Schultze et al., 2018), por se tratar de uma das principais causas de extinção, reduzindo os habitats disponíveis para a fauna e flora locais, e aumentando assim, o grau de isolamento entre as populações, gerando perdas de variabilidade genética. Este desparecimento da Caatinga tem maior relevância se considerarmos os altos níveis de endemismo da flora e fauna deste ecossistema, haja vista que o desaparecimento destas espécies mesmo antes de serem estudadas, dificulta o entendimento dos processos ecológicos e, consequentemente, de ações para minimizar esses impactos.

Além disso, diante dos cenários das mudanças climáticas globais, as plantas e animais da Caatinga constituem um patrimônio biológico de valor incalculável. Essas espécies estão totalmente adaptadas às condições locais, apresentando estratégias para conviver com a escassez de água, a irregularidade das chuvas, as altas temperaturas (Santos et al., 2014).

A flora da Caatinga desempenha importante papel na relação com a fauna seja como fonte forrageira para animais silvestres e domésticos, ou no fornecimento de néctar, pólen, óleos e resinas para diversos grupos de visitantes (abelhas, borboletas, moscas, besouros, aves e morcegos) (Martins et al., 2018). Os frutos de suas espécies são utilizados como alimento para grandes e pequenos vertebrados e invertebrados. Esses animais utilizam também as espécies da Catinga como locais de nidificação (Martens et al., 2015).

Como mencionado, a Caatinga é o ecossistema menos estudado entre as regiões fitogeográficas brasileiras e o menos protegido pelas unidades de conservação e proteção integral (Leal et al., 2003; Santos et al., 2011; Koch et al., 
2017). Assim, levando em consideração a importância deste ecossistema como patrimônio natural, a fragmentação do habitat e suas características como diferenças de pluviosidade, alta radiação solar e baixa nebulosidade, além da alta taxa de evaporação e a consequente dessecação do solo ao longo de praticamente todo ano (Trovão et al., 2007; Vico et al., 2015), o estudo destes eventos são fundamentais para a construção de políticas públicas e para a conservação e uso sustentável dos recursos ofertados pelo ecossistema (Siegmund-Schultze et al., 2018). Haja vista que todos estes fatores afetam a estrutura e distribuição das comunidades vegetais, bem como, o padrão e diversidade das interações planta-animal (Méndez-Toribio et al., 2020; Buzzard et al., 2015; Falcão et al., 2017; Fonseca et al., 2018).

\section{Interações multitróficas e a sazonalidade dos fatores bióticos e abióticos}

Os organismos de populações vegetais e animais possuem suas individualidades, as quais não se devem apenas às diferenças quanto à fase de desenvolvimento individual, sexo, pool gênico ou ao acaso, mas também, às condições bióticas e abióticas locais (Morais e Almeida, 2004; Lima et al., 2010). As condições características de cada ambiente promovem a seleção e a prevalência de fenótipos mais ajustados ao ambiente nas populações ali presentes (Stebbins, 1970). Todo o processo de crescimento e reprodução das espécies tanto animais quanto vegetais demanda a interação de uma miríade de fatores com o meio, porém, como os vegetais compõem o primeiro nível trófico (produtores), estes são diretamente afetados pelas características edáficas e climáticas locais, muito mais intensamente que os animais (Rodriguez et al., 2016).

Os vegetais como produtores, necessitam para obtenção de seus nutrientes de recursos abióticos como os nutrientes do solo, a água e luz, que por sua vez, são recursos imprescindíveis para o desenvolvimento, crescimento, defesas contra herbivoria e reprodução (Almeida-Cortez, 2005). Os fatores bióticos, como polinizadores, herbívoros, dispersores de sementes, bactérias fixadoras de nitrogênio nas raízes, entre outros, também desempenham um papel importante na vida do vegetal e juntos compõem as interações multitróficas (Del-Claro, 2004). A maioria dos estudos, porém, experimenta, de forma separada, pressões seletivas exercidas simultaneamente por múltiplas interações, como mutualismo e antagonismo, no entanto a polinização, a herbivoria, a defesa por recursos, e as interações entre presa e predador devem ocorrer simultaneamente em um sistema multitrófico (Martins et al. 2018) (Figura 1)

Assim, as interações multitróficas constituem sistemas onde várias espécies interagem simultaneamente e a evolução dessas interações resulta do desenvolvimento de adaptações cada vez mais sofisticadas, capazes de promover associações como uma forma de sobrevivência dos organismos interagentes (Thompson, 1999; Robinson et al., 2017).

De acordo Putman (1994), embora se possa estudar separadamente cada componente de um sistema, na realidade eles se acham todos interligados, formando a grande cadeia da existência do universo. Num contexto ecológico, é fato que um organismo ou população de uma espécie não ocorre isoladamente. Os indivíduos, na verdade, fazem parte de um sistema complexo e interdependente com outros organismos, de tal maneira que a dinâmica de todos é afetada mutuamente. No entanto, estudar essas cadeias tróficas, constitui-se em um trabalho complexo. Em pesquisas entomológicas o que se observa é o estudo de três pontos dessa teia, geralmente estudos com planta (produtor primário), inseto fitófago (consumidor primário) e a influência dessa interação no predador ou parasitóide (consumidor secundário). Ou seja, estudo de populações em situações experimentais são ainda fragmentadas e simplificadas, nas quais diversas interações podem não estar presentes.

Em ambientes áridos e semiáridos como as FTSS, o estudo das interações multitróficas desempenha um papel fundamental na compreensão dos processos ecológicos que envolvem as espécies, haja vista que seus resultados indicam variações sazonais possivelmente capazes de afetar a abundância e a diversidade das espécies em um determinado ambiente natural (Thompson et al., 2005; Robinson et al., 2017; Martins et al., 2020b, c). Além disso, refletem eventos climáticos cíclicos, tais como as oscilações de temperatura e pluviosidade anuais (Morellato et al., 1989; Morellato et al., 2000). Também indicam variações regionais que distinguem ambientes próximos como, por exemplo, os fragmentos de um mesmo ecossistema regional que podem ser afetados distintamente ao longo do tempo (Markis e Braker, 1994). Tais fatores influenciam as espécies de maneira particular ou ainda com intensidade variada ao longo do tempo e do espaço. 
A exemplo da ação conjunta de fatores bióticos e abióticos, Falcão et al. (2015), avaliaram como a irregularidade das chuvas e incidência luminosa em ambientes de Caatinga, limita a disponibilidade de nitrogênio moldando estratégias vegetais e alterando os padrões de interações, além disto estes efeitos assumem uma maior magnitude quando se considera atividades antrópicas como a produção agrícola e a criação extensiva de animais.

Os fatores abióticos interferem diretamente na performance reprodutiva das plantas, afetando consequentemente as interações mutualísticas com polinizadores e dispersores de sementes. De acordo com Rathcke e Lacey (1985), em áreas tropicais com clima sazonal, a maioria das ervas e arbustos floresce na estação chuvosa, ou tem aumento na produção de flores nesta estação, o que favorece para uma maior abundância e melhor performance dos polinizadores (Carvalho e Oliveira, 2003; Mantovani et al., 2003; Munhoz e Felfili, 2005), sendo que a precipitação pluviométrica é o fator mais importante que influencia na extensão do nicho polínico de abelhas (Oliveira et al., 2009). Guedes et al. (2011), observou déficit de polinização durante a estação seca em área de Caatinga em espécies arbóreas nativas no sertão da Paraíba, enquanto Martins et al. (2020), para a mesma área, registraram uma redução significativa no número de visitas durante a estação seca em uma espécie perene da família Convolvulaceae. Estes resultados podem ser afetados não só por aspectos da fenologia como a disponibilidade floral, que por sua vez, influencia a quantidade e qualidade dos voláteis florais emitidos pelas flores durante as estações seca e chuvosa (Schiestl, 2014). As abelhas, por exemplo, são capazes de perceber compostos produzidos por flores e conseguem discriminar as diferentes proporções dos constituintes produzidos por diferentes plantas (Wright et al., 2005). Estudos desta natureza podem apontar os efeitos das mudanças climáticas sobre o desempenho reprodutivo de plantas da Caatinga.

Ainda a respeito das interações mutualísticas, os fatores bióticos e abióticos contribuem para determinar a habilidade das plantas dispersarem sementes e, portanto, atuariam como fatores de seleção sobre essa etapa em seu ciclo de vida (Rodríguez-Riaño et al., 2019). Supõe-se que nos ecossistemas com pluviosidade elevada e bem distribuída ao longo do ano, ocorre predomínio de plantas dispersas por vertebrados e, à medida que aumenta o grau de sazonalidade e diminui a precipitação, os ambientes tornam-se mais secos e os vetores abióticos, tais como o vento e a gravidade, vão ganhando importância (Griz et al., 2002). Apesar disso, dentre os invertebrados, as formigas desempenham nas FTSS um importante papel como dispersor secundário de sementes.

Nesta perspectiva, Leal et al. (2007), estudaram a dispersão por sementes na Caatinga e observaram que a família Euphorbiaceae é a que possui o maior número de espécies cujas sementes são manipuladas por formigas. Neves e Viana (2008), relataram que através desse processo de dispersão, as sementes são lançadas a curtas distâncias, aumentando a densidade próxima à planta-mãe, o que reduz a possibilidade de colonização de novas áreas na ausência de dispersores secundários.

Apesar dos esforços por parte dos ecólogos em avaliar o papel dos dispersores secundários na propagação de espécies vegetais da Caatinga, algumas questões ainda precisam ser avaliadas em estudos futuros, por exemplo: Como a identidade de formigas é afetada pela sazonalidade e, portanto, como isso se reflete no forrageamento das sementes durante a estação seca e chuvosa? Existe especificidade entre as espécies de formigas no modo de manipulação das sementes? Existe sincronia entre a fenofase de frutificação de certas espécies com o recrutamento de formigas? Estas interações são condicionais, onde as vantagens e desvantagens podem ser alteradas e completamente influenciadas por outros fatores bióticos e abióticos?

As interações antagonistas dentro do contexto de interações planta-artrópodes também são completamente influenciadas pela sazonalidade climática das FTSS, a exemplo deste tipo de interação abordaremos aqui a herbivoria. Del-Claro (2004a) cita que a grande diversidade de espécies vegetais característica das comunidades tropicais, tem sido atribuída a padrões espaciais de mortalidade de sementes e plantas jovens, resultante da ação de herbívoros (Del-Claro, 2004a; Tavares et al. 2016; Schulz et al. 2019). Assim a herbivoria pode desempenhar um importante papel na dinâmica populacional de plantas, provocando um incremento na taxa de mortalidade das espécies ou uma alteração nas relações competitivas entre as espécies (Ehrlén, 1995).

Segundo Coley e Barone (1996), os herbívoros normalmente selecionam as partes das plantas que apresentam estruturas compostas por celulose e açúcares, consumindo preferencialmente as folhas jovens e as flores. Deste modo, uma pressão intensa de herbivoria pode consumir uma elevada proporção de tecidos fotossintéticos. Além 
disso, uma intensa herbivoria das partes reprodutivas pode prejudicar a fecundação e o desenvolvimento de frutos e sementes. Logo, a herbivoria pode afetar o crescimento, desenvolvimento e recrutamento das plantas (DelClaro e Oliveira, 2000).

Todos esses fatores abióticos interferem na reprodução das plantas, que envolve direta e indiretamente muitos aspectos relacionados à sua ecologia e aos fatores bióticos, como o estado nutricional dos indivíduos (Kennedy et al., 1992). Atualmente estudos desta natureza vêm sendo realizados em área de Caatinga. Entre os aspectos estudados, alguns autores avaliaram estratégias adotadas por plantas da Caatinga em meio a pressão da herbivoria (Fernandes et al., 2012; Schulz et al., 2019; Silva et al., 2018; Santos et al., 2017). Já Martins et al. (2018), avaliaram como a sazonalidade afeta a distribuição temporal dos recursos vegetais e as implicações para a riqueza e abundância de herbívoros em uma área de Caatinga na Paraíba, Brasil. Além destes, outros autores avaliaram como o estresse hídrico (Leal et al., 2020) e nutricional afetam as estratégias de defesas anti-herbivoria (Aquino et al., 2017), e o papel de todos estes fatores em um cenário de regeneração florestal (Cabral et al., 2013; Poorter et al., 2019).

A respeito das defesas contra herbivoria, que serão tratadas com mais profundidade nos tópicos seguintes, Denslow et al. (1987), observaram em três espécies do gênero Piper (Piperaceae) e três do gênero Miconia (Melastomataceae), num experimento com manipulação de solo, que o aumento do nível de nutrientes disponíveis levou a um aumento na produção de compostos fenólicos em cinco das seis espécies que estudou. Gershenson (1984), notou que parte da variação intraespecífica no dano foliar está associada à presença de compostos químicos secundários, diretamente dependentes dos nutrientes presentes no solo. Vários autores (Gullan e Cranston, 2007; Eldridge et al., 2017; Dong et al., 2019), demonstraram que fatores como condições nutricionais e estresse hídrico podem proporcionar alterações na qualidade de plantas, afetando a palatabilidade e até mesmo o desenvolvimento dos artrópodes (Kerpel et al., 2006). Assim plantas sob estresse hídrico ou nutricional são consideradas mais susceptíveis ao ataque por herbívoros por possuírem maior disponibilidade de nitrogênio solúvel e menor concentração de compostos de defesa (White, 1984).

Dentro de um cenário multitrófico, existem ainda os efeitos de um nível trófico sobre o outro, como por exemplo, as relações entre mutualistas condicionais que se destacam as interações plantaformigas, que podem estar associadas a outras espécies animais em dois, três ou mais níveis tróficos, as plantas podem oferecer local para nidificação (domácias, ramos ocos ou mortos) ou alimento (nectários extraflorais, corpúsculos nutritivos ou exudações) (Janzen, 1966).

$\mathrm{Na}$ Caatinga, alguns trabalhos têm sido realizados a fim de compreender o papel das formigas associadas a Nectários extraflorais sobre a proteção contra herbívoros, e os fatores que levam a mudanças destes resultados (Martins et al., 2020b). Além disso, Martins et al. (2020c) avaliaram como a sazonalidade dos fatores bióticos e abióticos em área de Caatinga alteram os resultados de proteção das plantas por formigas associadas a Nectários Extraflorais, os efeitos destas alterações sobre o índice de herbivoria e sobre a taxa de frutificação da planta.

Os resultados desta interação dependem de uma miríade de fatores como a identidade e abundância das formigas, a qualidade e quantidade do néctar extrafloral, a estratégia de forrageamento e recrutamento das formigas e a identidade e comportamento dos herbívoros (Apple e Feener Jr., 2001; Bächtold et al., 2014; Paz et al., 2016; Martins et al., 2020b), e todos estes fatores são fortemente influenciados pela sazonalidade dos índices de precipitações pluviométricas em Florestas Tropicais Secas (Silva e Del-Claro, 2014)

Desta forma o estudo das interações multitróficas associados a sazonalidade de fatores bióticos e abióticos desempenha papel fundamental na compreensão dos processos ecológicos que envolvem as espécies. A FTSS da América do Sul é o bioma menos estudado neste continente, principalmente quanto as interações entre plantas e artropodofauna associada. Porém, apesar de nos últimos anos terem focado esforços em tentar desvendar os diferentes aspectos da ecologia inseto-planta (Silva e Del-Claro, 2014), muito ainda resta a ser investigado no ecossistema Caatinga, principalmente no que diz respeito aos fatores que levam a variações nos papéis dos organismos que compõem estas interações (Leal et al., 2018; Martins et al., 2020 a, b, c). 


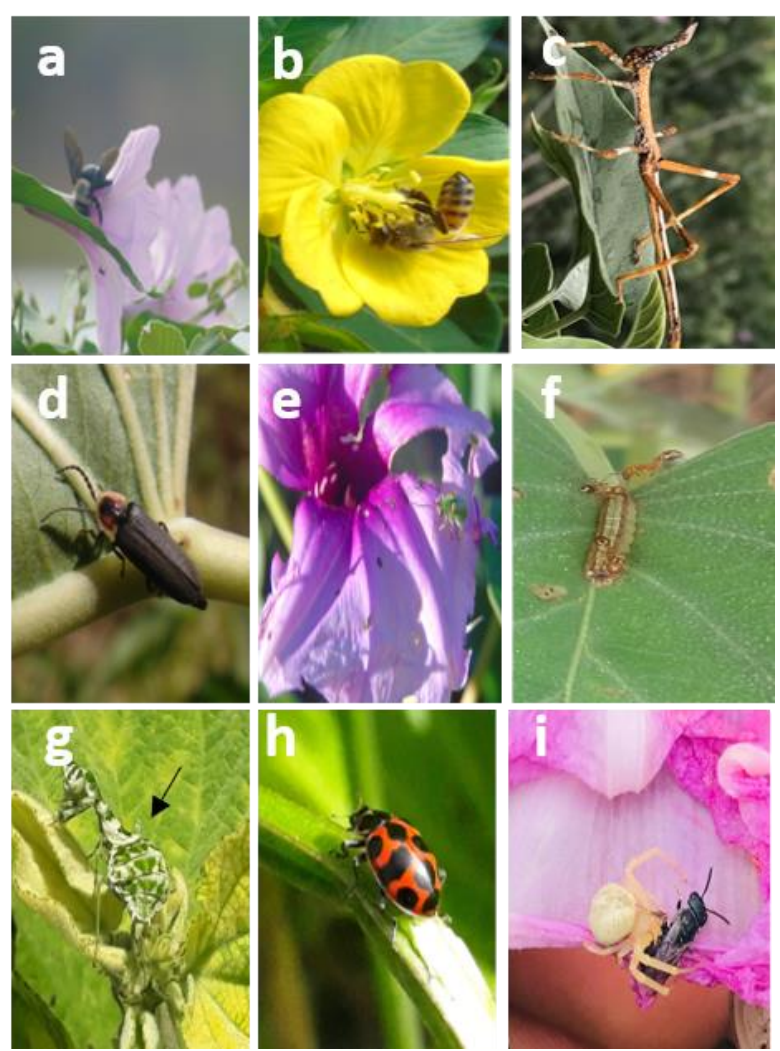

Figura 1. Interações multitróficas no ecossistema Caatinga, Paraíba, Brasil. a) Flor de Ipomoea carnea subs. fistulosa sendo visitada pela abelha Xylocopa frontalis; b) Espécie de Turneraceae sendo visitada por Apis melifera; c) Folha de I. carnea subs. fistulosa sendo herbivorada por um Phasmatodea; d) Coleptera Chantaridae forrageando Nectário Extrafloral em I. carnea subs. fistulosa e) Florivoria em I. carnea subs. fistulosa por Diabrotica speciosa; f) Mirmecofilia entre formigas do gênero Solepsis e larvas de Lepidoptera da família Lycaenidae; g) Mantodea (predador) forrageando camuflado (seta) em uma Euphorbiaceae; h) Coleomegilla maculata (predador) forrageando em I. carnea subs. fistulosa; i) Aranha da família Thomisidae predando abelha polinizadora em I. carnea subs. fistulosa.

\section{A importância da entomofilia na Caatinga: Polinização biótica}

Plantas com flores são recursos extremamente ricos na natureza, atraindo simultaneamente uma grande variedade de organismos tanto mutualistas (e.g. polinizadores e dispersores) quanto antagonistas, como herbívoros (Karban e Baldwin, 1997; Alves-dos-Santos et al., 2016; Antiqueira e Romero, 2016; Martins et al., 2018), enfrentando assim um trade-off na atratividade destes organismos (Galen, 1999; Cariveau et al., 2004).

A interação entre flores e seus polinizadores é um processo ecologicamente importante por se tratar de um mecanismo essencial para que a reprodução sexual cruzada ocorra. Essas interações afetam uma variedade de processos ecológicos e evolutivos (Silva et al., 2018; Paz et al., 2016), e são cruciais para o funcionamento dos ecossistemas terrestres (Kevan, 1999). Este é o tipo de interação planta-animal mais bem estudado na Caatinga e o conhecimento disponível já permite uma visão geral desse processo. Diversos vetores de polinização já foram documentados na Caatinga, distribuídos em cerca de 13 sistemas de polinização, dentre este, polinização abiótica como vento, bem como polinização biótica realizada por vertebrados representada por vetores como morcegos, beijaflores, lagartos e mamíferos não-voadores. A polinização biótica na Caatinga pode ainda ser realizada por invertebrados como formigas, abelhas, besouros, borboletas, mariposas, esfingídeos, vespas, moscas (Griz e Machado, 2001).

Ao estudar os sistemas de polinização da Caatinga, Machado e Lopes (2004), encontraram predomínio da entomofilia (polinização por insetos), onde $61,7 \%$ destas plantas eram melitófilas (polinizadas por abelhas). Neste mesmo trabalho registraram-se vários recursos florais apresentados por espécies vegetais da Caatinga (néctar, pólen, óleo, resina), sendo o néctar o mais frequente, ocorrendo em $71,5 \%$ das espécies estudadas. Vale ainda ressaltar que, apesar de Machado et al. (2006) terem encontrado índice de $83 \%$ para o hermafroditismo, a maioria das espécies são auto incompatíveis (61,5\%), necessitando assim dos serviços de polinizadores para se reproduzirem. Lavor e Ramos (2016) identificaram em uma área de Caatinga um conjunto de parâmetros florais e usaram para determinar as suas respectivas síndromes de polinização. A entomofilia foi o sistema de polinização mais frequente, ocorrendo em $76,12 \%$ das espécies, seguida pela ornitofilia $(17,91 \%)$ e quiropterofilia $(5,97 \%)$. A melitofilia prevaleceu em 52,24\% das espécies entomófilas, assim como no trabalho de Machado e Lopes (2004), porém, também corroborando com os padrões encontrados por Bawa et al. (1985) em floresta úmida, Gomes e Quirino (2016) na Caatinga, Kirmse et al., (2018) no Cerrado, e Kang e Bawa (2003) em uma Floresta seca. 
Entre os mais variados grupos de polinizadores, abelhas são os principais prestadores desse serviço para as angiospermas (Faegri e Van Der Pijl, 2013). No mundo existem aproximadamente 20.000 espécies de abelhas (Michener, 2000) e cerca de 3.000 delas são encontradas no Brasil (Silveira et al., 2002). Elas constituem um grupo bastante importante dentre os polinizadores, sendo consideradas como os principais animais vetores de pólen em todos os ecossistemas tropicais, chegando a polinizar cerca de 30 a $70 \%$ das Angiospermas (Machado e Lopes 2006 para revisão). Zanella (2000), compilou as informações existentes sobre a diversidade de abelhas na Caatinga e encontrou um total de 187 espécies, das quais $32 \%$ são endêmicas desta região. As abelhas constituem o grupo animal melhor adaptado à visita das flores (Feagri e Pjil, 1979).

De acordo com Zanella e Martins (2003), de modo geral, um dos fatores que levam ao elevado índice da síndrome melitofilia é que as abelhas necessitam diretamente de plantas com flores para obter recursos alimentares, além de outros recursos utilizados na construção das colmeias. Durante as visitas, as abelhas podem utilizar vários recursos florais, como pólen, néctar, resina e até mesmo óleo (Roubik, 1993). O pólen e o néctar consistem em fontes proteínas, carboidratos, vitaminas, sais minerais e gorduras, fornecendo uma dieta completa durante todas as fases de desenvolvimento das abelhas, sendo a base da nutrição destes insetos (Wnson et al., 1997; Melo Nascimento et al., 2019).

Adaptações florais morfológicas e fisiológicas foram selecionadas ao longo da evolução de modo a atrair diferentes animais capazes de transportar o pólen (Brocu et al., 2020), tais adaptações facilitam a localização da planta e o acesso ao recurso floral, bem como o transporte do pólen, aumentando assim a eficiência da polinização e otimizando a reprodução (Stebbins, 1980). Uma grande parte da biomassa floral é reservada para estruturas de atração, como as pétalas e o néctar (Pleasants e Chaplin, 1983). Características, como o odor, facilitam a localização da planta (Williams, 1983; Dobson et al., 1987). Já a estrutura da inflorescência influencia a estratégia de forrageamento do visitante (Schemske, 1980).

Os sistemas de polinização estudados na Caatinga demonstram que, apesar das restrições climáticas, há uma diversificação no conjunto de características morfológicas e de recursos florais, que possibilita uma heterogeneidade de polinizadores para a região estudada. Esses dados são importantes para aprimorar o conhecimento das interações existentes entre plantas e animais da Caatinga, sendo essas relações consideradas fundamentais para a compreensão da estrutura e da dinâmica das comunidades, constituindo, assim, importantes ferramentas para a conservação do ecossistema (Lavor e Ramos, 2016)

\section{Herbivoria e Florivoria: interações antagonistas}

A herbivoria é o consumo de diferentes partes das plantas, principalmente as folhas, por vertebrados ou invertebrados (Silva et al., 2012).Além da herbivoria foliar, as plantas recebem danos em outros tecidos, como sementes (Louda, 1983; Cariveau et al., 2004), raízes (Blossey e Hunt-Joshi, 2003; Hladun e Adler, 2009) e flores (Krupnick e Weis, 1999; Wolfe, 2002; Mc Ceall e Irwin, 2006; Mc Ceall, 2008; Oguro e Sakai, 2009). Esta importante interação pode desempenhar papel na dinâmica populacional de plantas, provocando um incremento na taxa de mortalidade das espécies ou alterando as relações competitivas entre as espécies (Price et al., 2012; Gorden e Adler, 2016).

Os insetos representam a principal fonte de consumo da produção vegetal primária terrestre, e constituem aproximadamente $80 \%$ da vida animal conhecida (Del-Claro e Torezan-Silingardi, 2012). Por apresentarem hábito herbívoro em pelo menos uma fase de suas vidas, desempenham um papel ecológico importante, e podem atuar como predadores, parasitoides, polinizadores, fitófagos, entre outros (Edwards e Wratten, 1981). O nitrogênio do tecido foliar é o mediador desta interação, sendo essencial para a nutrição dos insetos herbívoros, indispensável para o metabolismo, crescimento e consequentes alterações a nível de população, além de ser um fator limitante para este grupo animal, sendo um elemento de grande importância para esses consumidores (Mattson, 1980; Throop e Lerdau, 2004).

A alta diversidade e biomassa de insetos herbívoros os consolidam como os organismos que mais impactam a vegetação (Barbosa et al., 2005). Há estudos que indicam que insetos herbívoros chegam a restringir e até diminuir o sucesso reprodutivo vegetal (Maron e Gardner, 2000; Zvereva e Kozlov, 2001; Silva, 2009), outros sugerem que os insetos podem influenciar na evolução e na distribuição espacial (Barbosa et al., 2005; Dukes et al., 2009). 
Herrera (2002) e Sevegnoni (2007) calculam que cerca de $18 \%$ da biomassa vegetal terrestre é consumida por insetos herbívoros. Variações nas condições ambientais macro- ou microclimáticas, nutrientes do solo, qualidade da planta e consequente disponibilidade de recursos e inimigos naturais afetam as taxas de herbivoria sobre a flora (Coley, 1980; Wolda, 1988; Danks, 2002; Pinheiro et al., 2002; Stiling e Moon, 2005).

A herbivoria, além de se configurar como uma das interações mais dominantes nos ambientes terrestres, é também responsável por grandes impactos em nível individual e de comunidade, afetando a sobrevivência e crescimento de plantas, e a regeneração da floresta como um todo, atuando em distintas escalas de tempo (Forister et al., 2015). Em virtude destes fatores citados, é previsível, por outro lado que, uma grande variedade de estratégias de defesas tenha evoluído em espécies vegetais, a fim de minimizar ou cessar o ataque por parte dos herbívoros (Koslov et al., 2015; González-Esquivel et al., 2019). Essa contínua interação entre plantas e herbívoros acabam por gerar uma coevolução, onde as espécies vegetais desenvolvem uma variedade de defensivos a fim de reduzir o impacto sofrido pela herbivoria, e os insetos herbívoros adquirem características para burlar tais defesas, o que ficou conhecido como uma intensa "corrida armamentista" (Karban e Agrawal, 2002; Maron; Agrawal e Schemske, 2019).

Os insetos herbívoros pertencem a distintos grupos com diferentes formas de alimentação que por sua vez, respondem distintamente a qualidade do hospedeiro e do ambiente (Fernandes e Price, 1988; Weis e Berembaum 1989; Ribeiro et al. 1998). Assim, variações de fatores abióticos como a disponibilidade de água (White, 1969; Hahn e Maron, 2018) e nutrientes do solo (Coley et al., 1985) irão afetar a qualidade da planta que pode estender seus efeitos para os níveis tróficos seguintes (Cortina et al., 2013). Descrever a intensidade das interações entre e dentro dos níveis tróficos é imprescindível para compreender os padrões de distribuição das espécies e estabelecer estratégias para a conservação dos recursos naturais (Basset et al., 2003).

No Brasil, estudos desta natureza têm enfocado em questões amplas, porém em ecossistema de Cerrado, Mata Atlântica e Floresta Amazônica (Myers et al., 2000). Estudos que enfocam padrões de distribuição de insetos herbívoros, e os fatores que levam a associação a um hospedeiro particular entre habitats ainda são escassos (Fernandes e Price, 1992; Ribeiro et al., 1998; Cuevas-Reyes et al., 2004). E quando se trata de FTSS estes estudos são ainda mais necessários em virtude das poucas informações existentes.

A herbivoria gera impactos tanto em nível individual quanto de comunidade e em diferentes escalas de tempo (Coley, 1983; Lopeset al. 2011; Fonseca et al., 2018). Nas plantas, os efeitos negativos da herbivoria são muitas vezes percebidos no seu crescimento e capacidade reprodutiva, reduzindo a habilidade competitiva e assim implicando inclusive, na regeneração florestal (Agrawal et al., 2018), aspecto de extrema importância para o ecossistema Caatinga, haja vista que possui amplas áreas em processo de regeneração em virtude das atividades antrópicas, de uso de madeira e criação extensiva de caprinos (Schulz et al., 2018).

$\mathrm{Na}$ Caatinga, estudos sobre herbivoria foliar focados na resposta de insetos herbívoros aos estresses abióticos do ambiente já têm sido bem documentados (Fernandes et al., 2012; Coelho et al., 2012; Ribeiro et al., 2013; Neves et al., 2014; Leal et al., 2018; Martins et al., 2020b). Efeitos da estrutura da vegetação sobre comunidades de herbívoros em escalas locais e regionais também têm sido reportados (Novotny et al., 2007; Neves et al., 2014; Silva et al., 2017; Sousa-Souto et al., 2014).

Martins et al. (2018b) em área de Caatinga, demonstraram maior abundância de insetos herbívoros de vida livre durante a estação seca. Silva et al (2011), observaram grande abundância de insetos no início do período chuvoso para diferentes ordens, mostrando um pico de atividade imediatamente após as primeiras chuvas, e resultados similares foram encontrados por outros autores em outros ecossistemas com sazonalidade marcada (Pinheiro et al., 2002; Silva et al., 2011; Oliveira e Frizzas, 2008).

Alguns estudos já mostraram que a diversidade de herbívoros de vida livre durante a estação seca é baixa em FTSS como a Caatinga, sobretudo devido às características físicas das plantas (esclerofilia, altos níveis de polifenóis e baixo teor nutricional) e climáticas (períodos de secas longas e severas) (Ribeiro e Fernandes, 2000; Fernandes et al., 1012; Aquino et al., 2017). Por isso, a estação chuvosa é o período mais favorável para o desenvolvimento desses insetos herbívoros, que tem pico de atividade até a primeira metade desse período, resultado de uma maior palatabilidade das folhas, diminuição de inimigos naturais e menor conteúdo de fenólicos (Boege, 
2005; Pezzini et al., 2008; Gely et al., 2020) que será melhor debatido no tópico de defesas vegetais. Martins et al. (2020b), demonstraram na Caatinga, que, durante a estação seca, plantas não caducifólias podem suportar baixa riqueza de espécies de herbívoros e alta abundância, algumas vezes com números superiores ao do período chuvoso. Nesta situação, as plantas podem enfrentar maiores perdas foliares durante a estação seca, devido a ocorrência de espécies competitivamente superiores e até especialistas como por exemplo, coleópteros cassidíneos da família Chrysomellidae. Estes resultados mostram como as condições abióticas na Caatinga moldam a estrutura das comunidades e os padrões de interações planta-animal.

Dentro do contexto de herbivoria, a florivoria envolve a perda de tecidos florais ou órgãos reprodutivos (McCall e Irwin, 2006; McCall, 2008) e é ainda menos documentada que a herbivoria, não existindo ainda dados suficientes para gerar padrões de ocorrência e níveis de dano.

Espécies de herbívoros e florívoros interagem com diversas espécies de plantas, formando um emaranhado de redes de interações tróficas (Bagchi et al., 2014; Dáttilo e Rico-Gray, 2018). As análises de redes têm sido especialmente úteis para entender o papel das interações insetoplanta na organização e dinâmica de comunidades. Métricas diferentes êm sendo capazes de descrever as estruturas das redes de interações inseto-planta (e.g. Bascompte e Jordano, 2007; Costa et al., 2016; Dáttilo e Rico-Gray, 2018), mas o foco principal tem sido em alguns grupos em particular, como polinizadores (Dáttilo et al., 2016) e formigas (Costa et al., 2016), com poucos estudos ainda de redes antagonistas (Gompert et al., 2014; Becerra, 2015; Volf et al., 2017). Além disto, a estrutura e a dinâmica das redes de florívoros e herbívoros dentro das mesmas espécies de plantas tropicais ainda não é conhecida. Deste modo fica difícil estimar o prejuízo que essas interações antagônicas juntas podem causar ao fitness das plantas. Uma vez que flores e folhas bem como seus florívoros e herbívoros estão presentes simultaneamente em grande parte das espécies vegetais fica difícil separar estas duas interações.

Entretanto, mesmo com a documentada importância da florivoria e herbivoria para as interações inseto-planta ainda não existe um consenso a respeito da quantidade de biomassa vegetal que é perdida para os insetos através dessas interações. A herbivoria, apesar de ser um processo potencialmente determinante para a distribuição e performance de plantas, permanece amplamente pouco documentada. Uma das primeiras tentativas de revisar globalmente os níveis de herbivoria em plantas sugeriu que herbívoros removem em torno de 7,0\% de área foliar em plantas da região temperada e 11,0\% das plantas nos trópicos (Coley e Barone, 1996). Metcalfe et al. (2014), fizeram uma revisão nesses números avaliando os principais ecossistemas terrestres e encontraram uma remoção em torno de 7,0\% de área foliar, mas os dados das regiões tropicais e temperadas foram agrupados nessa revisão. Na revisão mais recente e mais inclusiva, Kozlov et al. (2015a), compilaram estudos publicados, além de dados coletados fazendo uso de protocolo padrão em gradientes latitudinais com 950 espécies botânicas. Estes autores encontraram perda foliar para herbivoria por insetos em torno de $7,5 \%$ para dados publicados e 4,73\% para dados coletados.

Apesar dos florívoros serem tão comuns em sistemas naturais quanto os herbívoros e, apesar da florivoria poder inclusive ultrapassar a herbivoria em forma, magnitude e impacto, poucos estudos até agora estimaram a quantidade de tecido floral que é perdido por insetos florívoros (Strauss et al., 2004; Oguro e Sakai, 2014), não permitindo nenhuma generalização nesse momento. Alguns estudos sugerem que a herbivoria e florivoria podem estar relacionadas (McCall et al., 2018), uma vez que a herbivoria pode induzir resistência das flores para a florivoria, ou quando os herbívoros podem se tornar florívoros à medida que a planta cresce. Os estudos publicados até agora sobre o funcionamento destas duas interações antagonísticas entre insetos e plantas e simultâneas, analisaram apenas as mudanças que uma pode exercer sobre a química defensiva da outra e, nenhum estudo comparou ainda se de fato essas mudanças influenciam as porcentagens de florivoria e herbivoria para uma mesma espécie vegetal, deixando uma imensa lacuna a respeito dos efeitos combinados dessas interações (Oguro e Sakai, 2014; Abdalsamee e Müller, 2015; West e Louda, 2018; Boyer et al., 2016; McCall et al., 2018).

A Hipótese da Defesa Ótima (Stamp, 2003) sugere que os tecidos vegetais mais valiosos para o fitness das plantas seriam mais bem defendidos e, dessa forma, as estruturas reprodutivas e folhas jovens seriam muito menos propensas a sofrerem perdas de biomassa por insetos do que outras estruturas como raízes, caules e folhas maduras (Ribeiro e Fernandes, 2000; Strauss et al., 2004; Schaffner et al., 2011, Gorden e Adler, 2016; Godschalx et al., 2016). Esta teoria foi testada diversas vezes do ponto de vista da 
química constitutiva dos tecidos foliares e florais Almeida-Cortez et al., 2003), mas, sua aplicabilidade prática - a quantidade de cada tipo de tecido que é efetivamente perdido para insetos foi testada em alguns poucos estudos em espécies de plantas da região temperada, e, a maioria destes estudos, avaliou as perdas por herbivoria e florivoria para apenas uma espécie ou um pequeno grupo de espécies relacionadas e não a comunidades vegetais em geral (Godschalx et al. 2016; Gorden e Adler, 2016; Boyer et al. 2016; McCall et al., 2018). Desta forma, apesar do que foi proposto pela teoria da defesa ótima, ainda não existe um consenso sobre qual dos dois tecidos, flor ou folha, é mais consumido por herbívoros e florívoros. A florivoria e a herbivoria podem estar inversamente relacionadas, como proposto pela Teoria da Defesa Ótima e quando a própria herbivoria induz a produção de flores com maiores concentrações de defesa (McCall e Irwin, 2006; McCall, 2008), ou diretamente relacionadas, se os herbívoros forem generalistas em suas preferências e se alimentarem tanto da flor quanto da folha. Mas o pouco que se sabe sobre o funcionamento dessa interação ainda não permite chegar a nenhuma conclusão (McCall e Irwin, 2006; Kozlov et. al., 2015a, b).

Traços funcionais intrínsecos e individuais das espécies e grupos de plantas podem estar diretamente relacionados às perdas de biomassa vegetal por herbivoria e florivoria (Ribeiro et al., 1994; Kozlov et al., 2015 a, b). O tamanho da planta e sua forma de vida, as síndromes florais, o tempo de durabilidade das folhas e a área foliar específica (do inglês SLA: Specific Leaf Area) são características funcionais que diferem entre os taxa vegetais e, apoiados em várias teorias ecológicas que podem explicar variações encontradas na quantidade de biomassa vegetal consumida por herbívoros e florívoros (Ribeiro e Fernandes, 2000; Wright et al., 2004; Kozlov et al., 2015a, b).

Outra teoria que tem sido largamente usada a fim de se buscar generalizações sobre a frequência de herbivoria e florivoria é a Teoria da aparência de plantas proposta por Feeny (1976) que prediz que plantas lenhosas, aquelas com maior porte e mais aparentes - as árvores, por exemplo podem ser localizadas mais facilmente por insetos herbívoros, ao contrário de plantas menos aparentes e de vida curta - como - arbustos e lianas (Feeny, 1976; Ribeiro e Fernandes, 2000; Kozlov et al., 2015b). Ainda, a durabilidade das folhas nas plantas pode torná-las mais ou menos aparentes devido à constância do recurso alimentar para herbívoros e, dessa forma, plantas decíduas em comparação com plantas perenes podem experienciar uma menor perda de biomassa vegetal (Givnish, 2002; Pringle et al., 2011).

O conjunto de características florais compartilhado entre espécies e grupos de plantas como a forma, tamanho e tempo de floração conhecido como síndromes florais (Fenster et al., 2004) tem a função de atrair grupos específicos de polinizadores, mas podem atrair também grupos específicos de florívoros capazes de causar danos de longo prazo a espécies e até comunidades (Ye et al., 2017). Dessa forma, os caracteres florais, em especial a morfologia, podem estar diretamente relacionados com a quantidade de biomassa floral consumida pelos florívoros (McCall, 2008; Carezza et al., 2011; Ye et al., 2017).

Por fim, a área foliar específica (SLA) - a razão entre a área da folha e sua massa seca - vem sendo apontada em diversos estudos como um bom previsor da taxa de crescimento das plantas e/ou da sua taxa fotossintética (Cornelissen et al., 2003; Kozlov, et. al., 2015b). Acredita-se que valores baixos de SLA indiquem alto investimento das espécies em defesas nas folhas e, portanto, esperase que plantas com SLA pequeno sejam menos atrativas e menos consumidas por herbívoros e, vice-versa (Ribeiro e Brown, 1999, Cornelissen et al., 2003; Wright et al., 2004). A região tropical e, principalmente o Brasil, é uma das mais ricas em diversidade de espécies de plantas (46.097 espécies, Zappi et al., 2015) e insetos (cerca de 90.000 espécies, Rafael et al., 2009), mas é ainda muito pouco representada em estudos mecanísticos sobre os padrões de herbivoria e florivoria, impedindo a generalização da ocorrência e implicações dessas interações nesta região.

Apesar de muitos estudos indicarem que a herbivoria seja capaz de induzir a produção de flores mais resistentes e assim reduzir os níveis de florivoria, os resultados de McCall et al. (2018) indicam que as duas interações não estão relacionadas para algumas espécies de plantas, de modo que a florivoria e a herbivoria podem ocorrer de maneira independente, e dependem de alguns fatores. Segundo Coley e Barone (1996), os herbívoros normalmente selecionam as partes das plantas que apresentam estruturas compostas por celulose e açúcares, consumindo preferencialmente as folhas jovens e as flores. Deste modo, uma pressão intensa de herbivoria pode consumir uma elevada proporção de tecidos fotossintéticos. Além disso, a intensa herbivoria das partes reprodutivas pode prejudicar a fecundação e o desenvolvimento de frutos e sementes. Logo, a herbivoria pode afetar o crescimento, desenvolvimento e recrutamento 
das plantas (Del-Claro e Oliveira, 2000) e até mesmo na polinização (Martins et al., 2020a).

Tanto os herbívoros foliares quanto florais podem reduzir a aptidão (Martins et al., 2020a). Os principais efeitos provocados por herbívoros foliares que poderiam interferir na efetividade dos polinizadores são atraso do período de floração (Marquis, 1988), redução do número de flores (Quesada et al., 1995; Juenger e Bergelson, 1997; Lehtilä e Strauss, 1999; Mothershead e Marquis, 2000), decréscimo no tamanho da flor (Strauss et al., 1996; Strauss, 1997; Mothershead e Marquis, 2000) e redução na qualidade ou quantidade da recompensa ao polinizador (Quesada et al., 1995; Strauss et al., 1996; Mothershead e Marquis, 2000).

Efeitos variáveis têm sido detectados em estudos sobre influências de herbivoria foliar sobre a produção de pólen que pode ser reduzida por herbívoros a depender do tempo despendido na alimentação e da intensidade, (Quesada et al., 1995; Ávila-Sahar et al., 2003), podendo não exercer efeito algum (Ávila-Sakar et al., 2003) ou aumentar a produção de pólen nas plantas (ÁvilaSakar e Stephenson, 2006).

Vários estudos mostraram que grande parte da biomassa floral é alocada para estruturas de atração para os polinizadores, como as pétalas e o néctar (Pleasants e Chaplin, 1983). Desse modo, quando a herbivoria ocorre em áreas produtoras de recurso como perfume, néctar, óleos e resinas, ou até mesmo quando as anteras ou o estigma sofrem danos, a qualidade da polinização biótica tende a cair, prejudicando assim a produção de frutos e sementes (Canela e Sazima, 2003).

Desse modo, os efeitos sobre a aptidão das plantas podem ser diretos, através do consumo de toda flor ou partes das flores, afetando a produção de frutos (Bell, 1985), ou indiretos, já que alterações morfológicas causadas por danos nas pétalas, sépalas, pistilo, anteras ou na inflorescência como um todo, podem afetar direta e negativamente a polinização, pois a atração visual fica prejudicada devido a modificação da qualidade e quantidade dos atributos florais importantes para a polinização (Mothershead e Marquis, 2000; Antiqueira e Romero, 2016; Martins et al., 2020a), já que várias espécies de abelhas, que é o principal grupo relacionado à polinização tendem a evitar flores que apresentam pétalas e/ou estames com danos (Krupnick et al., 1999).

Dados de florivoria são escassos (Antiqueira e Romero, 2016). Em área de Caatinga, Martins et al., (2020a) registraram que a perda de atributos florais provocados pela florivoria em diferentes proporções provocam reduções significativas de visitas de polinizadores efetivos. Porém, quando se trata do ecossistema Caatinga muitas lacunas precisam ainda ser preenchidas. Estudos que relacionem a variação sazonal na qualidade e quantidade dos recursos alimentares para os insetos herbívoros ainda precisam ser realizados.

Adicionalmente, os danos florais podem afetar o comportamento de polinizadores através de estímulos químicos induzidos pelo dano (Halitschke et al., 2011). As substâncias voláteis emitidas pelas flores são em sua grande maioria líquidos lipofílicos com altas pressões de vapor (Shi et al., 2019). Quando estes se encontram livremente difundidos no citoplasma (não conjugados) e sem barreiras para se difundir, podem atravessar as membranas celulares e volatilizar-se na atmosfera circundante da flor, criando o que se denomina: "headspace" floral (Pichersky et al., 2006). Estes voláteis produzidos pelas flores são originados a partir de vias do metabolismo secundário (especializado) de plantas (Ichersky et al., 2006).

Flores podem ser iguais em textura ou cor, mas dificilmente serão iguais na sua composição de odores e pigmentos, devido à grande diversidade de compostos presentes e de sua abundância relativa na constituição do "bouquet" floral (Schlindwein et al., 2014). Os voláteis produzidos pelas flores, sob seleção imposta pelos polinizadores, guiam os insetos até a fonte de néctar ou pólen e são essenciais para que estes consigam discriminar diferentes espécies de plantas, ou até mesmo localizar diferentes flores em uma mesma planta (Dudareva et al., 2005).

Por outro lado, voláteis emitidos por flores danificadas podem alterar o comportamento dos polinizadores (Kessler e Halitschke, 2009; LucasBarbosa et al., 2011), repelindo ou mesmo atraindo insetos visitantes florais (Goyret et al., 2007) por alteração na produção de componentes voláteis (VOCs) da flor (Theis et al., 2009). Dependendo das circunstâncias, as plantas podem equalizar a emissão de VOCs, ou seja, produzir compostos ativos para polinizadores e quando houver um ataque, produzir os metabólitos de defesa (Theis et al., 2009). Além disso, as plantas também podem apresentar compostos com função defensiva em seus "bouquets" florais (Camargo et al., 2001).

A herbivoria é responsável por grande parte da riqueza vegetal e complexidade de interações existentes nos sistemas terrestres (Ohgushi, 2005), mesmo assim os efeitos de florivoria são pouco estudados, apesar de algumas pesquisas mostrarem ser relativamente comuns na 
natureza (Mccall e Irwin, 2006). Além disso muitos estudos avaliam o papel da simetria na preferência de herbívoros e polinizadores (Antiqueira e Romero, 2016; Salinas-Esquivel et al., 2018) e poucos estudos foram realizados em ambientes tropicais (Ishino et al., 2011). Até o momento o único trabalho realizado no ecossistema Caatinga levando em consideração atributos florais visuais (e.g. corola grande e vistosa, plataforma de pouso e guias de néctar) foi o de Martins et al. (2020a). Existe ainda uma lacuna, no que diz respeito aos voláteis emitidos por flores danificadas decorrente da ação dos herbívoros e suas implicações para atratividade e comportamento de polinizadores, independentemente da perda de simetria floral, essa lacuna dificulta ainda mais a compreensão acerca da pressão exercida pela florivoria sobre a estrutura e dinâmica das comunidades vegetais da Caatinga, bem como dificulta a compreensão dos fatores que envolvem estas interações (plantaherbívoro-polinizador).

$O$ percentual de perdas de tecidos provocados pela herbivoria ou florivoria é influenciado por uma série de fatores que atua em níveis ascendentes e descendentes (Tylianakis e Morris, 2017; Dekeukeleire et al., 2019). No controle ascendente podemos citar a complexidade do ambiente, mudanças na riqueza, composição e diversidade de plantas, bem como suas estratégias, como também a qualidade e disponibilidade de nutrientes dos tecidos vegetais, irão influenciar a diversidade de insetos herbívoros e a intensidade da herbivoria (Fonseca et al., 2018; GonzálezEsquivel et al., 2019; Martins et al., 2020b). Em nível descendente, a regulação da abundância de herbívoros se dá diretamente por meio dos inimigos naturais (Terborgh, 2015; Moreira et al., 2017; Martins et al., 2020b).

De acordo com Mckey (1974), a atribuição de defesas nas plantas é determinada pelo custo que perdas daquele tecido vão causar na aptidão da espécie. Deste modo, as plantas não são inertes aos ataques sofridos pelos herbívoros e produzem diversos mecanismos de proteção (Fonseca et al., 2018; González-Esquivel et al., 2019), envolvendo, portanto, distintas estratégias (Hernán et al., 2019).

\section{Estratégias das plantas contra herbivoria}

Em resposta a pressão exercida pela herbivoria, as plantas desenvolveram estratégias de tolerância que podem ser classificadas em induzidas, constitutivas ou compensatórias (Soler et al., 2007; Van-Velzen e Etienne, 2015; Ramula et al., 2019)

As estratégias induzidas são expressas somente após o ataque, com atuação direta sobre os herbívoros (Soler et al., 2007). As respostas podem aparecer logo após a injúria, depois de algumas horas, ou apenas na próxima estação de crescimento. Já as estratégias constitutivas consistem em defesas de forma contínua, independente do dano por herbívoros (Melo e Silva-Filho, 2002; Van-Velzen e Etienne, 2015). A estratégia compensatória, por sua vez, envolve uma miríade de mecanismos de tolerância que acabam por minimizar os efeitos negativos da herbivoria sobre o fitness da planta por meio de reconfigurações em suas vias metabólicas, sendo estes mecanismos ainda pouco compreendidos (Fornoni, 2011; Quijano e Medina et al., 2019; Ramula et al., 2019). Apesar disso, estudos recentes mostram que a quantidade ou gravidade dos danos sofridos influenciam a resposta compensatória por parte das plantas, sendo que danos menores são os mais facilmente compensados (Quijano-Medina et al., 2019; Ramula et al., 2019).

Tanto as estratégias induzidas quanto as constitutivas, bem como as compensatórias podem ocorrer de forma conjunta na mesma planta. Do mesmo modo que podem ocorrer de maneira substitutiva, em que plantas com maior resposta induzida alocam menos recursos para as estratégias constitutiva (Rasmann et al., 2015).

As defesas em plantas podem ser classificadas ainda quanto as suas propriedades, em químicas ou físicas (Almeida-Cortez, 2005; Hinman et al., 2019) As defesas físicas referem-se às características morfológicas e/ou estruturais que dificultam a herbivoria ou deposição de ovos por parte dos insetos herbívoros (González-Esquivel et al., 2019). Já as defesas químicas consistem na produção de substâncias secundárias que atuam com diferentes níveis de toxicidade, ou que reduzem a palatabilidade dos tecidos vegetais, e até mesmo a digestibilidade, afetando o crescimento, fecundidade e sobrevivência dos herbívoros (Dourado et al., 2016). E por último, mas não menos importante, as plantas podem ainda apresentar mecanismos de defesas bióticas que está associada à produção de recompensas alimentares, entre as quais corpos de alimentação e nectários extraflorais, os quais atraem parceiros mutualistas que são inimigos naturais dos herbívoros (Heil e Mckey, 2003). 
As defesas produzidas pelas plantas envolvem inúmeros fatores, dentre eles os custos do investimento, os benefícios trazidos por essas defesas e os recursos disponíveis nos ambientes (Van-Velzen et al., 2015). Dentre as principais demandas conflitantes citaremos o custo de alocação, quando recursos investidos para o crescimento da planta não estão disponíveis para a produção de tecidos foliares mais duráveis e protegidos contra herbivoria. Em geral, plantas que vivem em ambientes ricos em nutrientes podem produzir folhas com menores custos e reduzido investimento em defesas, por outro lado, em ambientes com recursos mais escassos, o custo de construção da folha pode ser maior, sendo vantajoso o investimento em defesas e o aumento da longevidade foliar (Donovan et al., 2011; Falcão et al., 2017; Funk et al., 2017).

A seguir discutiremos de forma mais detalhadas as defesas físicas, químicas e bióticas, suas implicações e principais resultados encontrados em Florestas Tropicais Sazonalmente Secas com foco especial no ecossistema Caatinga.

\section{Defesas físicas}

As defesas físicas/morfológicas ou mecânicas são adaptações morfológicas da planta que atuam como barreira, e de forma negativa sobre o inseto, diminuindo os riscos de ataques ou oviposição, preservando as plantas de danos mais sérios (Lara, 1991; Lucas et al., 2000; AlmeidaCortez, 2005). Estas adaptações podem ser depósitos cuticulares, epiderme e parede celular espessadas, tricomas e fibras na folha.

A epiderme foliar é revestida por uma camada lipídica denominada cutícula (Edwards e Wratten, 1981). A cutícula atua como barreira impedindo a penetração de fungos e a ação de insetos herbívoros, dificultando a fixação, locomoção e penetração de insetos em tecidos vitais (Edwards e Wratten, 1981; Almeida-Cortez, 2005). A cutícula e formada pela cutina e recoberta pela cera epicuticular, camada mais externa da cutícula vegetal composta por uma mistura complexa de substâncias alifáticas de cadeias longas ( $n$-alcanos, ácidos graxos, álcoois, cetonas, aldeídos e ésteres) e de estruturas cíclicas como triterpenoides e flavonoides (Shepherd et al., 1995). As ceras epicuticulares constituem a primeira superfície de contato entre a planta e o meio externo, atuando como interface entre a planta e o meio ambiente (Lichston e Godoy, 2006). É sabido que a cera epicuticular pode inibir ou estimular a oviposição e a alimentação de insetos herbívoros ou mesmo afetar a adesão e a locomoção desses (Eigenbrode, 1996; Eigenbrode e Jetter, 2002). Neste sentido, Silva et al. (2018), avaliaram em área de Caatinga, como as várias composições de cera epicuticular afeta a infestação de galhas em espécies de Croton (Euphorbiaceae), mostrando que um maior teor de ácidos graxos na composição favorece uma maior infestação de galhas para as espécies estudadas.

Anatomicamente, a dureza da folha implica em paredes espessadas e/ou feixes de fibras, lignificadas ou não (Fernandes, 1994; Peeters, 2002). Uma epiderme com textura rígida por deposição de sílica e/ou lignina, é uma barreira mecânica que reduz a oviposição para alguns insetos, a palatabilidade e digestão (Dourado et al., 2016).

Algumas folhas apresentam tricomas. Estes são apêndices epidérmicos que podem ser formados por uma ou mais células, promovendo a proteção do vegetal. Os tricomas consistem em defesas físicas ao dificultar a oviposição e locomoção do herbívoro, além de possuírem substâncias como terpenos, fenóis, alcaloides ou outras substâncias repelentes, seja pelo odor ou sabor (Saasse et al., 2016). Assim comumente existe uma relação inversa entre a densidade de tricomas e proporções de herbivoria. Sendo assim, os tricomas são estruturas adaptativas vantajosas para plantas ambientes áridos e semiáridos com alta incidência de luz, e exposição aos efeitos de ventos, já que uma densa camada de tricomas controla a perda de água pela transpiração (Karabourniotis et al., 1999; Medeiros e Morretes, 1995). Na Caatinga, Barros e Soares (2013), avaliaram o papel destas estruturas na eficiência do uso de água, porém avaliar a eficiência destas estruturas na defesa contra herbivoria ainda surge como uma janela para novas pesquisas. Dourado et al. (2014), avaliaram a presença de tricomas, relacionando com a proporção de herbivoria em plantas de Caatinga, porém a presença de tricomas não afetou de modo significativo a ocorrência de herbivoria.

Outros tipos de defesas físicas são as próprias alterações na anatomia foliar, como por exemplo, a espessura das epidermes e o número de camadas do mesófilo, que contribui para a espessura foliar e dureza dos tecidos vegetais (Edwards e Wratten, 1981). A presença de hipoderme também pode constituir em mais um obstáculo para inibir o ataque dos insetos herbívoros (Correia et al., 2008).

A presença de cristais de oxalato de cálcio pode desempenhar um importante papel contra 
herbivoria, devido à sua propriedade irritante (Sunell e Healey, 1979; Pimentel et al., 2011; Franco e Albiero, 2018). Esses cristais podem ocorrer em várias partes da planta, como nas flores, folhas (Sunell e Healey, 1985; Doaigey, 1991; Giordano et al., 2020), caule (Doaigey, 1991), raízes e sementes (Sunell e Healey, 1985).

Estudos sobre características físicas de defesa das plantas contra herbívoros na Caatinga ainda são mais raros (Oliveira et al., 2012; Dourado et al., 2016), mas indicam que defesas físicas são mais comuns/efetivas que defesas químicas. Dourado et al. (2016), avaliaram características físicas de espécies da Caatinga que atuavam como defesas mecânicas contra herbivoria, e os resultados mostraram que a presença de tricomas e espinhos não parecem interferir no consumo por herbívoros. No entanto, as plantas com maiores médias de dureza foliar apresentaram menores proporções de área foliar herbivorada.

De acordo com Dirzo e Boege (2008), em FTSS, a dureza foliar de espécies perenes é geralmente duas vezes maior do que a de espécies decíduas. Deste modo, uma maior dureza foliar em plantas, ou seja, maior deposição cuticular celular, altera a textura das folhas, tornando-as mais rígidas e dificulta a penetração dos aparelhos bucais, bem como a digestão por herbívoros (Lucas et al., 2000; Angelo e Dalmolin, 2007). Adicionalmente, fecha possíveis portas de entradas para patógenos e é uma importante estratégia para diminuir a evapotranspiração em períodos de estresse hídrico (Fürstenberg-Hägg et al., 2013).

A densidade e espessura foliar podem ser considerados caracteres escleromórficos de acordo com Wright e Cannon (2001). O aumento da densidade foliar está associado à proteção da planta contra herbivoria, agindo como barreira para diversos tipos de herbívoros generalistas, resultando em folhas mais rígidas, que reduzem a palatabilidade e nutrição dos tecidos (Chauvin et al., 2018; Coley et al., 2018). Muiruri et al. (2019), avaliando os efeitos da herbivoria a partir de alterações em características foliares da arbórea Betula pendula, na Finlândia, indicaram que a espessura das folhas teve significativamente $o$ maior efeito sobre herbívoros, destacando ainda que características físicas foram mais determinantes para as taxas de herbivoria que características nutricionais e químicas (Carmona et al., 2011; Caldwell et al., 2016), corroborando com os resultados encontrados por Dourado et al. (2016) em ecossistema de Caatinga.

\section{Defesas químicas}

Quando se trata de defesas químicas, as plantas são ricas em substâncias que, aparentemente, não estão diretamente relacionadas com os processos metabólicos normais da fotossíntese, respiração e crescimento (Edwards e Wratten, 1981). A estas substâncias dá-se o nome de compostos secundários, cujos produtos, embora não necessariamente essenciais para o organismo, garantem vantagens para sua sobrevivência e perpetuação da espécie no planeta (Edwards e Wratten, 1981; Almeida-Cortez, 2005).

Os compostos vegetais secundários podem ser divididos em três grandes classes, com base em sua biossíntese: os compostos nitrogenados, os terpenoides e os fenólicos. Entre os compostos nitrogenados enquadram-se os alcaloides, aminoácidos não-proteicos e glicosídeos cianogênicos. Os terpenoides incluem óleos essenciais, triterpenos, saponinas e glicosídeos cardioativos. Entre os compostos fenólicos estão as ligninas, flavonoides e os taninos (Carvalho et al., 2007).

Durante muito tempo, os metabólitos secundários foram considerados como produtos de excreção do vegetal, sem função definida. Atualmente está confirmado que muitas destas substâncias estão diretamente envolvidas nos mecanismos que permitem o ajuste das plantas ao meio ambiente (Santos, 2004). A coevolução das plantas, insetos, microrganismos e mamíferos conduziu à síntese de metabólitos secundários com função de defesa ou atração. Os metabólitos secundários podem ser encontrados em uma ou mais partes das plantas, e, normalmente, suas concentrações variam com o estádio fenológico (Lara, 1991).

As plantas produzem substâncias de defesa sob duas formas, como substâncias constitutivas que repelem os herbívoros provocando toxicidade direta ou reduzindo a digestibilidade do tecido vegetal, e como substâncias induzidas, sintetizadas em resposta ao dano causado ao tecido pelos herbívoros (Melo e Silva-Filho, 2002). Tais estratégias são capazes de prevenir um aumento do número de herbívoros, embora exista um número reduzido de insetos capazes se adaptarem a uma determinada espécie vegetal; estas substâncias conferem à planta uma melhor capacidade reprodutiva, uma vez que os tecidos responsáveis pela fotossíntese são conservados (Melo e SilvaFilho, 2002).

A síntese de defesas químicas vegetais é diretamente influenciada por fatores ambientais (abióticos), os quais podem influenciar o perfil de 
metabólitos secundários de uma planta. Os principais fatores abióticos que influência o teor e composição dos metabólitos de defesa são temperatura, índice pluviométrico, sazonalidade, radiação ultravioleta, composição atmosférica, ritmo circadiano e composição do solo. Os principais fatores bióticos que influenciam a biossíntese dos metabólitos secundários são a idade da planta, o ataque de herbívoros e de fitopatógenos (Gobbo-Neto e Lopes, 2007). Estudos que relacionam fatores abióticos como a temperatura e a radiação ultravioleta com a biossíntese de metabólitos secundários foram conduzidos por Gobbo-Neto e Lopes (2007). Por outro lado, o efeito da sazonalidade na biossíntese de metabólitos secundários envolvidos com a defesa vegetal em FTSS são raros.

A estação do ano para a planta é um fator fundamental na produção de metabólitos secundários. A quantidade e a natureza dos constituintes ativos não são constantes durante o ano. Várias classes de metabólitos secundários apresentam variações sazonais como óleos essenciais, lactonas sesquiterpênicas, flavonoides, cumarinas, saponinas, alcaloides, taninos e ácidos fenólicos (Gobbo-Neto e Lopes, 2007; Southwell e Bourke, 2001). Assim, de modo geral, plantas que sofrem estresse hídrico ou nutricional constituem melhor fonte de alimento do que plantas nãoestressadas, pois nestas condições apresentam uma maior disponibilidade de nitrogênio solúvel, disponível para os insetos (White, 1969).

A quantidade de nitrogênio no tecido foliar pode influenciar a ocorrência e a densidade populacional de insetos herbívoros, que podem variar negativamente ou positivamente em relação ao conteúdo de nitrogênio e defesas químicas disponíveis nas folhas consumidas (Boege, 2005).

O conjunto de características químicas e estruturas físicas das folhas vem sendo consideradas peças chaves na evolução e no papel ecológico da defesa em plantas desde os estudos mais pioneiros (Dethier, 1941; Janzen, 1973). Porém, o papel dessas características na efetividade da defesa vegetal, não pode ser considerado universal (Fonseca et al., 2018; Gonzalez-Esquivel et al., 2019). Alguns autores não encontraram relação geral entre as concentrações de compostos secundários e a suscetibilidade aos herbívoros, apesar de ser uma relação bem conhecida em inúmeros estudos (Poorter et al., 2004; Fürstenberg-Hägg et al., 2013; Aboshi et al., 2018; Coley et al., 2018). Por outro lado, Baobour et al. (2015) citam que, os efeitos das características vegetais sobre os herbívoros, é, também, influenciado pelo comportamento alimentar e a fisiologia dos mesmos, variando entre eles (Barbour et al., 2015).

De acordo com Van-Velzen e Etienne (2015), a produção de determinado tipo de defesa é resultado dos custos e investimentos, dos benefícios trazidos por aquela defesa específica e da disponibilidade de recursos presentes para o desenvolvimento da estratégia de defesa. A hipótese de disponibilidade dos recursos proposta por Coley et al. (1985) é uma das mais conhecidas e testadas para descrever os padrões de defesa e uso de recursos pelas plantas. A hipótese prediz que o gasto energético para o desenvolvimento de características defensivas é mediado pela taxa de crescimento das plantas, sendo influenciada pelas condições ambientais. No ecossistema Caatinga e em outras FTSS esta hipótese representa uma das demandas conflitantes mais fundamentais mediada pelo espectro de economia da folha (Wright et al., 2004). Assim, espécies em ambientes ricos em nutrientes apresentariam estratégias mais aquisitivas, ou seja, alocando recursos para maiores taxas de crescimento, construção rápida de folhas, ricas em nutrientes e mais palatáveis para os herbívoros. A substituição do tecido foliar perdido, por sua vez, é menos custoso (Coley 1983; Poorter et al., 2004). Por outro lado, espécies conservadoras alocariam mais carbono na construção foliar, investindo em defesas e com o retorno do investimento a longo prazo (Wright et al., 2004; Shipley et al., 2006). Apesar de ser considerada uma importante ferramenta na explicação das distintas estratégias defensivas em diferentes ambientes, alguns estudos têm refutado, total ou parcialmente, essa hipótese, visto que em comunidades naturais de plantas, as demandas conflitantes podem se apresentar de forma mais complexa (Kitajima e Poorter, 2008; Endara e Coley, 2011; Chauvin et al., 2018; Fonseca et al., 2018).

Em floresta tropical seca os trabalhos relacionados ao tema citado, avaliam as mudanças funcionais nas plantas, que por sua vez, também influenciam as interações entre planta e herbívoros (Lohbeck et al., 2013; Buzzard et al., 2016), porém estes trabalhos não avaliam de maneira direta o efeito destas mudanças funcionais nas comunidades de insetos associados as plantas. Assim, a influência por agentes seletivos do ambiente sobre as defesas químicas e herbivoria, já foram relacionados. Entretanto, maior parte dos estudos que abordam tais parâmetros se concentra em florestas tropicais úmidas e em florestas temperadas (Coley e Barone, 1996), e pouco se 
sabe da relação entre produção de compostos de defesas, abundância de herbívoros, disponibilidade de água e nutrientes do solo em FTSS como Caatinga (Silva et al., 2009), e como isto afeta a abundância do nível trófico posterior (efeito bottom-up).

\section{Defesas bióticas: Nectários Extraflorais}

As plantas podem utilizar como estratégia contra herbivoria as defesas indiretas, ou também chamadas de defesas bióticas. Nessa estratégia, as plantas dependem de inimigos naturais dos herbívoros, em geral, são predadores para influenciar na abundância e no nível de ataque dos herbívoros sobre os tecidos vegetais, agindo como protetores bióticos (Koptur, 2005; Del-Claro e Torezan-Silingardi, 2009).

Nesse contexto, as plantas, ao longo de sua história evolutiva, desenvolveram características para a atração e permanência de visitantes (e.g. formigas e aranhas), tais como, nectários extraflorais (NEFs) e corpúsculos alimentares (como elaiossomos), que servem de alimento (Nahas et al., 2012). Mas também, estruturas como domácias, que servem de local para nidificação, criação dos jovens e abrigo de formigas contra predadores (Rico-Gray e Oliveira, 2007). Algumas plantas ainda podem manter associações com herbívoros trofobiontes, que liberam secreções açucaradas, servindo de fonte de alimento para formigas, que indiretamente protegem as plantas (Del-Claro, 2004; Moreira e Del-Claro, 2005).

$\mathrm{Na}$ Caatinga, embora não existam plantas com domácias, plantas com NEFs são muito diversificadas e abundantes nesse ecossistema (Magrin et al., 2014; Leal et al., 2018) e sua interação com formigas parece ser um componente chave da biodiversidade da região (Leal et al., 2018), sendo assim as interações entre plantas e formigas associadas aos nectários extra florais irão mediar nossas discussões neste tópico.

Os NEFs são estruturas produtoras de néctar que, ao contrário de nectários florais, não estão diretamente relacionados à polinização (Heil, 2011; Marazzi et al., 2013a). O néctar extrafloral é secretado por glândulas especializadas (Bentley, 1977). Essa substância pode conter açúcares, aminoácidos, proteínas, lipídios e outros compostos orgânicos (Oliveira e Pie, 1998) que quando comparado ao néctar floral, frequentemente apresenta maior concentração de açúcar (Wäckers, 2005). Plantas com nectários extraflorais são diversas e abundantes em vários ecossistemas (Heil e Mckey, 2003) e atraem grande diversidade de parceiros mutualistas, podendo ter seu valor adaptativo aumentado (Byk e Del-Claro, 2010).

Em se tratando de associações entre animais e NEFs, as interações entre formigas e plantas têm sido estudadas intensamente nas últimas três décadas (Becerra e Venable, 1989; Santos e Del-Claro, 2001; Vilhena-Potiguara et al., 2012, Martins et al., 2020a). No início desses estudos, muitos pesquisadores afirmaram que formigas atraídas pelos NEFs protegiam a planta, mas falharam em mostrar, experimentalmente, evidências que suportassem tais conclusões (Bentley, 1977). Entretanto, em 1966, Janzen apresentou os primeiros dados experimentais na América Central que demonstraram efetivamente uma relação obrigatória entre Acacia cornigera (Fabaceae) L. e Pseudomyrmex ferruginea F. Smith (1877) (Formicidae, Hymenoptera). A planta oferece espaço físico para construção de ninhos (domácias), alimento na forma de corpos proteicos (também conhecidos com corpos Beltianos) e açúcares provenientes dos NEFs em troca de proteção contra herbívoros.

Oliveira et al. (1987) foram os primeiros a apresentar evidências experimentais em plantas com NEFs no Cerrado. Muitos experimentos de exclusão de formigas na região dos trópicos demonstram que as formigas podem de fato beneficiar as plantas reduzindo os impactos da herbivoria (Del Claro et al., 1996; Marazzi et al., 2013a).

Leal et al. (2018) citam que a importância das espécies de formigas para as plantas da Caatinga pode ser observada em três tipos de situações: 1) Os herbívoros são expulsos ou caçados pelas formigas nos ramos e flores, evitando assim a perda de área fotossintetizante e área reprodutiva do vegetal (Bentley, 1977; Martins et al., 2020b). 2) As formigas utilizam os NEFs, oferecidos por várias famílias vegetais (Elias, 1983; Koptur, 1992; Koptur et al., 1998). E 3) As formigas podem utilizar outra fonte alimentar muito interessante, as exsudações oferecidas por outros insetos associados as plantas com NEFs ou não, entre estes, podemos citar homópteros adultos e imaturos, e larvas de Lepidoptera que são mirmecófilas.

Esses insetos são protegidos ativamente por diversas espécies de formigas, as quais constantemente os tocam com suas antenas, antes e depois de coletar as gotas exsudadas por eles (DelClaro e Oliveira, 1999; Del-Claro e Oliveira, 2000). 
Martins et al. (2020b) avaliaram como a magnitude destes benefícios variam temporalmente em ambientes com sazonalidade climática marcada como a Caatinga, mostrando que mutualismos de proteção podem ser condicionais em virtude das mudanças sazonais de fatores abióticos que afetam diretamente os fatores bióticos como abundância e riqueza dos insetos herbívoros (O'dowd e Catchpole, 1983; Del Claro, 2004) e abundância e identidade das formigas (O'dowd e Catchpole, 1983; Rashbrook et al., 1992).

Martins et al. (2020) ainda registraram menores proporções de herbivoria em plantas com maior diversidade de formigas forrageando nos nectários extraflorais durante a estação seca na Caatinga, porém durante a estação chuvosa, a presença de herbívoros mirmecófilos afetou negativamente a proteção das plantas pelas formigas. Estas larvas liberam exsudações muitas vezes mais açucaradas do que o próprio néctar extrafloral, atraindo assim, as formigas para sua proteção.

Bronstein (1998) discute que a presença de outro nível trófico altera as consequências das interações mutualísticas entre plantas e formigas devido às variações na abundância e riqueza desses animais ao longo do tempo, além das variações de comportamento e modos de alimentação entre a diferentes espécies (Marquis e Braker, 1994; Del Claro e Oliveira, 2000). Com isso, as plantas com NEFs normalmente associam-se com guildas de espécies de formigas onívoras que mudam em composição e abundância no tempo e espaço (Bentley, 1976), o que pode comprometer a magnitude dos benefícios recebidos pelo parceiro mutualista (Bronstein, 1998).

Variações similares nos benefícios têm sido encontradas em outros estudos de interações formiga-planta (Falcão et al., 2003; Martins et al., 2020b). Cabe ressaltar que, em alguns casos, o benefício da associação pode também não ser evidenciado (O'dowd e Catchpole, 1983; Rashbrook et al., 1992). O trabalho desenvolvido por O'dowd e Catchpole (1983) não demonstrou evidências significativas de proteção das formigas contra os predadores de sementes em Asteraceae. Os autores discutiram que fatores como a atratividade da secreção dos NEFs, a disponibilidade de recursos alternativos, a densidade e a localização dos ninhos das formigas, as características intrínsecas desses animais, a densidade dos predadores de sementes e os fatores abióticos contribuíram para a variação temporal e espacial da intensidade e fidelidade do atendimento das formigas às plantas. Com esse trabalho, os autores sugeriram que é inviável a generalização da hipótese de proteção das formigas para todas as plantas com NEFs. Esses resultados foram corroborados por Rashbrook et al. (1992) que também não detectaram efeitos positivos na interação entre formigas e Pteridium aquilinum (Polypodiaceae). Nesse caso, os autores sugeriram que a baixa densidade de formigas foi $\mathrm{o}$ fator limitante para a ocorrência do mutualismo.

Adicionalmente, apesar da grande maioria dos estudos abordarem os benefícios para a planta há aqueles que indicam o oposto, como os casos em que polinizadores e dispersores de sementes que evitam flores e frutos devido à presença de formigas (Horvitz e Shemske, 1984). Quando se leva em consideração o comportamento agressivo das formigas, associado ao seu hábito carnívoro, somado ao sítio de forrageamento próxima das flores, o patrulhamento de formigas atraídas pelos recursos oferecidos nos NEFs pode afastar potenciais polinizadores (Wagner e Kay, 2002; Heil e Mckey, 2003), por criarem um cenário de risco quando presentes, provocando alterações comportamentais nos visitantes florais (Martins et al., 2020b).

\section{Efeitos indiretos de predadores nas interações planta-artrópodes}

Os efeitos de uma espécie sobre outra, mediados por uma terceira espécie são denominados efeitos indiretos (Wootton, 1994). Estes efeitos em cascatas têm importância para a estrutura e produtividade das comunidades ecológicas e, portanto, são muito estudados por ecólogos para elucidar sua prevalência na natureza (Paine, 1980; Polis et al., 2000; Suttle, 2003).

A cascata trófica pode ocorrer quando um predador reduz a abundância de sua presa, tendo repercussão no nível trófico abaixo, de modo que os recursos da própria presa aumentam em abundância. $\mathrm{O}$ efeito top-down, quando promovido pelas aranhas ou formigas associadas a NEFs, por exemplo, reduz a abundância de herbívoros resultando em um aumento na produtividade e consequentemente na melhora da aptidão do produtor primário (Romero e Vasconcellos-Neto, 2004).

Além desta visão clássica de predação, em que predadores provocam efeitos em cascata quando consomem suas presas (e.g. efeito indireto mediado pela densidade), outros efeitos transmitidos por predadores seriam de forma não letal, em que, atributos do predador provocam 
respostas comportamentais anti-predatórias em suas presas, o que afetaria toda a rede de interações tróficas por ela interligadas (e.g. efeito indireto mediado por atributos da presa) (Schmitz et al., 2000; Werner e Peacor, 2003; Terborgh e Estes, 2010).

Os efeitos da predação podem variar de acordo com o modo de forrageio do predador (e.g. se possuem estratégia do tipo senta-e-espera ou são caçadores ativos), sendo que, predadores que permanecem por longo período sobre determinado sítio (e.g. aranhas Thomisidae) podem exercer maior impacto direto na abundância de polinizadores quando comparado a predadores que vagueiam a longas distâncias (e.g. aves) (Suttle, 2003, Werner e Peacor, 2003). Além disso, a sazonalidade pode afetar o efeito top-down a partir de modificações na necessidade de ingestão de alimentos mais ricos em épocas de seca.

De acordo com Martins et al. (2019), as formigas associadas a nectários extraflorais podem afugentar os polinizadores efetivos em alguns sistemas de polinização na Caatinga, aspectos estes que podem ter um efeito importante sobre o fitness na planta. Isso por que, condições abióticas como a sazonalidade, influenciam pressão de herbivoria, taxas de visitação de formigas ou ambos (La Fuente e Marquis, 1999; Martins et al., 2020a), determinando variações nos custos e benefícios dessas associações para plantas (Di Giusto et al., 2001). Assim, há uma forte condicionalidade nas relações mutualísticas entre formigas e plantas com NEFs (Del-Claro, 2004).

Martins et al. (2020a), registraram, em área de Caatinga, um efeito negativo da interação planta-formiga sobre o fitness de uma espécie de Convolvulaceae. Durante a estação seca as formigas defendiam ativamente $\mathrm{o}$ ataque de herbívoros, reduzindo de modo significativo as taxas de herbivoria, em contrapartida, afugentavam os polinizadores de tal maneira que houve um decréscimo no sucesso reprodutivo em relação ao período chuvoso. Os mesmos autores registraram que a identidade das formigas associadas aos NEFs durante as estações seca e chuvosa, eram completamente diferentes.

A presença dos NEFs pode também ser um fator de atração para outros animais, que se beneficiam dos recursos oferecidos pela planta, por exemplo, as aranhas, que maximizam sua eficiência de captura de presas ao colonizar plantas que possuem nectários (Ruhren e Handel, 1999; Nahas et al., 2012).

Associações específicas entre aranhas e plantas são pouco conhecidas, mas há exemplos que sugerem preferência desses aracnídeos por determinadas características e/ou espécies de plantas. Por exemplo, aranhas do gênero Peucetia (Oxyopidae) ocorrem em plantas com tricomas glandulares (Morais Filho e Romero, 2010), provavelmente devido à maior facilidade de capturar presas nessas estruturas. Outro exemplo Psecas chapoda (Salticidae) que ocorre quase exclusivamente em Bromelia balansae (Bromeliaceae), passando todo o seu ciclo reprodutivo sobre a planta. As folhas da bromélia possuem arquitetura em forma de rosetas, possibilitando locais de proteção contra dessecação e inimigos naturais (Romero e Vasconcellos-Neto, 2005).

Apesar de serem quase exclusivamente carnívoras, alguns estudos têm mostrado que néctar pode ser uma importante fonte de energia para aranhas (Taylor e Pfannenstiel, 2008). Assim, a presença de néctar extrafloral pode mediar interações mutualísticas entre aranhas e plantas (Ruhren e Handel, 1999).

Como predadores extremamente diversos e abundantes que forrageiam na vegetação, aranhas tem o potencial de indiretamente aumentar o valor adaptativo das plantas que visitam, por meio da diminuição de herbívoros e consequentemente, herbivoria. Uma série de estudos demonstram tal efeito benéfico da presença de aranhas em plantas (Romero e Vasconcellos-Neto, 2004). Apesar disso, as aranhas capturam indiscriminadamente qualquer presa que pouse em seu sítio de forrageamento, assim alguns estudos demonstram efeitos negativos da presença desses predadores para plantas. Geralmente nestes casos, as aranhas atacam espécies que mantém relações mutualísticas com as plantas, como polinizadores ou outros predadores (Romero e VasconcellosNeto, 2007).

Os efeitos da predação nas interações bióticas têm sido intensamente debatidos. Entretanto, apenas recentemente tem-se dado maior atenção nos efeitos não-letais dos predadores (Lima, 1998; Werner e Peacor, 2003: Martins et al., 2019; Martins et al., 2020a, b), ou seja, a capacidade de predadores em provocar respostas comportamentais nas presas, resultando em efeitos indiretos para demais níveis tróficos da comunidade (Schmitz et al., 1997; Lima, 1998; Gonçalves-Souza et al., 2008).

O comportamento adaptativo de esquiva (Stoks et al., 2003) exibido pelos polinizadores pode ser exercido devido ao reconhecimento da presença do predador, sendo que este pode ser notado através de caracteres morfológicos 
(Gonçalves-Souza et al., 2008), do comportamento de agressividade (Ings e Chittka, 2009), bem como odores químicos (Dicke e Grostal, 2001), fornecendo assim informações decisivas e confiáveis sobre o risco de predação (Lima, 1998). Aranhas da família Thomisidae são tipicamente encontradas forrageando em flores ou folhas de diversas espécies de plantas (Lam e Tan, 2019). Essas aranhas tendem a escolher seu sítio de forrageio baseado na disponibilidade de itens alimentares (Morse e Fritz, 1982; Morse, 1984), sendo que, em sítios ótimos de forrageio elas se alimentam indiscriminadamente de diversos grupos de artrópodes (Agnew e Smith, 1989; Morse, 2007). Martins et al. (2020b) observaram, em área de Caatinga, uma redução significativa de visitas de abelhas em flores de Ipomoea carnea subs. fistulosa com aranhas artificiais, mostrando que as abelhas reconhecem os atributos dos predadores e assim evitam flores com alto risco de predação. Porém, para o mesmo sistema anteriormente falado, as abelhas não são apenas afugentadas, mas são potencialmente predadas por aranhas da família Thomisidae, que durante a espreita faz uma espécie de "toca" na extremidade da pétala floral e se camufla, atacando ativamente o polinizador (Figura 1i) (observação pessoal).

$\mathrm{O}$ estudo realizado por Martins et al. (2020b) abordou também a diversidade de aranhas que forrageiam sobre flores na Caatinga, de modo que o inventário de aranhas demonstrou grande diversidade deste grupo de predadores, sendo, portanto, necessário a realização de estudos que avaliem, de forma efetiva, o papel destas aranhas sobre as flores e o custo-benefício desta interação, levando em consideração fatores abióticos, como a sazonalidade, que é uma variável marcante no ecossistema.

Assim predadores do tipo "senta-espera", que permanecem por longo período sobre determinado sítio (e.g. aranhas Thomisidae e formigas associadas a NEFs) podem exercer maior impacto na abundância e taxa de visita de polinizadores (Suttle, 2003). Além disso, a abundância de aranhas e formigas associadas aos NEFs deve ter relação com a disponibilidade de presas local (e.g. herbívoros), que por sua vez varia sazonalmente conforme a disponibilidade e qualidade de recursos vegetais, e poucos são os estudos que avaliam os efeitos da sazonalidade climática em custos/benefícios destas interações em Florestas Tropicais Secas.

\section{O papel da fenologia nas interações multitróficas}

Fenologia é o estudo das fases ou atividades do ciclo de vida de plantas ou animais e sua ocorrência temporal ao longo do ano, contribuindo para o entendimento dos padrões reprodutivos e vegetativos de plantas e animais que delas dependem (Morellato, 1995). Estes estudos são de suma importância para compreensão da complexa dinâmica dos ecossistemas florestais, sendo o conhecimento fenológico escasso e fragmentário nas regiões tropicais (Fournier e Charpantier, 1975), e vem sendo amplamente utilizado como ferramenta em estudos de comunidades, revelando padrões de sazonalidade em espécies vegetais, que são influenciadas pela alternância das estações seca e chuvosa (Pirani e Pedroni, 2009; Lacerda et al., 2018), e, auxiliando na compreensão das interações das entre plantas e guildas de animais que utilizam seus recursos (Gadelha et al., 2017).

A evolução das interações entre animais e plantas pode ser melhor compreendida quando se considera a fenologia dos eventos vegetativos e reprodutivos das plantas (Morellato e Leitão Filho, 1996). O registro da variação das características fenológicas reúne informações sobre a dinâmica das espécies vegetais, permitindo reconhecer as diferentes estratégias de floração e com isso, as formas de organização temporal dos recursos disponíveis para polinizadores, herbívoros e consequentemente predadores (Gentry, 1974; Van Schaik et al., 1993). Os estudos fenológicos também permitem uma melhor compreensão de como esses recursos influenciam na variação temporal dessa fauna interagente (Kubota, 2003).

$\mathrm{Na}$ Caatinga, destacam-se dois comportamentos fenológicos nas plantas: caducifólias (precoces e tardias) e sempre-verdes (Lopes et al., 2019). De acordo com as definições propostas por Barbosa et al. (1989), plantas caducifólias precoces perdem as folhas no início do período seco, as caducifólias tardias perdem as folhas gradativamente durante o período seco e as sempre verdes permanecem com suas folhas ao longo do ano. A disponibilidade de água não é o único fator limitante para a fenologia da região, uma vez que, espécies sempre verdes coocorrem com espécies decíduas (Lima e Rodal, 2010), enfrentando ainda os efeitos bióticos das interações.

Em ecossistemas tropicais, a sazonalidade climática, com oscilação típica de temperatura associada, é um fator conhecido pela capacidade de desencadear as fenofases vegetativas e reprodutivas (Wright et al., 2019; Opler et al., 
1976; Borchert, 1999; Torezan-Silingardi e Oliveira, 2004; Lacerda et al., 2018). A queda foliar é concentrada geralmente na estação seca, com a rebrota ocorrendo posteriormente com o início das chuvas (Williams et al., 1997; Pirani et al., 2009; Lacerda et al., 2018). Nesses ambientes, a maioria das plantas floresce na estação seca, época em que as plantas são mais visíveis aos animais devido à queda foliar (Wright et al., 2019), ou no início da estação chuvosa, antes das chuvas mais fortes, que possivelmente danificariam as flores (Wright et al., 2019; Janzen, 1980). Os frutos, quando zoocóricos, geralmente são produzidos nas duas estações, permitindo uma maior oferta de recursos para os frugívoros, e os anemocóricos ou autocóricos, durante a seca, estando mais relacionados às condições ambientais favoráveis para a dispersão dos diásporos (Wright et al., 2019; Levin et al., 2003; Kuhlmann e Ribeiro, 2016).

Porém, de acordo com Silva (2015), nas regiões de clima tropical seco, as características de fenofases acontecem com maior constância na estação chuvosa, sendo as chuvas o fator de contribuição para o desenvolvimento das plantas, pois, as mesmas, precisam de água para o desenvolvimento de suas atividades biológicas. Um dos primeiros estudos de fenologia da Caatinga foi desenvolvido por Pereira et al. (1989) que analisaram a fenologia das espécies melíferas lenhosas e herbáceas no estado do Ceará. Lima (2007) observou que o florescimento de algumas espécies lenhosas ocorreu na estação chuvosa, e outras na estação seca, e que as espécies herbáceas floresceram apenas na estação chuvosa. Esse período também coincide com explosões populacionais das comunidades de artrópodes em todos os níveis tróficos e diferentes guildas (Martins et al., 2018).

$O$ estudo das interações inseto-planta desempenha um papel fundamental na compreensão dos processos ecológicos que envolvem as espécies, sendo importantes na descrição da estrutura, da organização e da dinâmica das comunidades (Blüthgen et al., 2008; Dáttilo et al., 2016; Dáttilo e Rico-Gray, 2018). Em função dos conhecimentos gerados sobre a fenologia é possível elaborar uma síntese das fenofases tanto vegetativas quanto reprodutivas das espécies perenifólias e decíduas. Tendo esse estudo grande importância para dar subsídio a compreensão da dinâmica das comunidades e populações do ecossistema Caatinga (Barbosa et al., 2003). Neste contexto, os artrópodes são os animais mais diversos e abundantes nos ecossistemas florestais (Price, 2002; Basset et al., 2012). Desta forma, os mecanismos que organizam as comunidades de artrópodes como a fenologia, por exemplo, devem ser bem compreendidos, especialmente para se preservar estes organismos e gerar hipóteses que possam explicar os processos reguladores e mantenedores da diversidade (Basset et al., 2003)

\section{Fenologia e polinização}

Em FTSS a fenologia de floração pode ser determinada por um conjunto de fatores e pela interação entre eles e não somente por restrições climáticas, que funcionariam mais como um gatilho, sinalizando a ocorrência de floração (Oliveira, 2008). A dinâmica de floração implica diretamente na disponibilidade de recursos alimentares utilizados por visitantes florais, como no caso das abelhas, que dependem exclusivamente desses recursos (pólen, néctar, resinas e óleos florais) para sua sobrevivência (Michener, 2000; Minckely e Roulston, 2006). As abelhas utilizam os recursos florais, tanto para a alimentação do adulto, como também para a alimentação da sua cria e construção de seus ninhos (Vogel, 1974; Neff e Simpson, 1981; Simpson e Neff, 1987; Buchmann, 1987; Lokvam e Braddock, 1999). A interação planta-abelha é particularmente importante nos trópicos (Roubik, 1979; Silva et al., 2019; Arroyo et al., 1985; Bawa et al., 1985; Gous et al., 2017). Mesmo em ambientes como Caatinga, existe uma interdependência entre abelhas e plantas, que é resultado da predominância de sistemas alógamos obrigatórios e das próprias limitações fenológicas na disponibilidade de recursos (Silberbauer-Gottsberger e Gottsberger, 1988; Barbosa, 1997; Oliveira e Gibbs, 2000; Barbosa e Sazima, 2008).

Como as abelhas são os principais polinizadores na região (Oliveira e Gibbs, 2002; Barbosa e Sazima, 2008), a disponibilidade de recursos florais utilizados por elas pode ser influenciada por estas características comunitárias gerais. A compreensão desses padrões de floração pode ajudar a explicar a capacidade de suporte do ambiente e as variações comportamentais nas populações das abelhas e de outros grupos de polinizadores na região. A oferta de recursos florais no tempo e no espaço também deve influenciar a distribuição e demografia dos insetos visitantes. Portanto, a composição florística, a distribuição dos sistemas de polinização, a fenologia e a guilda de abelhas podem estar relacionados com base na oferta de recursos florais (Mantovani e Martins, 
1988; Batalha et al., 1997; Batalha e Mantovani, 2000; Batalha e Martins, 2004; Oliveira e Gibbs, 2000; Lenza e Klink, 2006; Oliveira, 2008).

Plantas que apresentam sistemas radiculares profundos ou órgãos de reservas, como as espécies arbustivas e arbóreas, podem ser mais independentes das restrições sazonais (Tannus et al., 2006). O ajustamento na fenologia para espécies arbóreas foi bem discutido por Oliveira e Gibbs (1994) e Oliveira (1998, 2008) e estaria mais relacionado a uma interação de fatores, dentre eles, a atividade dos polinizadores (Janzen, 1967; Wright et al., 2019; Oliveira, 1998; Talora e Morellato, 2000), restrições filogenéticas (Kochmer e Handel, 1986) e estratégias diversificadas de alocação de recursos (Sarmiento e Monasterio, 1983).

Outros fatores que estariam envolvidos com a fenologia de floração seriam o período de maturação dos frutos, a ação dos dispersores e o estabelecimento das plântulas (Oliveira, 2008). Contudo, a sazonalidade pode influenciar as espécies dos estratos herbáceo e subarbustivo, que apresentam ciclos de vida curtos e limitados pela disponibilidade hídrica, em função da presença de sistemas subterrâneos superficiais (Monasterio e Sarmiento, 1976; Sarmiento, 1983; Mantovani e Martins, 1988; Tannus et al., 2006).

\section{Fenologia e herbivoria}

Estudos sobre interações inseto-planta consideram que a riqueza de espécies em comunidades de insetos herbívoros é influenciada pelas características de suas plantas hospedeiras, como área de distribuição e sua complexidade estrutural (Strong et al., 1993). A qualidade e a quantidade de recursos oferecidos pela planta hospedeira também exercem papel preponderante sobre a diversidade de insetos herbívoros (Price, 1992). A hipótese do vigor de plantas (HVP) prevê que plantas ou suas partes mais vigorosas são preferencialmente selecionadas por fêmeas de insetos indutores de galhas como sítios de oviposição, por proporcionarem melhor performance larval da prole (Price, 1991). O vigor é entendido como o crescimento de plantas ou módulos de plantas acima do crescimento médio de uma dada população (Price, 1991). O tamanho da planta pode ter um efeito positivo sobre a diversidade de insetos devido ao efeito da área per se (Strong et al., 1993). Plantas maiores disponibilizam maior quantidade de recursos (possuem mais sítios de oviposição) e são mais aparentes para o inseto galhador (Lawton, 1983; Fernandes e Price, 1988).

Em ambientes tropicais, é sugerido que a defesa de plantas seja um mecanismo evolutivo em resposta a grande pressão de herbívoros (Coley e Barone, 1996; Johnson, 2011). Alguns artigos recentes destacam a convergência adaptativa de características foliares defensivas entre diferentes grupos fenológicos de plantas (e.g. decíduo e sempre verde) (Franco et al., 2005; Chaturvedi et al., 2011; Pringle et al., 2011; Méndez-Alonzo et al., 2012). O contraste na disponibilidade de folhas entre esses grupos fenológicos tem potencial para afetar as interações herbívoro-planta (Dirzo e Domínguez, 1995; Pringle et al., 2011). Assim, a constante disponibilidade de folhas em plantas sempre verdes poderia: (1) acarretar um maior risco de ataque por herbívoros; e (2) ter favorecido uma pressão seletiva para maior investimento em defesas estruturais por estas plantas (Stanton, 1979; Janzen e Waterman, 1984; Dirzo e Boege, 2008). Em outros casos, algumas plantas desenvolveram um mecanismo de escape no tempo, produzindo folhas quando a probabilidade de herbivoria é baixa (Coley e Barone 1996), ou seja, antes do início da estação chuvosa (Aide, 1991; 1992; Sloan et al., 2006).

Para herbívoros mastigadores, durante a estação chuvosa predominaram famílias que se alimentam de folhas novas como Chrysomelidae e Curculionidae. Na transição chuva-seca e estação seca houve uma redução dessas famílias, que aumentaram em abundância após formação de brotos foliares na transição seca-chuva. $\mathrm{Na}$ transição chuvosa-seca e estação seca ocorreram herbívoros generalistas com intestino longo e mandíbulas robustas (Ortopteróides - Orthoptera e Phasmida), capazes de se alimentarem de folhas maduras ou velhas de baixa qualidade nutricional (Didham e Springate, 2003; Wardhaugh, 2014).

A deciduidade é um fenômeno que pode separar temporalmente comunidades de herbívoros e florívoros, já que em muitas espécies vegetais decíduas flor e folha fazem parte de períodos fenológicos distintos (Sanchez-Azofeifa et al., 2005). Nos trópicos onde acredita-se que a diversificação dos insetos esteja relacionada de forma mais intensa com a diversificação das plantas, existem poucos estudos sobre florivoria e nenhum ainda que tenha comparado as porcentagens de biomassa vegetal perdida por florívoros e herbívoros para a mesma espécie vegetal. Poucos estudos analisaram o funcionamento das redes tróficas de herbívoros nesta região e nenhum ainda comparou redes de 
florívoros e herbívoros para espécies de plantas filogeneticamente relacionadas. A maioria dos estudos sobre redes ecológicas na região tropical se concentram na análise de redes mutualistas, como as redes de frugivoria e dispersão de sementes (Mello et al., 2015; Dáttilo et al., 2016; Guerra et al., 2017).

A Teoria da Aparência de Plantas (Feeny, 1976) sugere que qualquer característica que possa tornar a planta aparente, ou mesmo previsível no tempo e no espaço, potencialmente aumenta a sua vulnerabilidade à herbivoria e, portanto, plantas aparentes e previsíveis tendem a investir fortemente em defesas químicas nos órgãos vegetativos e plantas não aparentes em defesas mecânicas, menos custosas (Ribeiro e Fernandes, 2000). Essa teoria é normalmente aplicada para danos por herbivoria, mas, como herbívoros podem se tornar florívoros à medida que a planta se desenvolve (McCall, 2008; McCall et al., 2018), a forma de crescimento e o tempo de duração das folhas podem influenciar igualmente a florivoria. Em uma recente análise quantitativa, Smilanich et al. (2016) indicaram que apesar do que propõe a teoria da aparência, as defesas mecânicas de plantas não aparentes podem ser mais eficazes contra a herbivoria do que as defesas químicas de plantas aparentes.

As espécies de insetos de ecossistemas com sazonalidade marcada como a Caatinga podem apresentar duas estratégias para atravessar o período desfavorável: migrar no tempo, por meio de processos de diapausa, ou migrar no espaço, deslocando-se para setores que apresentem recursos necessários à sobrevivência (Janzen, 1987; Stanton, 1979; Dirzo e Domínguez, 1995; Silva e Neves, 2014). Durante a estação seca, apenas plantas sempre verdes permanecem com folhas (Murphy e Lugo, 1986; Pezzini et al., 2014) e alguns estudos têm demonstrado uma redução marcante na diversidade de insetos (Janzen, 1973, 1987).

Dessa forma, florestas ripárias adjacentes ou plantas sempre verdes inseridas na FTSS podem atuar como sítios de refúgio para insetos durante períodos secos (Janzen, 1973; Silva e Neves, 2014). Espécies vegetais deste grupo fenológico poderiam contribuir para a manutenção da fauna residente durante a severa estação seca.

Vários estudos conduzidos nos trópicos têm revelado uma maior atividade diária de insetos, principalmente herbívoros, em períodos noturnos (Basset e Springate, 1992; Novotny et al., 1999; Wardhaugh 2014). Janzen (1983) propõe duas hipóteses para explicar a maior atividade noturna de herbívoros: (1) a existência de uma "janela" livre de inimigos naturais; e (2) uma alta concentração foliar de fotoassimilados que ainda não teriam sido translocados ou respirados. Além disso, especificamente para FTSS, pode existir uma grande variação na disponibilidade diária de recursos, temperatura, umidade e microhabitats entre as estações do ano (Murphy e Lugo, 1986, Sánchez-Azofeifa et al., 2005), afetando a atividade diária de diferentes grupos funcionais de insetos (Janzen, 1973). Assim, em FTSS, em especial na Caatinga, muito ainda precisa ser feito quanto a estudos fenológicos e seu papel na distribuição temporal da fauna associada, além de estudos que levem em consideração as flutuações da qualidade dos recursos ofertados a essa fauna de artrópodes em virtude da sazonalidade climática.

\section{Conclusão}

A Caatinga e outras florestas secas compartilham várias características, como a prevalência do sistema de polinização biótico e a dispersão abiótica de sementes. Apresentam também a ocorrência de sistemas de polinização muito especializados. As plantas com NEFs são frequentes entre as espécies de plantas da Caatinga sendo diversificada e abundante. Portanto, os mutualismos de proteção baseados em NEFs são comuns nas florestas secas, porém os custos e benefício destas relações variam sazonalmente. Logo, pode se dizer que a maioria das interações que ocorrem em Caatinga e nas Florestas secas é sazonal.

Do mesmo modo que em outras florestas secas, pesquisas que abordem temáticas básicas referentes as interações planta-animal na Caatinga são de extrema necessidade. Porém, alguns pontos possuem prioridade quanto a necessidade de estudos, haja vista que a Caatinga vem passando por níveis cada vez mais alarmantes de perturbações antrópicas, entre estes podemos citar o uso do solo, gerando perda e fragmentação de habitats, coleta de lenha, além da criação extensiva de animais domésticos.

As mudanças climáticas é outro fator que ameaça a Caatinga - com previsão de redução de 30-40\% nos níveis de precipitação até o final deste século, e já temos evidências de efeitos negativos da redução de chuvas nas assembleias de plantas.

Todos os fatores previamente citados têm sido propostos como responsáveis por alterarem a natureza, os padrões, a frequência, e a persistência de várias interações mutualísticas na Caatinga, como por exemplo as que ocorrem entre espécies endêmicas, ou com distribuição um pouco mais 
restrita, ou ainda as que envolvem recursos altamente sazonais, que estão associados a eventos fenológicos de plantas controlados por variáveis climáticas.

Assim, a quebra ou alterações nas interações causam efeitos múltiplos em vários distintos níveis biológicos que irão repercutir desde o nível de população ao nível de ecossistemas, tornando-se essencial a compreensão das interações ecológicas em termos de dinâmica florestal para que só assim ocorra de forma apropriada o planejamento para restauração e melhores práticas de conservação na Caatinga.

Os Efeitos em Cascata Trófica (ECT) basetopo e topo-base possuem forte relação com os fatores abióticos na determinação e limitação das interações e abundância das espécies. Assim, as interações entre plantas, polinizadores, herbívoros, formigas e aranhas que forrageiam em flores são fortemente influenciados pela sazonalidade, isso se dá pelo fato de a abundância e composição de espécies, comportamento e preferência alimentar variam durante a estação seca e chuvosa, assim o custo-benefício destas interações também podem variar. Do mesmo modo, a produção de compostos químicos pelas plantas recebe forte influência dos fatores ambientais como sazonalidade, nutrientes do solo, estágios fenológicos e interações entre animais.

\section{Agradecimentos}

Ao Programa de Pós-Graduação em Biologia Vegetal-PPGBV da Universidade Federal de Pernambuco-UFPE, ao Instituto Tamanduá, pelo apoio financeiro e logístico. Aos organismos de fomento: Fundação de Amparo à Ciência e Tecnologia do Estado de Pernambuco - FACEPE (PBPG-1487 - 2.05/16), Conselho Nacional de Desenvolvimento Científico e Tecnológico $(\mathrm{CNPq}$ - PQ 307422/2012-7 e PQ 309965/2016-0), Coordenação de Aperfeiçoamento de Pessoal de Nível Superior (CAPES), Brasil (Código de financiamento 001) pelo auxílio financeiro.

\section{Referências}

Aboshi, T., Ishiguri, S., Shiono, Y., Murayama, T. 2018. Flavonoid glycosides in Malabar spinach Basella alba inhibit the growth of Spodoptera litura larvae. Bioscience, Biotechnology, and Biochemistry 82, 9-14.

Agnew, C.W., Smith Jr, J.W. 1989. Ecology of spiders (Araneae) in a peanut agroecosystem. Environmental Entomology 18, 30-42.

Agrawal, A.A., Hastings, A.P., Fines, D.M., Bogdanowicz, S., Huber, M. 2018. Insect herbivory and plant adaptation in an early successional community. Evolution 72, 10201033.

Almeida Cortez, J. 2005. Herbivoria e mecanismos de defesa vegetal. In: Nogueira, R.J.M.C, Araújo, E.L., Willadino LG, Cavalcante UMT, (eds.)/(Org.). Estresses ambientais: danos e benefícios em plantas. Editora UFPE, Recife, pp. 389-396.

Almeida-Cortez, J., Shipley, B., Arnason, J.T. 2003. Effects of nutrient availability on the production of pentaynene, a secondary compound related to defense, in Rudbeckia hirta. Plant Species Biology 18, 85-89.

Alves-dos-Santos, I., Silva, C. I., Pinheiro, M., Kleinert, A. M. P. 2016. Quando um visitante floral é um polinizador? Rodriguésia 67: 295307.

Andrade, L.A., Pereira, I.M., Leite, U.T., Barbosa, M.R.V. 2005. Análise da cobertura de duas fitofisionomias de caatinga, com diferentes históricos de uso, no município de São João do Cariri, Estado da Paraíba. Cerne 11, 253-262.

Antiqueira, P.A.P., Romero, G.Q. 2016. Floral asymmetry and predation risk modify pollinator behavior, but only predation risk decreases plant fitness. Oecologia 181, 475-485.

Antonelli, A., Sanmartín, I. 2011. Why are there so many plant species in the Neotropics? Taxon 60, 403-414.

Apple, J.L., Feener, D.H. 2001. Ant visitation of extrafloral nectaries of Passiflora: The effects of nectary attributes and ant behavior on patterns in facultative antplant mutualisms. Oecologia 127, 409-416.

Aquino, R.E., Falcao, H.M., Almeida-Cortez, J.S. 2017. Variação nas concentrações de compostos fenólicos e nas taxas de herbivoria em Aspidosperma pyrifolium Mart. em áreas antropizadas de Caatinga. Journal of Environmental Analysis and Progress 2, 61-71.

Araújo, W.S. 2018. A importância de fatores temporais para a distribuição de insetos herbívoros em sistemas Neotropicais. Revista da Biologia 10, 1-7.

Arroyo, M.T., Muñoz, M.S., Henríquez, C., TillBottraud, I., Pérez, F. 2006. Erratic pollination, high selfing levels and their correlates and consequences in an altitudinally widespread above-tree-line species in the high Andes of Chile. Acta Oecologica30, 248-257.

Avila-Sakar, G., Leist, L.L., Stephenson, A.G. 2003. Effects of the spatial pattern of leaf damage on growth and reproduction: nodes and branches. Journal of Ecology 91, 867-879. 
Avila-Sakar, G., Stephenson, A.G. 2006. Effects of the spatial pattern of leaf damage on growth and reproduction: whole plants. International Journal of Plant Sciences 167, 1021-1028.

Bächtold, A., Alves-Silva, E., Kaminski, L.A., DelClaro, K. 2014. The role of tending ants in host plant selection and egg parasitism of two facultative myrmecophilous butterflies. Naturwissenschaften 101, 913-919.

Bagchi, R., Gallery, R.E., Gripenberg, S. 2014. Pathogens and insect herbivores drive rainforest plant diversity and composition. Nature 506, 85-88.

Barbosa, A.A.A., Sazima, M. 2008. Biologia reprodutiva de plantas herbáceo-arbustivas de uma área de campo sujo de cerrado. In: Sano, S. M., Almeida, S.P. Ribeiro, J.F (eds.) Cerrado: ecologia e flora. Embrapa, Brasília, DF, vol. 1, pp. 291-307.

Barbosa, D.D.A., Barbosa, M.D.A., Lima, L.D. 2003. Fenologia de espécies lenhosas da Caatinga. In: Leal IR, Tabarelli M, Silva (eds). Ecologia e Conservação da Caatinga. Editora Universitária UFPE, Recife, pp. 657-693.

Barbosa, V.S., Leal, I.R., Iannuzzi, L.J. A. 2005. Distribution Pattern of Herbivorous Insects in a Remnant of Brazilian Atlantic Forest. Neotropical Entomology 34, 701-711.

Barbour, M.A., Rodriguez-Cabal, M.A., Wu, E.T., Julkunen-Tiitto, R., Ritland, C.E., Miscampbell, A.E., Jules, E.S., Crutsinger, G.M. 2015. Multiple plant traits shape the genetic basis of herbivore community assembly. Functional Ecology 29, 995-1006.

Barros, I.O., Soares, A.A. 2013. Adaptações anatômicas em folhas de marmeleiro e velame da caatinga brasileira. Revista Ciência Agronômica 44, 192-198.

Bascompte, J., Jordano, P. 2007. Plant-animal mutualistic networks: the architecture of biodiversity. Annual Review of Ecology, Evolution, and Systematics 38, 567-593.

Basset, Y., Favaro, A., Springate, N.D., Battisti, A. 1992. Observations on the relative effectiveness of Scolytus multistriatus (Marsham) and Scolytus pygmaeus (Fabricius) (Coleoptera: Scolytidae) as vectors of the Dutch elm disease. Mitteilungen der Schweizerischen Entomologischen Gesellschaft 65, 61-67.

Basset, Y., Kitching, R., Miller, S., Novotny, V. 2003. Arthropods of tropical forests: spatiotemporal dynamics and resource use in the canopy. (Eds.). Cambridge University Press.

Bastin, J.F., Berrahmouni, N., Grainger, A., Maniatis, D., Mollicone, D., Moore, Aloui, K.
2017. The extent of forest in dryland biomes. Science 356, 635-638.

Batalha, M.A., Aragaki, S., Mantovani, W. 1997. Variaçoes fenológicas das espécies do cerrado em Emas-Pirassununga, SP. Acta Botanica Brasilica 11, 61-78.

Batalha, M.A., Mantovani, W. 2000. Reproductive phenological patterns of cerrado plant species at the Pé-de-Gigante Reserve (Santa Rita do Passa Quatro, SP, Brazil): a comparison between the herbaceous and woody floras. Revista Brasileira de Biologia 60, 129-145.

Batalha, M.A., Martins, F.R. 2004. Reproductive phenology of the cerrado plant community in Emas National Park (central Brazil). Australian Journal of Botany 52, 149-161.

Bawa, K.S., Bullock, S.H., Perry, D.R., Coville, R.E., Grayum, M.H. 1985. Reproductive biology of tropical lowland rain forest trees. II. Pollination systems. American Journal of Botany 72, 346-356.

Becerra, J. 2015. On the factors that promote the diversity of herbivorous insects and plants in tropical forests. Proceedings of the National Academy of Sciences of the United States of America 112, 6098-6103.

Becerra, J., Venable, D. L. 1989. Extrafloral nectaries: a defense against ant-Homoptera mutualisms? Oikos 276-280.

Bell, G. 1985. On the function of flowers. Proceedings of the Royal Society of London. Series B 224, 223-265.

Bentley, B.L. 1976. Plants bearing extrafloral nectaries and the associated ant community: interhabitat differences in the reduction of herbivore damage. Ecology 57, 815-820.

Bentley, B.L. 1977. Extrafloral nectaries and protection by pugnacious bodyguards. Annual Review of Ecology and Systematics 8, 407-427.

Blossey, B., Hunt-Joshi, T.R. 2003. Belowground herbivory by insects: influence on plants and aboveground herbivores. Annual Review of Entomology 48, 521-547.

Blüthgen, N., Fründ, J., Vázquez, D. P., Menzel, F. 2008. What do interaction network metrics tell us about specialization and biological traits. Ecology 89, 3387-3399.

Boege, K. 2005. Herbivore attack in Casearia nitida influenced by plant ontogenetic variation in foliage quality and plant architecture. Oecologia 143, 117-125.

Borchert, R. 1999. Climatic periodicity, phenology, and cambium activity in tropical dry forest trees. Iawa Journal, 20, 239-247. 
Boyer, M.D.H., Gorden, N.L.S., Barber, N.A., Adler, L.S. 2016. Floral damage induces resistance to florivory in Impatiens capensis. Arthropod-Plant Interactions 10, 121-131.

Brochu, K.K., van Dyke, M.T., Milano, N.J., Petersen, J.D., McArt, S.H., Nault, B.A., Danforth, B.N. 2020. Pollen defenses negatively impact foraging and fitness in a generalist bee (Bombus impatiens: Apidae). Scientific reports 10, 1-12.

Bronstein, J. L. 2015. Mutualism. (Ed.). Oxford University Press, USA.

Bronstein, J.L. 1998. The contribution of ant-plant protection studies to our understanding of mutualism. Biotropica 30, 150-161.

Buchmann, S.L. 1987. The ecology of oil flowers and their bees. Annual Review of Ecology and Systematics 18, 343-369.

Buzzard, V., Hulshof, C. M., Birt, T., Violle, C., Enquist, B. J. 2016. Re-growing a tropical dry forest: functional plant trait composition and community assembly during succession. Functional Ecology 30, 1006-1013.

Byk, J., Del-Claro, K. 2010. Nectar-and pollengathering Cephalotes ants provide no protection against herbivory: a new manipulative experiment to test ant protective capabilities. Acta Ethologica 13, 33-38.

Caldwell, E., Read, J., Sanson, G.D. 2016. Which leaf mechanical traits correlate with insect herbivory among feeding guilds? Annals of Botany 117, 349-361.

Camargo, F.A.D.O., Zonta, E., Santos, G.D.A., Rossiello, R.O.P. 2001. Aspectos fisiológicos e caracterização da toxidez de ácidos orgânicos voláteis em plantas. Ciência Rural 31, 523-529.

Cane, J.H., Minckley, R.L., Kervin, L.J., Roulston, T.A.H., Williams, N.M. 2006. Complex responses within a desert bee guild (Hymenoptera: Apiformes) to urban habitat fragmentation. Ecological Applications 16, 632-644.

Canela, M.B.F., Sazima, M. 2003. Aechmea pectinata: a Hummingbird-dependent Bromeliad with Inconspicuous Flowers from the Rainforest in South-eastern Brazil. Annals of Botany 92, 731-737.

Carezza, B.M., Patricia, A.R., Carmen, G.O., Rodrigo, M., Manuel, O.C., Alejandra, V.G. 2011. Floral herbivory affects female reproductive success and pollinator visitation in the perennial herb Alstroemeria ligtu (Alstroemeriaceae). International Journal of Plant Sciences 172, 1130-1136.
Cariveau, D., Irwin, R.E., Alison K.B., Mayeya, L.S.G., von der, D. O. 2004. Direct and indirect effects of pollinators and seed predators to selection on plant and floral traits. Oikos 104, 15-26.

Carmona, D., Lajeunesse, M. J., Johnson, M. T. 2011. Plant traits that predict resistance to herbivores. Functional Ecology 25, 358-367.

Carvalho, D.A., Oliveira, P.E. 2003. Reproductive biology and pollination of Senna sylvestris (Vell.) HS Irwin e Barneby (Leguminosae, Caesalpinoideae). Brazilian Journal of Botany 26, 319-328.

Carvalho, J.C.T., Gosmann, G., Schenkel, E.P. 2007. Compostos fenólicos simples e heterosídicos. Farmacognosia: da planta ao medicamento 6, 519-535.

Chaturvedi, R.K., Raghubanshi, A.S., Singh, J.S. 2011. Plant functional traits with particular reference to tropical deciduous forests: A review. Journal of biosciences 36, 963-981.

Chauvin, K.M., Asner, G.P., Martin, R.E., Kress, W.J., Wright, S.J., Field, C.B. 2018. Decoupled dimensions of leaf economic and anti-herbivore defense strategies in a tropical canopy tree community. Oecologia 186, 765-782.

Coelho, M.S., Belmiro, M.S., Santos, J.C. Fernandes, G.W. 2012. Herbivory among habitats on the Neotropical tree Cnidoscolus quercifolius Pohl. in a seasonally deciduous forest. Brazilian Journal of Biology 72, 453457.

Coley, P.D. 1980. Effects of leaf age and plant life history patterns on herbivory. Nature $284,545-$ 546.

Coley, P.D. 1983. Herbivory and defensive characteristics of tree species in a lowland tropical forest. Ecological Monographs 53, 209234.

Coley, P.D., Barone, J.A. 1996. Herbivory and plant defenses in tropical forests. Annual Review of Ecology and Systematics 27, 305335.

Coley, P.D., Bryant, J.P., Chapin, F.S. 1985. Resource availability and plant antiherbivore defense. Science 230, 895-899.

Coley, P.D., Endara, M.J., Kursar, T.A. 2018. Consequences of interspecific variation in defenses and herbivore host choice for the ecology and evolution of Inga, a speciose rainforest tree. Oecologia 187, 361-376.

Córdula, E., Queiroz, L.P.D., Alves, M. 2008. Checklist da flora de Mirandiba, Pernambuco: Leguminosae. Rodriguésia 59, 597-602. 
Cornelissen, J.H.C., Lavorel, S., Garnier, E., Díaz, S., Buchman, N., Gurvich, D.E., Poorter, H. 2003. A handbook of protocols for standardised and easy measurement of plant functional traits worldwide. Australian Journal of Botany 51, 335-380.

Corrêa, P.G., Pimentel, R.M.D.M., Cortez, J.S.D.A., Xavier, H.S. 2008. Herbivoria e anatomia foliar em plantas tropicais brasileiras. Ciência e Cultura 60, 54-57.

Cortina, J., Vilagrosa, A., Trubat, R. 2013. The role of nutrients for improving seedling quality in drylands. New Forests 44, 719-732.

Cuevas-Reyes, P., Quesada, M., Hanson, P., Dirzo, R., Oyama, K. 2004. Diversity of gallinducing insects in a Mexican tropical dry forest: the importance of plant species richness, life-forms, host plant age and plant density. Journal of Ecology 92, 707-716.

Cuevas-Reyes, P., Quesada, M., Oyama, K. 2006. Abundance and Leaf Damage Caused by GallInducing Insects in a Mexican Tropical Dry Forest. Biotropica: The Journal of Biology and Conservation 38, 107-115.

Danks, H.V. 2002. Modification of adverse conditions by insects. Oikos 99, 10-24.

Dáttilo, W., Lara-Rodríguez, N., Jordano, P., Guimarães Jr, P.R., Thompson, J.N., Marquis, R.J., Rico-Gray, V. 2016. Unravelling Darwin's entangled bank: architecture and robustness of mutualistic networks with multiple interaction types. Proceedings of the Royal Society B: Biological Sciences 283, 1-9.

Dáttilo, W., Rico-Gray, V. 2018. Ecological networks in the tropics. Cham, Switzerland: Springer.

Dekeukeleire, D., van Schrojenstein Lantman, I.M., Hertzog, L.R., Vandegehuchte, M.L., Strubbe, D., Vantieghem, P., Lens, L. 2019. Avian top-down control affects invertebrate herbivory and sapling growth more strongly than overstorey species composition in temperate forest fragments. Forest Ecology and Management 442, 1-9.

Del-Claro, K. 2004. Multitrophic relationships, conditional mutualisms, and the study of interaction biodiversity in tropical savannas. Neotropical Entomology 33, 665-672.

Del-Claro, K., Berto, V., Réu, W. 1996. Effect of herbivore deterrence by ants on the fruit set of an extrafloral nectary plant, Qualea multiflora (Vochysiaceae). Journal of Tropical Ecology 12, 887-892.

Del-Claro, K., Oliveira, P.S. 1999. Ant-Homoptera Interactions in a Neotropical Savanna: The
Honeydew-Producing Treehopper, Guayaquila xiphias (Membracidae), and its Associated Ant Fauna on Didymopanax vinosum (Araliaceae). Biotropica 31, 135-144.

Del-Claro, K., Oliveira, P. S. 2000. Conditional outcomes in a neotropical treehopper-ant association: temporal and species-specific variation in ant protection and homopteran fecundity. Oecologia 124, 156-165.

Del-Claro, K., Torezan-Silingardi, H.M. 2009. Insect-plant interactions: new pathways to a better comprehension of ecological communities in Neotropical savannas. Neotropical Entomology 38, 159-164.

Del-Claro, K., Torezan-Silingardi, H.M. 2012. Ecologia das interações plantas-animais: Uma abordagem ecológico-evolutiva, 1 ed. Technical Books Editora, USA.

Denslow, J.S., Vitousek, P.M., Schultz, J.C. 1987. Bioassays of nutrient limitation in a tropical rain forest soil. Oecologia 74, 370-376.

Dethier, V.G. 1941. The function of the antennal receptors in lepidopterous larvae. The Biological Bulletin 80, 403-414.

Dicke, M., Grostal, P. 2001. Chemical detection of natural enemies by arthropods: an ecological perspective. Annual Review of Ecology and Systematics 32, 1-23.

Didham, R.K., Springate, N.D. 2003. Determinants of temporal variation in community structure. Arthropods of tropical forests: spatio-temporal dynamics and resource use in the canopy 1,2839.

Doaigey, A.R. 1991. Occurrence, type, and location of calcium oxalate crystals in leaves and stems of 16 species of poisonous plants. American Journal of Botany 78, 1608-1616.

Dobson, H.E.M., Bergström, J., Bergström, G., Groth, I. 1987. Pollen and flower volatiles in two Rosa species. Phytochemistry 26, 31713173.

Domingos'melo, A., Milet'pinheiro, P., Amaral, F.N., Daniela, M., Lopes, A.V., Machado, I.C. 2019. It's raining fragrant nectar in the Caatinga: evidence of nectar olfactory signaling in bat-pollinated flowers. Ecology 101, 2914.

Dominguez, C.A., Dirzo, R. 1995. Rainfall and flowering synchrony in a tropical shrub: Variable selection on the flowering time of Erythroxylum havanense. Evolutionary Ecology 9, 204-216.

Dong, B.C., Alpert, P., Yu, F.H. 2019. Transgenerational effects of herbivory and soil nutrients transmitted via vegetative reproduction in the clonal plant Alternanthera 
philoxeroides. Perspectives in Plant Ecology, Evolution and Systematics 41, 125498.

Donovan, L.A., Maherali, H., Caruso, C.M., Huber, H., Kroon, H. 2011. The evolution of the worldwide leaf economics spectrum. Trends in Ecology \& Evolution 26, 88-95.

Dourado, A.C.P., Sá-Neto, R.J., Gualberto, S.A., Corrêa, M.M.2016. Herbivoria e características foliares em seis espécies de plantas da Caatinga do nordeste brasileiro. Revista Brasileira de Biociências 14, 145-151.

Dourado, M.N., Souza, L.A., Martins, P.F., Peters, L.P., Piotto, F.A., Azevedo, R.A. 2014. Burkholderia sp. SCMS54 triggers a global stress defense in tomato enhancing cadmium tolerance. Water, Air, \& Soil Pollution 225, 116.

Dudareva, N., Andersson, S., Orlova, I., Gatto, N., Reichelt, M., Rhodes, D., Gershenzon, J. 2005. The nonmevalonate pathway supports both monoterpene and sesquiterpene formation in snapdragon flowers. Proceedings of the National Academy of Sciences 102, 933-938.

Dukes, J.S., Pontius, J., Orwig, D., Garnas, J.R., Rodgers, V.L., Brazee, N., Cooke, B., Theoharides, K.A., Stange, E.E., Harrington, R., Ehrenfeld, J., Gurevitch, J., Lerdau, M., Stinson, K., Wick, R., Ayres, M. 2009. Responses of insect pests, pathogens, and invasive plant species to climate change in the forests of northeastern North America: What can we predict? Canadian Journal of Forest rRsearch, 39, 231-248.

Durigan, G., Ratter, J.A. 2016. The need for a consistent fire policy for Cerrado conservation. Journal of Applied Ecology 53, 11-15.

Edwards, P.J., Wratten, S.D. 1981. Ecologia das interações entre insetos e plantas, 1ed. Fonseca VLI (Trad.) EPU, São Paulo.

Ehrlen, J. 1995. Demography of the perennial herb Lathyrus vernus. II. Herbivory and population dynamics. Journal of Ecology 83, 297-308.

Eldridge, D.J., Delgado-Baquerizo, M., Travers, S. K., Val, J., Oliver, I. 2017. Do grazing intensity and herbivore type affect soil health? Insights from a semi-arid productivity gradient. Journal of Applied Ecology 54, 976-985.

Elias, P.M. 1983. Epidermal lipids, barrier function, and desquamation. Journal of Investigative Dermatology 80, 44-49.

Endara, M.J., Coley, P.D. 2011. The resource availability hypothesis revisited: a metaanalysis. Functional Ecology 25, 389-398.

Espírito-Santo, M.R.M., Fagundes, M., Nunes, Y.R.F., Fernandes, G.W., Azofeifa, G.A.S.,
Quesada, M. 2006. Bases para a conservação e uso sustentável das florestas estacionais deciduais brasileiras: a necessidade de estudos multidisciplinares. Unimontes Científica 8, 1322.

Faegri, K., Van Der Pijl, L. 2013. Principles of pollination ecology, 3 ed. Pergamon Press, Elsevier.

Falcão, H.M., Medeiros, C.D., Almeida-Cortez, J., Santos, M.G. 2017. Leaf construction cost is related to water availability in three species of different growth forms in a Brazilian tropical dry forest. Theoretical and Experimental Plant Physiology 29, 95-108.

Feeny, P. (1976). Plant apparency and chemical defense. In Biochemical interaction between plants and insects(pp. 1-40). Springer, Boston, MA.

Fenster, C.B., Armbruster, W.S., Wilson, P., Dudash, M.R., Thomson, J.D. 2004. Pollination syndromes and floral specialization. Annual Review of Ecology, Evolution, and Systematics 35, 375-403.

Fernandes, G.W. 1994. Plant mechanical defenses against insect herbivory. Revista Brasileira de Entomologia 38, 421-433.

Fernandes, G.W., Price, P.W. 1988. Biogeographical gradients in galling species richness. Oecologia 76, 161-167.

Fernandes, G.W., Price, P.W. 1992. The adaptive significance of insect gall distribution: survivorship of species in xeric and mesic habitats. Oecologia, 90, 14-20.

Fernandes, S.P.C., Ferreira, A.L.N., AlmeidaCortez, J.S. 2012. Riqueza de galhas entomógenas em áreas antropizadas e preservadas de caatinga. Revista Árvore 36, 269-277.

Fine, P.V., Miller, Z.J., Mesones, I., Irazuzta, S., Appel, H.M., Stevens, M.H.H., Coley, P.D. 2006. The growth-defense trade-off and habitat specialization by plants in Amazonian forests. Ecology 87, S150-S162.

Fonseca, M.B., Silva, J.O., Falcão, L.A., Dupin, M.G., Melo, G.A., Espírito-Santo, M.M. 2018. Leaf damage and functional traits along a successional gradient in Brazilian tropical dry forests. Plant Ecology 219, 403-415.

Forister, M.L., Novotny, V., Panorska, A.K., Baje, L., Basset, Y., Butterill, P.T., Drozd, P. 2015. The global distribution of diet breadth in insect herbivores. Proceedings of the National Academy of Sciences 112, 442-447. 
Fornoni, J. 2011. Ecological and evolutionary implications of plant tolerance to herbivory. Functional Ecology 25, 399-407.

Forrest, J.K.R. 2015. Plant-pollinator interactions and phenological change: what can we learn about climate impacts from experiments and observations? Oikos 124, 4-13.

Fournier-Origgi, L.A., Charpentier-Esquivel, C. 1975. El tamaño de la muestra y la frecuencia de las observaciones en el estudio de las características fenológicas de los árboles tropicales. Turrialba 25, 45-48.

Franco, A.C., Bustamante, M., Caldas, L.S., Goldstein, G., Meinzer, F.C., Kozovits, A.R., Coradin, V.T. 2005. Leaf functional traits of Neotropical savanna trees in relation to seasonal water deficit. Trees 19, 326-335.

Franco, M.J.C.S., Albiero, A.L.M. 2018. Estruturas secretoras em folha e caule de Esenbeckia febrifuga (A. St.-Hil.) A. Juss. ex Mart. e Esenbeckia grandiflora Mart. (Rutaceae). Hoehnea 45, 468-483.

Funk, J.L., Larson, J.E., Ames, G.M., Butterfiel, B.J., Cavender-Bares, J., Firn, J., Laughlin, D.C., Sutton-Grier, A.E., Williams, L., Wright, J. 2017. Revisiting the Holy Grail: using plant functional traits to understand ecological processes. Biological Reviews 92, 1156-1173.

Fürstenberg-Hägg, J., Zagrobelny, M., Bak, S. 2013. Plant defense against insect herbivores. International journal of molecular sciences 14 , 10242-10297.

Gadelha, Y.E., Lange, D., Dattilo, W., Lopes, B.C. 2017. Phenological phases of the host plant shape plant-treehopper interaction networks. Ecological entomology 42, 827-837.

Galen, C. 1999. Why do flowers vary? The functional ecology of variation in flower size and form within natural plant populations. Bioscience 49, 631-640.

Gely, C., Laurance, S.G., Stork, N.E. 2020. How do herbivorous insects respond to drought stress in trees? Biological Reviews 95, 434-448.

Gentry, A.H. 1974. Coevolutionary patterns in Central American Bignoniaceae. Annals of the Missouri Botanical Garden 61, 728-759.

Giordano, C., Maleci, L., Agati, G., Petruccelli, R. 2020. Ficus carica L. leaf anatomy: Trichomes and solid inclusions. Annals of Applied Biology 176, 47-54.

Giusto, B., Anstett, M.C., Dounias, E., McKey, D.B. 2001. Variation in the effectiveness of biotic defence: the case of an opportunistic antplant protection mutualism. Oecologia 129, 367-375.
Givnish, T.J. 2002. Adaptive significance of evergreen vs. deciduous leaves: solving the triple paradox. Silva Fennica 36, 703-743.

Gobbo-Neto, L., Lopes, N.P. 2007. Plantas medicinais: fatores de influência no conteúdo de metabólitos secundários. Química Nova 30, 374-381.

Godschalx, A.L., Stady, L., Watzig, B., Ballhorn, D.J. 2016. Is protection against florivory consistent with the optimal defense hypothesis? BMC Plant Biology, 16, 1-9.

Gomes, V.G.N., Meiado, M.V., Quirino, Z.G.M., Machado, I.C. 2016. Seed removal by lizards and effect of gut passage on germination in a columnar cactus of the Caatinga, a tropical dry forest in Brazil. Journal of Arid Environments135, 85-89.

Gomes, V.G.N., Quirino, Z.G.M. 2016. Síndromes de dispersão de espécies vegetais no Cariri Paraibano. Revista Brasileira de Geografia Física 9, 1157-1167.

Gomes, V.G.N., Quirino, Z.G.M. Machado, I.C. 2014b. Pollination and seed dispersal of Melocactus ernestii Vaupel subsp. Ernestii (Cactaceae) by lizards: an example of double mutualism. Plant Biology 16, 315-322.

Gomes, V.G.N., Quirino, Z.G.M., Araujo, H.F.P. 2014a. Frugivory and seed dispersal by birds in Cereus jamacaru DC. ssp. Jamacaru (Cactaceae) in the Caatinga of northeastern Brazil. Brazilian Journal of Biology 74, 32-40.

Gompert, Z., Lucas, L.K., Buerkle, C.A., Forister, M.L., Fordyce, J.A., Nice, C.C. 2014. Admixture and the organization of genetic diversity in a butterfly species complex revealed through common and rare genetic variants. Molecular Ecology 23, 4555-4573.

Goncalves-Souza, T., Omena, P.M., Souza, J.C., Romero, G.Q. 2008. Trait-mediated effects on flowers: artificial spiders deceive pollinators and decrease plant fitness. Ecology 89, 24072413.

González-Esquivel, J.G., Cuevas-Reyes, P., González-Rodríguez, A., Ávila-Cabadilla, L.D., Álvarez-Añorve, M.Y., Fagundes, M., Maldonado-López, Y. 2019. Functional attributes of two Croton species in different successional stages of tropical dry forest: effects on herbivory and fluctuating asymmetry patterns. Tropical Ecology 60, 238-251.

Goodland, R., Pollard, R. 1973. The Brazilian cerrado vegetation: a fertility gradient. The Journal of Ecology, 61, 219-224.

Gous, A., Willows-Munro, S., Eardley, C., Swanevelder, Z.H.D. 2017. Pollination: Impact, 
role-players, interactions and study-A South African perspective. South African Journal of Science 113, 1-8.

Goyret, J., Markwell, P.M., Raguso, R.A. 2007. The effect of decoupling olfactory and visual stimuli on the foraging behavior of Manduca sexta. Journal of Experimental Biology 210, 1398-1405.

Griz, L.M.S., Machado, I.C. 2001. Fruiting phenology and seed dispersal syndromes in Caatinga, a tropical dry forest in the northeast of Brazil. Journal of Tropical Ecology 17, 303321.

Griz, L.M.S., Machado, I.C.S., Tabarelli, M. 2002. Ecologia de dispersão de sementes: progressos e perspectivas. Diagnóstico da biodiversidade de Pernambuco. Secretaria de Ciência, Tecnologia e Meio Ambiente, Recife.

Guedes, R.S., Zanella, F.C.V., Martins, C.F., Schlindwein, C. 2011. Déficit de polinização da aceroleira no período seco no semiárido paraibano. Revista Brasileira de Fruticultura 33, 465-471.

Guerra, J.V.S., Carvalho, A.J.D., Medeiros, J.C., Souza, A.A.D., Brito, O.G. 2017. Agronomic performance of erect and semi-erect cowpea genotypes in the north of Minas Gerais, Brazil. Revista Caatinga 30, 679-686.

Gullan, P.J., Cranston, O.S. 2007. Os Insetos: Um Resumo de Entomologia, 4 Ed. Roca, São Paulo.

Hahn, P.G., Maron, J.L. 2018. Plant water stress and previous herbivore damage affect insect performance. Ecological Entomology 43, 4754.

Halitschke, R., Hamilton, J.G., Kessler, A. 2011. Herbivore-specific elicitation of photosynthesis by mirid bug salivary secretions in the wild tobacco Nicotiana attenuata. New Phytologist 191, 528-535.

Heil, M. 2011. Nectar: generation, regulation, and ecological functions. Trends in plant science 16, 191-200.

Heil, M., Mckey, D. 2003. Protective ant-plant interactions as model systems in ecological and evolutionary research. Annual Review of Ecology, Evolution, and Systematics 34, 425553.

Hernán, M.A., Hsu, J., Healy, B. 2019. A second chance to get causal inference right: a classification of data science tasks. Chance 32, 42-49.

Herrera, C.M. 2002. Seed dispersal by vertebrates.In: Carlos M.H., Pellmyr, O. (eds.)
Plant-animal interactions: an evolutionary approach, Blackwell Publishing, pp. 185-208.

Hinman, E. D., Fridley, J. D., Parry, D. 2019. Plant defense against generalist herbivores in the forest understory: a phylogenetic comparison of native and invasive species. Biological invasions, 21(4), 1269-1281.

Hladun, K.R., Adler, L.S. 2009. Influence of leaf herbivory, root herbivory, and pollination on plant performance in Cucurbita moschata. Ecological Entomology 34, 144-152.

Horvitz, C.C., Schemske, D.W. 1984. Effects of ants and an ant-tended herbivore on seed production of a neotropical herb. Ecology 65, 1369-1378.

Ings, T.C., Chittka, L. 2009. Predator crypsis enhances behaviourally mediated indirect effects on plants by altering bumblebee foraging preferences. Proceedings of the Royal Society of London B: Biological Sciences 276, 2031-2036.

Ishino, M.N., De Sibio, P.R., Rossi, M.N. 2011. Leaf trait variation on Erythroxylum tortuosum (Erythroxylaceae) and its relationship with oviposition preference and stress by a hostspecific leaf miner. Austral Ecology 36, 203211.

Janzen, D.H. 1966. Coevolution of mutualism between ants and acacias in Central America. Evolution 20, 249-275.

Janzen, D.H. 1973. Sweep samples of tropical foliage insects: effects of seasons, vegetation types, elevation, time of day, and insularity. Ecology 54, 687-708.

Janzen, D.H. 1980. Specificity of seed-attacking beetles in a Costa Rican deciduous forest. The Journal of Ecology, 929-952.

Janzen, D.H. 1983. Seasonal change in abundance of large nocturnal dung beetles (Scarabaeidae) in a Costa Rican deciduous forest and adjacent horse pasture. Oikos, 274-283.

Janzen, H.H. 1987. Soil organic matter characteristics after long-term cropping to various spring wheat rotations. Canadian Journal of Soil Science 67, 845-856.

Johnson, M. T. 2011. Evolutionary ecology of plant defences against herbivores. Functional Ecology 25, 305-311.

Juenger, T., Bergelson, J. 1997. Pollen and resource limitation of compensation to herbivory in scarlet gilia, Ipomopsis aggregata. Ecology 78, 1684-1695.

Kang, H., Bawa, K. S. 2003. Effects of successional status, habit, sexual systems, and pollinators on flowering patterns in tropical rain 
forest trees. American Journal of Botany 90, 865-876.

Karabourniotis, G., Bornman, J. F., Liakoura, V. 1999. Different leaf surface characteristics of three grape cultivars affect leaf optical properties as measured with fiber optics: possible implication in stress tolerance. Functional Plant Biology 26, 47-53.

Karban, R. B., Baldwin, I. T. 1997. University of Chicago Press Karban Induced responses to herbivory.

Karban, R., Agrawal, A.A. 2002. Herbivore offense. Annual Review of Ecology and Systematics 33, 641-664.

Kennedy, B. S., Nielsen, M. T., Severson, R. F., Sisson, V. A., Stephenson, M. K., Jackson, D. M. 1992. Leaf surface chemicals from Nicotiana affecting germination of Peronospora tabacina (adam) sporangia. Journal of Chemical Ecology, 18(9), 1467-1479.

Kerpel, S.M., Soprano, E., Moreira, G.R.P. 2006. Effect of nitrogen on Passiflora suberosa L. (Passifloraceae) and consequences for larval performance and oviposition in Heliconius erato phyllis (Fabricius) (Lepidoptera: Nymphalidae). Neotropical Entomology 35, 192-200.

Kessler, A., Halitschke, R. 2009. Testing the potential for conflicting selection on floral chemical traits by pollinators and herbivores: predictions and case study. Functional Ecology 23, 901-912.

Kevan, P.G. 1999. Pollinators as bioindicators of the state of the environment: species, activity and diversity. Agriculture, Ecosystems and Environment 74, 373-393.

Kirmse, S., Chaboo, C.S. 2018. Polyphagy and florivory prevail in a leaf-beetle community (Coleoptera: Chrysomelidae) inhabiting the canopy of a tropical lowland rainforest in southern Venezuela. Journal of Natural History 52, 2677-2721.

Kitajima, K., Poorter, L. 2008. Functional basis for resource niche partitioning by tropical trees. Tropical forest community Ecology 160-181.

Koptur, S. 1992. Plants with extrafloral nectaries and ants in Everglades habitats. Florida Entomologist 38-50.

Koptur, S. 2005. Nectar as fuel for plant protectors. Plant-provided food for carnivorous insects: a protective mutualism and its applications. Cambridge University Press, Cambridge, pp. 75-108.

Koptur, S., Rico-Gray, V., Palacios-Rios, M. 1998. Ant protection of the nectaried fern Polypodium plebeium in central Mexico. American Journal of Botany 85, 736-739.

Kozlov, M.V., Lanta, V., Zverev, V., Zvereva, E.L. 2015b. Global patterns in background losses of woody plant foliage to insects. Global Ecology and Biogeography 24, 1126-1135.

Kozlov, M.V., Stekolshchikov, A.V., Söderman, G., Labina, E.S., Zverev, V., Zvereva, E.L. (2015a). Sap-feeding insects on forest trees along latitudinal gradients in northern Europe: a climate-driven patterns. Global Change Biology 21,106-116.

Krupnick, G.A., Weis, A.E. 1999. The effect of floral herbivory on male and female reproductive success in Isomeris arborea. Ecology 80, 135-149.

Kubota, U. 2003. Fenologia da comunidade de Asteraceae, variação temporal e determinantes locais de riqueza de insetos endófagos de capítulos.

Kuhlmann, M., Ribeiro, J.F. 2016. Evolution of seed dispersal in the Cerrado biome: ecological and phylogenetic considerations. Acta Botanica Brasilica 30, 271-282.

La Fuente, M.A.S., Marquis, R.J. 1999. The role of ant-tended extrafloral nectaries in the protection and benefit of a Neotropical rainforest tree. Oecologia 118, 192-202.

Lacerda, B.N., R., Araújo, P.E.I., Maciel, M.S.C., de Paula, A., Tagliaferre, C. 2018. Fenologia de Astronium graveolens Jacq. em floresta estacional decidual em vitória da conquista, Bahia. Ciência Florestal (01039954), 28.

Lam, W. N., \& Tan, H. T. (2019). The crab spiderpitcher plant relationship is a nutritional mutualism that is dependent on prey-resource quality. Journal of Animal Ecology, 88(1), 102113.

Lara, F.M. 1991. Princípios de resistência de plantas a insetos. 2 ed. Ícone, São Paulo.

Lavor, D.T., Brito-Ramos, A.B. 2016. Estudo preliminar das síndromes de polinização em um fragmento de Caatinga, PE, Brasil. Biotemas 29, 19-30.

Lawton, J. H. 1983. Plant architecture and the diversity of phytophagous insects. Annual Review of Entomology 28, 23-39.

Leal, C.C.P., Torres, S.B., Dantas, L.N.B., Aquino, G.S.M., Alves, T.R.C. 2020. Water stress on germination and vigor of 'mofumbo' (Combretum leprosum Mart.) seeds at different temperatures. Revista Ciência Agronômica 51, $1-7$.

Leal, I. R., Lopes, A. V., Machado, I. C., Tabarelli, M. 2018. Interações planta-animal na Caatinga: 
visão geral e perspectivas futuras. Ciência e Cultura 70, 35-40.

Leal, I.R., Leal, L.C., Andersen, A.N. 2015. The benefits of myrmecochory: a matter of stature. Biotropica 47, 281-285.

Leal, I.R., Lopes, A.V., Machado, I.C. Tabarelli, M. 2018. Interações planta-animal na Caatinga: visão geral e perspectivas futuras. Ciência e Cultura,70.

Leal, I.R., Tabarelli, M., Silva, J.M.C. 2003. Ecologia e conservação da Caatinga. Editora Universitária UFPE.

Leal, I.R., Wirth, R., Tabarelli, M. 2007. Seed dispersal by ants in semiarid Caatinga of northeastern Brazil". Annals of Botany 99, 885894.

Leal, L.C., Andersen, A. N., Leal, I. R. 2011. Anthropogenic disturbance reduces seeddispersal services for myrmecochorous plants in the Brazilian Caatinga. Oecologia 174, 173171.

Leavitt, H., Robertson, I.C. 2006. Petal herbivory by chrysomelid beetles (Phyllotreta sp.) is detrimental to pollination and seed production in Lepidium papilliferum (Brassicaceae). Ecological Entomology 31, 657-660.

Lehtilä, K., Strauss, S.Y. 1999. Effects of foliar herbivory on male and female reproductive traits of wild radish, Raphanus raphanistrum. Ecology 80, 116-124.

Lenza, E., Klink, C. A. 2006. Comportamento fenológico de espécies lenhosas em um cerrado sentido restrito de Brasília, DF. Revista Brasileira de Botânica 29, 627-638.

Levin, S.A., Muller-Landau, H.C., Nathan, R., Chave, J. 2003. The ecology and evolution of seed dispersal: a theoretical perspective. Annual Review of Ecology, Evolution, and Systematics 34, 575-604.

Lewinsohn, T.M. et al. 2005. Conservação de invertebrados terrestres e seus habitats no Brasil. Megadiversidade 1, 62-69.

Lima, A.L.A., Rodal, M.J.N. 2010. Phenology and wood density of plants growing in the semi-arid region of northeastern Brazil. Journal of Arid Environments 74, 1363- 1373.

Lima, C.G.A., Sampaio, E.V.D.S.B., Silva, J. 2013. Estrutura Espacial e Biomassa da Parte Aérea em Diferentes Estádios Sucessionais de Caatinga, em Santa Terezinha, Paraíba. Revista Brasileira de Geografia Fisica 6, 66-574.

Lima, N.E., Carvalho, A.A., Lima-Ribeiro, M.S., Manfrin, M.H. 2018. Caracterização e história biogeográfica dos ecossistemas secos neotropicais. Rodriguésia 69, 2209-2222.
Lima, S.L. 1998. Nonlethal effects in the ecology of predator-prey interactions. Bioscience 48, 25-34

Lohbeck, M. et al. 2013. Successional changes in functional composition contrast for dry and wet tropical forest. Ecology 94, 1211-1216.

Lokvam, J., Braddock, J.F. 1999. Anti-bacterial function in the sexually dimorphic pollinator rewards of Clusia grandiflora (Clusiaceae). Oecologia 119, 534-540.

Lopes, A.P.S., Diniz, I.R., Moraes, M.C.B., Borges, M., Laumann, R.A. 2012. Defesas induzidas por herbivoria e interações específicas no sistema tritrófico sojapercevejos-parasitoides de ovos. Pesquisa Agropecuária Brasileira, 47, 875-878.

Lopes, I., Montenegro, A.A., Lima, J.L. 2019. Performance of conservation techniques for semiarid environments: Field observations with Caatinga, mulch, and cactus forage palma. Water 11, 1-15.

Louda, S.M. 1983. Seed predation and seedling mortality in the recruitment of a shrub, Haplopappus venetus (Asteraceae), along a climatic gradient. Ecology 64, 511-521.

Lucas, P.W., Turner, I.M., Dominy, N.J., Yamashita, N. 2000. Mechanical defences to herbivory. Annals of Botany 86, 913-920.

Lucas-Barbosa, D., Van Loon, J.Ja, Dicke, M. 2011. The effects of herbivore-induced plant volatiles on interactions between plants and flower-visiting insects. Phytochemistry 72, 647-1654.

Machado, I. C., Lopes, A. V. 2004. Floral traits and pollination systems in the Caatinga, a Brazilian tropical dry forest. Annals of Botany 94, 365376.

Machado, I. C., Lopes, A. V. Sazima, M. 2006. Plant sexual systems and review of the breeding system studies in the Caatinga, a Brazilian tropical dry forest. Annals of Botany 97, 277287.

Magrin, G.O., Marengo, J.A., Boulanger, J.P., Buckeridge, M.S., Castellanos, E., Poveda, G., Scarano, F.R., Vicuña, S. "Central and South America. 2014. In: Climate change: Impacts, adaptation, and vulnerability. Part B: Regional aspects. Contribution of working group II to the fifth assessment report of the Intergovernmental Panel on Climate Change. Barros, V. R., Field, C. B., Dokken, D. J., Mastrandrea, M. D., Mach, K. L., Bilir, T. E. (eds) Cambridge University Press, Cambridge, United Kingdom and New York, NY, USA, pp. 1499-1566. 
Malheiros, R. 2016. A influência da sazonalidade na dinâmica da vida no bioma cerrado (The seasonality influence in the dynamics of life on cerrado biome). Revista Brasileira de Climatologia 19.

Mantovani, M. et al. 2003. Fenologia reprodutiva de espécies arbóreas em uma formação secundária da floresta atlântica. Revista Árvore 27, 451-458.

Mantovani, W., Martins, F.R. 1988. Variações fenológicas das espécies do cerrado da Reserva Biológica de Moji Guaçu. Revista Brasileira de Botânica11, 101-12.

Marazzi, B., Bronstein, J. L., Koptur, S. 2013a. The diversity, ecology and evolution of extrafloral nectaries: current perspectives and future challenges. Annals of Botany,111, 1243-1250.

Maron, J. L., Gardner, S. N. 2000. Consumer pressure, seed versus safe-site limitation, and plant population dynamics. Oecologia 124, 260269.

Marquis, R.J. 1988. Phenological variation in the neotropical understory shrub Piper arielanum: causes and consequences. Ecology, 69, 15521565.

Marquis, R.J., Braker, H.E. 1994. Plant-herbivore interactions: Diversity, specificity, and impact. La Selva: Ecology and Natural History of a Neotropical Rainforest (eds. L. McDade, G. H. Hartshorn, H. Hespenheide \& K. Bawa) University of Chicago Press, Chicago, pp 263281.

Martens, J., Almeida-Cortez, J. S., Germer, J., Sauerborn, J. 2015. Umbuzeiro (Spondias Tuberosa): a systematic review. Revista Brasileira de Ciências Ambientais, 179-197.

Martins, J.K.S.S., Carneiro, A., Souza, L., Almeida-Cortez, J.S 2020a. How pollinator visits are affected by flower damage and ants presence in Ipomoea carnea subs. fistulosa (Martius and Choise) (Convolvulaceae)? Brazilian Journal of Biology 80(1): 47-56

Martins, J.K.S.S., Moreira, A., Assunção, M., Oliveira, A.F.M., Almeida, J.S 2020b. Tradeoff in plant-ant interactions: seasonal variations. Brazilian Journal of Biology, 80 (4), 921-933.

Martins, J.K.S.S., Silva, A.D. L. M., Assunção, M.A.S., Oliveira, A.F.M., Almeida, J.S. 2020c. Efeitos indiretos de predadores sobre o comportamento dos polinizadores de Ipomoea carnea subs. fistulosa (Convolvulaceae) em Floresta Tropical Seca. Journal of Environmental Analysis and Progress, 5, 049057.
Martins, J.K.S.S., Souza, L.S., Carneiro, A.G., Almeida-Cortez, J.S. 2018. Variação temporal e espacial da artropodofauna associada a Ipomoea carnea subs. fistulosa (Convolvulaceae) em um ecossistema de Floresta Tropical Seca. Journal of Environmental Analysis and Progress 3, 356378.

Mattson, Jr., W.J. 1980. Herbivory in relation to plant nitrogen content. Annual Review of Ecology and Systematics 11, 119-161.

Mayle, F.E. 2006. The Late Quaternary biogeographical history of South American seasonally dry tropical forests: insights from palaeo-ecological data. In: Pennington RT \& Ratter JA (eds.) Neotropical savannas and seasonally dry forests plant diversity biogeography, and conservation. Taylor \& Francis, Boca Raton. Pp. 395-416.

McCall, A.C. 2008. Florivory affects pollinator visitation and female fitness in Nemophila menziesii. Oecologia 155, 729-737.

McCall, A.C., Case, S., Espy, K., Adams, G., Murphy, S.J. 2018. Leaf herbivory induces resistance against florivores in Raphanus sativus. Botany 96, 337-343.

McCall, A.C., Irwin, R.E. 2006. Florivory: the intersection of pollination and herbivory. Ecology letters 9, 1351-1365.

McKey, D. 1974. Adaptive patterns in alkaloid physiology. The American Naturalist, 108, 305320.

Medeiros, J.D., Morretes, B. L. 1995. Dimensões da folha e herbivoria em Miconia cabucu Hoehne (Melastomataceae). Biotemas 8, 97112.

Mello, M.A.R., Rodrigues, F.A., Costa, L.D.F., Kissling, W.D., Şekercioğlu, Ç.H., Marquitti, F.M. D., Kalko, E.K.V. 2015. Keystone species in seed dispersal networks are mainly determined by dietary specialization. Oikos 124, 1031-1039.

Melo Nascimento, J.E., Freitas, B.M., Souza, Pacheco Filho, S.A.J., Pereira, E.S., Meneses, H.M., Alves, J.E., Silva, C.I. 2019. Temporal variation in production and nutritional value of pollen used in the diet of Apis mellifera L. in a seasonal semideciduous forest. Sociobiology 66, 263-273.

Melo, M.O., Silva-Filho, M.C. 2002. Plant-insect interaction: an evolutionary arms race between two distinct defense mechanisms. Brazilian Journal of Plant Physiology 14, 7181.

Méndez-Toribio, M., Ibarra-Manríquez, G., Paz, H., Lebrija-Trejos, E. 2020. Atmospheric and soil drought risks combined shape community 
assembly of trees in a Tropical Dry Forest. Journal of Ecology 108: 1347-1357.

Méndez-Toribio, M., Ibarra-Manríquez, G., Paz, H., Lebrija-Trejos, E. 2020. Atmospheric and soil drought risks combined shape community assembly of trees in a Tropical Dry Forest. Journal of Ecology. 108: 1347-1357.

Metcalfe, D.B., Asner, G.P., Martin, R.E., Silva Espejo, J.E., Huasco, W.H., Farfán Amézquita, F.F., Huaraca Quispe, L.P. 2014. Herbivory makes major contributions to ecosystem carbon and nutrient cycling in tropical forests. Ecology letters 17, 324-332.

Michener, C. D. (2000). The bees of the world (Vol. 1). JHU press.

Moraes, C. P. D., Almeida, M. D. 2004. Influência climática sobre a plasticidade fenotípica floral de Catasetum fimbriatum Lindley. Ciência e Agrotecnologia 28, 942-948.

Morais-Filho, M.J.C., Romero, G. Q. 2010. Plant glandular trichomes mediate protective mutualism in a spider-plant system. Ecological Entomology 35, 485-494.

Moreira, V. S., Del-Claro, K. 2005. The outcomes of an ant-treehopper association on Solanum lycocarpum St. Hill: increased membracid fecundity and reduced damage by chewing herbivores. Neotropical Entomology 34, 881887.

Moreira, X., Castagneyrol, B., Abdala-Roberts, L., Berny-Mier y Teran, J.C., Timmermans, B. G., Bruun, H.H., Covelo, F., Glauser, G., Rasmann, S., Tack A. J. M., 2018. Latitudinal variation in plant chemical defences drives latitudinal patterns of leaf herbivory. Ecography 41 (7), 1124-1134.

Morellato, L.P., Rodrigues, R.R., Leitão-Filho, H.D., Joly, C.A. 1989. Estudo comparativo da fenologia de espécies arbóreas de floresta de altitude e floresta mesófila semidecídua na Serra do Japi, Jundiaí, São Paulo. Revista Brasileira de Botânica 12, 85-98.

Morellato, L.P.C. 1995. As estações do ano na floresta. Ecologia e preservação de uma floresta tropical urbana: Reserva de Santa Genebra. Campinas: UNICAMP, 187-192.

Morellato, L.P.C., Haddad, C.F. 2000. Introduction: The Brazilian Atlantic Forest 1. Biotropica 32, 786-792.

Morellato, P.C., Leitao-Filho, H.F. 1996. Reproductive phenology of climbers in a southeastern Brazilian forest. Biotropica 28, 180-191.

Moro, M.F. Lughadha, E.M., Filer, D.L., Araújo, F.S., Martins, F.R. 2014. A catalogue of the vascular plants of the Caatinga phytogeographical domain: A synthesis of floristic and phytosociological surveys. Phytotaxa 160, 1-30.

Moro, M.F., Lughadha, E.N., de Araújo, F.S., Martins, F.R. 2016. A phytogeographical metaanalysis of the semiarid Caatinga domain in Brazil. The Botanical Review 82, 91-148.

Morse, D.H. 1984. How crab spiders (Araneae, Thomisidae) hunt at flowers. Journal of Arachnology 12, 307-316.

Morse, D.H. 2007. Predator upon a flower: life history and fitness in a crab spider. Harvard University Press.

Morse, D.H., Fritz, R.S. 1982. Experimental and observational studies of patch choice at different scales by the crab spider Misumena vatia. Ecology 63, 172-182.

Mothershead, K., Marquis, R. J. 2000. Fitness impacts of herbivory through indirect effects on plant-pollinator interactions in Oenothera macrocarpa. Ecology 81, 30-40.

Muiruri, E.W., Barantal, S., Iason, G.R., Salminen, J.P., Perez-Fernandez, E., Koricheva, J. 2019. Forest diversity effects on insect herbivores: do leaf traits matter? New Phytologist, 221, 22502260.

Munhoz, C.B.R., Felfili, J. M. 2005. Fenologia do estrato herbáceo-subarbustivo de uma comunidade de campo sujo na Fazenda Água Limpa no Distrito Federal, Brasil. Acta Botanica Brasilica 19, 979-988.

Murphy, P.G., Lugo, A.E. 1986. Ecology of tropical dry forest. Annual Review of Ecology and Systematics 17, 67-88.

Myers, J.H., Simberloff, D., Kuris, A.M., Carey, J.R. 2000. Eradication revisited: dealing with exotic species. Trends in Ecology \& Evolution 15, 316-320.

Nahas, L., Gonzaga, M. O., Del-Claro, K. 2012. Emergent impacts of ant and spider interactions: herbivory reduction in a tropical savanna tree. Biotropica 44, 498-505.

Nascimento, F.R., Souza, M.J.N., Cruz, M.L.B. 2007. Enfoque geoambiental para o tratamento da degradação/desertificação no município de Sobral-Nordeste do Brasil/Ceará. Ateliê Geográfico 1, 80-101.

Neff, J.L., Simpson, B.B. 1981. Oil-collecting structures in the Anthophoridae (Hymenoptera): morphology, function, and use in systematics. Journal of the Kansas Entomological Society 54, 95-123.

Neves, E. L., Viana, B. F. 2008. Dispersão e predação de Sementes de três espécies de 
Jatropha L. (Euphorbiaceae) da Caatinga, semiárido do Brasil. Candombá 4, 146-157.

Neves, F.S., Silva, J.O., Espírito-Santo, M.M., Fernandes, G.W. 2014. Insect herbivores and leaf damage along successional and vertical gradients in a tropical dry forest. Biotropica 46, 14-24.

Novotny, V., Basset, Y., Auga, J., Boen, W., Dal, C., Drozd, P., Manumbor, M. 1999. Predation risk for herbivorous insects on tropical vegetation: a search for enemy-free space and time. Australian Journal of Ecology 24, 477483.

Novotny, V., Miller, S. E., Hulcr, J., Drew, R. A., Basset, Y., Janda, M., Isua, B. 2007. Low beta diversity of herbivorous insects in tropical forests. Nature 448, 692-695.

O'Dowd, D. J., Catchpole, E. A. 1983. Ants and extrafloral nectaries: no evidence for plant protection in Helichrysum spp. - ant interactions. Oecologia 59, 191-200.

Oguro, M., Sakai, S. 2009. Floral herbivory at different stages of flower development changes reproduction in Iris gracilipes (Iridaceae). Plant Ecology 202, 221-234.

Oguro, M., Sakai, S. 2014. Difference in defense strategy in flower heads and leaves of Asteraceae: multiple-species approach. Oecologia 174, 227-239.

Ohgushi, T. 2005. Indirect interaction webs: herbivore-induced effects through trait change in plants. Annual Review of Ecology, Evolution, and Systematics. 36, 81-105.

Oliveira, C. M., \& Frizzas, M. R. 2008. Insetos de Cerrado: distribuição estacional e abundância.1 ed. Embrapa Cerrados, Planaltina.

Oliveira, F.P.M., Absy, M.L., Miranda, I.S. 2009. Recurso polínico coletado por abelhas sem ferrão (Apidae, Meliponinae) em um fragmento de floresta na região de Manaus-Amazonas. Acta Amazonica 39, 505-518.

Oliveira, K.N., Espírito-Santo, M.M., Silva, J.O., Melo, G.A. 2012. Ontogenetic and temporal variations in herbivory and defense of Handroanthus spongiosus (Bignoniaceae) in a Brazilian tropical dry forest. Environmental Entomology 41, 541-550.

Oliveira, M.P.M.D , Santos, C.I.R., AlmeidaCortez, J. S . 2011. Herbivory rate on woody species of the caatinga and NDVI as indicators of plant stress. Revista Brasileira de Geografia Física 04, 909-921.

Oliveira, P., Gibbs, P. 1994. Pollination biology and breeding systems of six Vochysia species
(Vochysiaceae) in Central Brazil. Journal of Tropical Ecology 10, 509-522.

Oliveira, P.E., Gibbs, P.E. 2000. Reproductive biology of woody plants in a cerrado community of Central Brazil. Flora 195, 311329.

Oliveira, P.S., Pie, M.R. 1998. Interaction between ants and plants bearing extrafloral nectaries in cerrado vegetation. Anais da Sociedade Entomológica do Brasil 27, 161-176.

Opler, P.A., Frankie, G.W., Baker, H.G. 1976. Rainfallas afactor in the release, timing, andsynchronization of anthesis by tropical trees and shrubs. Journal of Biogeography 3, 231-236

Paine, R.T. 1980. Food webs: linkage, interaction strength and community infrastructure. Journal of animal ecology 49, 667-685.

Paz, J.R.L.D., Silva, W.P., Pigozzo, C.M. 2016. Vespas aculeata e abelhas visitantes de nectários extraflorais em Ipomoea carnea subsp. fistulosa no semiárido baiano, Nordeste do Brasil. Boletim do Museu de Biologia Mello Leitão 38, 113-132.

Peeters, P.J.2002. Correlations between leaf structural traits and the densities of herbivorous insects guilds. Biological Journal of the Linnean Society 77, 43-65.

Pennington, R. T., Ratter, J. A., Lewis, G.P. 2006. An overview of the plant diversity, biogeography and conservation of neotropical savannas and seasonally dry forests. In R.T. Pennington, G.P. Lewis J.A. Ratter (eds). Neotropical savannas and seasonally dry forests: plant diversity, biogeography and conservation. pp. 1-29. CRC Press, Florida

Pennington, R. T., Lavin, M., Oliveira-Filho, A. 2009. Woody plant diversity, evolution, and ecology in the tropics: perspectives from seasonally dry tropical forests. Annual Review of Ecology, Evolution, and Systematics, 40, 437-457.

Pereira, C.A., Fiedler, N.C., Medeiros, M.B. 2004. Análise de ações de prevenção e combate aos incêndios florestais em unidades de conservação do cerrado. Floresta 34, 95-100.

Pezzini, F.F., Brandão, D., Ranieri, B.D., EspíritoSanto, M.M., Jacobi, C.M., Fernandes, G.W. 2008. Polinização, dispersão de sementes e fenologia de espécies arbóreas no Parque Estadual da Mata Seca. MG Biota 1, 37-45.

Pezzini, F.F., Ranieri, B.D., Brandão, D.O., Fernandes, G.W., Quesada, M., Espírito-Santo, M.M., Jacobi, C.M. 2014. Changes in tree phenology along natural regeneration in a seasonally dry tropical forest. Plant 
Biosystems-An International Journal Dealing with all Aspects of Plant Biology,148, 965-974.

Pichersky, E., Noel, J. P., Dudareva, N. 2006. Biosynthesis of plant volatiles: nature's diversity and ingenuity. Science, 311, 808-811.

Pimentel, R.R., Machado, S.R., Rocha, J.F. 2011. Estruturas secretoras de Pavonia alnifolia (Malvaceae), uma espécie ameaçada de extinção. Rodriguésia 62, 253-262.

Pinheiro, F., Diniz, I. R., Coelho, D., Bandeira, M. P. S. 2002. Seasonal pattern of insect abundance in the Brazilian cerrado. Austral Ecology 27, 132-136.

Pirani, F.R., Pedroni, F. 2009. Fenologia de uma comunidade arbórea em cerrado sentido restrito, Barra do Garças, MT, Brasil. Acta Botanica Brasilica 23, 1096-1110.

Pleasants, J.M., Chaplin, S.J. 1983. Nectar production rates of Asclepias quadrifolia: causes and consequences of individual variation. Oecologia 59, 232-238.

Polis, G.A., Sears, A.L., Huxel, G.R., Strong, D.R., Maron, J. 2000. When is a trophic cascade a trophic cascade? Trends in Ecology \& Evolution, 15, 473-475.

Poorter, L., Van de Plassche, M., Willems, S., \& Boot, R. G. A. (2004). Leaf traits and herbivory rates of tropical tree species differing in successional status. Plant Biology, 6(06), 746754.

Poorter, L.R., Danaë M.A. Bongers, F., AlmeidaCortez, J.S., Almeyda, Z., Angélica, M.Á., Francisco S. A., Villa, J.L., Balvanera, L.F.A., Becknell, P., Justin, M.B., Tony, V. B., Radika, B., Brancalion, V., Broadbent, P.H.S., Eben, N.C., Chave, R.G., Chazdon, J., Robin, L.C., Craven, G.D., De Jong, D., Denslow, B.H.J., Dent, J.S., Dewalt, D.H., García, S.J., Díaz, H. 2019. Wet and dry tropical forests show opposite successional pathways in wood density but converge over time. Nature Ecology \& Evolution v, 1-7.

Prado, D.E. 2003. As caatingas da América do Sul. Ecologia e conservação da Caatinga 2, 3-74.

Prado, D.E., Gibbs, P.E. 1993. Patterns of species distributions in the dry seasonal forests of South America. Annals of the Missouri Botanical Garden 80, 902-927.

Price, A., Maher, W., Kirby, J., Krikowa, F., Duncan, E., Taylor, A., Potts, J. 2012. Distribution of arsenic species in an open seagrass ecosystem: relationship to trophic groups, habitats and feeding zones. Environmental Chemistry 9, 77-88.
Price, P.W. 1991. The plant vigor hypothesis and herbivore attack. Oikos, 244-251.

Price, P.W. 1992. The resource-based organization of communities. Biotropica, 273-282.

Price, P.W. 2002. Resource-driven terrestrial interaction webs. Ecological Research 17, 241247.

Pringle, E. G., Adams, R. I., Broadbent, E., Busby, P. E., Donatti, C. I., Kurten, E. L., Katherine, R., Dirzo, R. 2011. Distinct leaf-trait syndromes of evergreen and deciduous trees in a seasonally dry tropical forest. Biotropica 43, 299-308.

Pringle, J., Drummond, J., McLafferty, E., \& Hendry, C. 2011. Interpretative phenomenological analysis: a discussion and critique. Nurse researcher, 18(3).

Putman, R.J. 1994. Community ecology. Chapman \& Hall, London

Queiroz, L.P. 2006. The Brazilian Caatinga: phytogeographical patterns inferred from distribution data of the Leguminosae. In: Pennington, T., Lewis, G.P., Ratter, J.A. (Eds.), Neotropical Savannas and Seasonally Dry Forests. CRC Press. London, pp. 121-157.

Quesada, M., Bollman, K., Stephenson, A. G. 1995. Leaf damage decreases pollen production and hinders pollen performance in Cucurbita texana. Ecology 76, 437-443.

Quesada, M., Rosas, F., Aguilar, L., Ashworth, L., Rosas-Guerreiro, V.M., Sayago, R., Lobo, J.A., Herrerías-Diego, Y., Sánches-Montoya, G. 2011. Human impacts on pollination, reproduction and breeding systems in tropical forest plants". In: Dirzo, R., Young, H. S., Mooney, H. A., Ceballos, G. (eds.), Seasonally dry tropical forests: Ecology and conservation, Island Press, London, pp. 173-194.

Quesada, M., Sanchez-Azofeifa, G.A., AlvarezAnorve, M., Stoner, K. E., Avila-Cabadilla, L., Calvo-Alvarado, J., Gamon, J. 2009. Succession and management of tropical dry forests in the Americas: Review and new perspectives. Forest Ecology and Management 258, 1014-1024.

Quijano-Medina, T., Covelo, F., Moreira, X., Abdala-Roberts, L. 2019. Compensation to simulated insect leaf herbivory in wild cotton (Gossypium hirsutum): responses to multiple levels of damage and associated traits. Plant Biology 21, 805-812.

Rafael, J.A., Aguiar, A.P., Amorim, D.D.S. 2009. Knowledge of insect diversity in Brazil: challenges and advances. Neotropical Entomology 38, 565-570. 
Ramula, S., Paige, K.N., Lennartsson, T., Tuomi, J. 2019. Overcompensation: a 30-year perspective. Ecology 100, e02667.

Rashbrook, V.K., Compton, S.G., Lawton, J.H. 1992. Ant-herbivore interactions: reasons for the absence of benefits to a fern with foliar nectaries. Ecology 73, 2167.

Rasmann, S., Chassin, E., Bilat, J., Glauser, G., Reymond, P. 2015. Trade-off between constitutive and inducible resistance against herbivores is only partially explained by gene expression and glucosinolate production. Journal of Experimental Botany 66, 2527-2534.

Rathcke, B., Lacey, E.P. 1985. Phenological patterns of terrestrial plants. Annual review of ecology and systematics 16, 179-214.

Ratter, J.A., Ribeiro, J.F. Bridgewater, S. 1997. The brazilian cerrado vegetation and threats to its biodiversity. Annals of Botany 80, 223-230.

Reddy, S.J., 1983. Climatic classification: the semi-arid tropics and its environment - a review. Pesquisa Agropecuária Brasileira 18, 23-847.

Ribeiro, S. P., Brown, V.K. 1999. Insect herbivory in tree crowns of Tabebuia aurea and $T$. ochracea (Bignoniaceae) in Brazil: contrasting the cerrado with the Pantanal Matogrossense. Selbyana, 159-170.

Ribeiro, S.P., Carneiro, M.A., Fernandes, G.W. 1998. Free-feeding insect herbivores along environmental gradients in Serra do Cipó: basis for a management plan. Journal of Insect Conservation 2, 107-118.

Ribeiro, S.P., Fernandes, G.W. 2000. Interações entre insetos e plantas no cerrado: teoria e hipóteses de trabalho.pp 299-320. In Martins, R.P., Lewinsohn, T.M., Barbeitos, M.S. (eds). Ecologia e comportamento de Insetos. Série Oecologia Brasiliensis 8. PPGE-UFRJ, Rio de Janeiro

Ribeiro, S.P., Pimenta, H.R., Fernandes, G.W. 1994. Herbivory by chewing and sucking insects on Tabebuia ochracea. Biotropica, 302307.

Ribeiro, V.A., Silva, R.N.D., Sousa-Souto, L., Neves, F.D.S. 2013. Fluctuating asymmetry of and herbivory on Poincianella pyramidalis (Tul.) LP Queiroz (Fabaceae) in pasture and secondary tropical dry forest. Acta Botanica Brasilica 27, 21-25.

Rico-Gray, V., Oliveira, P. S., Oliveira, P. S. 2007. The ecology and evolution of ant-plant interactions. University of Chicago Press.

Rodrigues, A. L., Watzlawick, L. F., Genú, A. M., Hess, A. F., Ebling, Â. A. 2016. Atributos de um solo florestal em uma topossequência e relações com a comunidade arbórea. Floresta 46, 145-154.

Rodríguez-Riaño, T., Pérez-Bote, J.L., López, J., Mayo, C., Valtueña, F.J., González, M., OrtegaOlivencia, A. 2019. Effects of different abiotic and biotic factors on spatial primary seed dispersal in the semachorous species Scrophularia canina. Plant Species Biology 34, 152-165.

Romero, G. Q., Vasconcellos-Neto, J. 2007. Aranhas sobre plantas: dos comportamentos de forrageamento às associações específicas. Ecologia e comportamento de aranhas, 1, 67-87.

Romero, G. Q., Vasconcelos Neto, J. 2005. Flowering phenology, seed set and arthropod guilds in Trichogoniopsis adenantha (DC)(Asteraceae) in south-east Brazil. Brazilian Journal of Botany 28, 171-178.

Romero, G.Q., Vasconcelos-Neto, J. 2004. Benefical effects of flower-dwelling predators on their host plant. Ecology 85, 446-457.

Roubik, D.W. 1979. Nest and colony characteristics of stingless bees from French Guiana (Hymenoptera: Apidae). Journal of the Kansas entomological Society 52, 443-470.

Roubik, D.W. 1993. Tropical pollinators in the canopy and understory: field data and theory for stratum preferences. Journal of Insect Behavior 6, 659-673.

Ruhren, S., Handel, S.N. 1999. Jumping spiders (Salticidae) enhance the seed production of a plant with extrafloral nectaries. Oecologia 119, 227-230.

Salinas-Esquivel, L.A., Lara, C., Arizmendi, M.D.C. 2018. Evaluation of the symmetric effect of antagonists in the floral morphs of the distylic shrub Bouvardia ternifolia: a field study. Botanical Sciences 96, 1-10.

Sampaio, E., 1995. Overview of the Brazilian caatinga. In Bullock, S.H., Mooney, H.A., Medina, E. (Eds.), Seasonally dry tropical forests. Cambridge: Cambridge University Press. Pp. 35-63.

Sánchez-Azofeifa, A., Powers, S.J., Fernandez, G.W., Quesada, M. 2014. Tropical dry forests in the Americas: Ecology, conservation, and management. CRC Press, Taylor \& Francis Group, Boca Raton.

Sánchez-Azofeifa, G.A., Portillo-Quintero, C.A. 2010. Extent and conservation of tropical dry forests in the America. Biology Conservation 143, 144-155.

Sánchez-Azofeifa, G.A., Quesada, M., Rodríguez, J.P., Nassar, J.M., Stoner, K.E., Castillo, A., Fajardo, L. 2005. Research priorities for 
Neotropical dry forests. Biotropica: The Journal of Biology and Conservation, 37, 477-485.

Santos, A.M., Jacobi, C.M., Silveira, F.A. 2017. Frugivory and seed dispersal effectiveness in two Miconia (Melastomataceae) species from ferruginous campo rupestre. Seed Science Research 27, 65-73.

Santos, J. C., Almeida-Cortez, J.S.D., Fernandes, G.W. 2011. Richness of gall-inducing insects in the tropical dry forest (caatinga) of Pernambuco. Revista Brasileira de Entomologia 55, 45-54.

Santos, J.C., Almeida-Cortez, J.S., Fernandes, G.W. 2011. Richness of gall-inducing insects in the tropical dry forest (caatinga) of Pernambuco. Revista Brasileira de Entomologia 55, 45-54.

Santos, J.C., Del-Claro, K. 2001. Interação entre formigas, herbívoros e nectários extraflorais em Tocoyena formosa (Cham. \& Schlechtd.) K. Schum (Rubiaceae) na vegetação do cerrado. Revista Brasileira de Zoociências 3(1).

Santos, M.G., Oliveira, M.T., Figueiredo, K.V., Falcão, H.M. , Arruda, E.C.P., Almeida-Cortez, J.S., Sampaio, E.V.S.B., Ometto, J.P.H.B., Menezes, R.S.C., Oliveira, A.F.M., Pompelli, M.F., Antonino, A.C.D. 2014. Caatinga, the Brazilian dry tropical forest: can it tolerate climate changes? Theoretical and Experimental Plant Physiology 26, 83-99.

Santos, M.R.A., Lima, R.A., Silva, A.G., Lima, D.K.S., Sallet, L.A.P., Teixeira, C.A.D., Facundo, V.A. 2013. Composição química e atividade inseticida do óleo essencial de Schinus terebinthifolius Raddi (Anacardiaceae) sobre a broca-do-café (Hypothenemus hampei) Ferrari. Revista Brasileira de Plantas Medicinais 15, 757-762.

Sasse, J., Schlegel, M., Borghi, L., Ullrich, F., Lee, M., Liu, G. W., Kretzschmar, T. 2016. Petunia hybrida PDR2 is involved in herbivore defense by controlling steroidal contents in trichomes. Plant, Cell \& Environment 39, 2725-2739.

Schaffner, U., Ridenour, W. M., Wolf, V. C., Bassett, T., Müller, C., Müller-Schärer, H., Callaway, R.M. 2011. Plant invasions, generalist herbivores, and novel defense weapons. Ecology 92, 829-835.

Schemske, D.W. 1980. Evolution of floral display in the orchid Brassavola nodosa. Evolution 34, 489-493.

Schiestl, F.P. 2014. Correlation analyses between volatiles and glucosinolates show no evidence for chemical defense signaling in Brassica rapa. Frontiers in Ecology and Evolution 2, 1-10.
Schiestl, F.P. 2015. Ecology and evolution of floral volatile-mediated information transfer in plants. New Phytologist 206, 571-577.

Schlindwein, C., Westerkamp, C., Carvalho, A.T., Milet-Pinheiro, P. 2014. Visual signalling of nectar-offering flowers and specific morphological traits favour robust bee pollinators in the mass-flowering tree (Bignoniaceae). Botanical Journal of the Linnean Society 176, 396-407.

Schmitz, O. J., Hambäck, P. A., Beckerman, A. P. 2000. Trophic cascades in terrestrial systems: a review of the effects of carnivore removals on plants. The American Naturalist 155, 141-153.

Schmitz, O.J., Beckerman, A.P., O’Brien, K.M. 1997. Behaviorally mediated trophic cascades: effects of predation risk on food web interactions. Ecology 78, 1388-1399.

Schulz, K., Guschal, M., Kowarik, I., AlmeidaCortez, J.S., Sampaio, E.V.S.B., Cierjacks, A. 2019. Grazing reduces plant species diversity of Caatinga dry forests in north-eastern Brazil. Applied Vegetation Science 22, 1-12.

Schulz, K., Guschal, M., Kowarik, I., AlmeidaCortez, J.S., Sampaio, E.V.S.B., Cierjacks, A. 2018. Grazing, forest density, and carbon storage: towards a more sustainable land use in Caatinga dry forests of Brazil. Regional Environmental Change 18, 1-13.

Sena, F. H., Lustosa, B. M., Almeida-Cortez, J. S. 2017. Ecofisiologia da germinação de sementes de Anadenanthera colubrina (Vell.) Brenan (Fabaceae). Gaia Scientia 11,1-8.

Sevegnani, L. 2007. A herbivoria como limitador do desenvolvimento e sobrevivência das plantas na floresta. In: Rego, G. M., Negrelle, R. R. B., Morellato, L. P. C. (Eds.), Fenologia: ferramenta para conservação, melhoramento e manejo de recursos vegetais arbóreos. Colombo, Embrapa Florestas, pp. 25-36.

Shi, T., Yue, Y., Shi, M., Chen, M., Yang, X., \& Wang, L. (2019). Exploration of Floral Volatile Organic Compounds in Six Typical Lycoris taxa by GC-MS. Plants, 8(10), 422.

Shipley, B., Vile, D., Garnier, É. 2006. From plant traits to plant communities: a statistical mechanistic approach to biodiversity. Science $314,812-814$.

Siegmund-Schultze, M., Sobral, M. C., Alcoforado, M., Márcia, M.G., AlmeidaCortez, J.S., Azevedo, J.R.G., Candeias, A.L., Cierjacks, A., Gomes, E.T.A., Gunkel, G., Hartje, V., Hattermann, F.F., Kaupenjohann, M., Koch, H., Köppel, J. 2018. The legacy of 
large dams and their effects on the water-land nexus. Regional Environmental Change 1, 1-6.

Silva, A.E., Del-Claro, K. 2014. Fire triggers the activity of extrafloral nectaries, but ants fail to protect the plant against herbivores in a neotropical savanna. Arthropod-Plant Interactions 8, 233-240.

Silva, B.L.R., Tavares, F.M., Almeida-Cortez, Jarcilene S. 2012. Composição florística do componente herbáceo de uma área de caatinga Fazenda Tamanduá, Paraíba, Brasil. Revista De Geografia 29, 54-64.

Silva, F.O.D.R., Ramos, J.D., Oliveira, M.C., Rufini, J. C. M., Siqueira Ramos, P. 2015. Fenologia reprodutiva e caracterização físicoquímica de abacateiros em Carmo da Cachoeira, Minas Gerais. Ceres 61, 105-111

Silva, J.L.S.E., Cruz-Neto, O., Peres, C.A., Tabarelli, M., \& Lopes, A.V. 2019. Climate change will reduce suitable Caatinga dry forest habitat for endemic plants with disproportionate impacts on specialized reproductive strategies. PloS One, 14(5), e0217028-e0217028.

Silva, J.O., Espírito-Santo, M.M., Leal, C.R.O. 2017. Seasonal and diel variations in the activity of canopy insect herbivores differ between deciduous and evergreen plant species in a tropical dry forest. Journal of Insect Conservation 21, 667-676.

Silva, J.O., Jesus, F.M., Fagundes, M., Fernandes, G.W. 2009. Esclerofilia, taninos e insetos herbívoros associados a Copaifera lagsdorffii Desf. (Fabaceae: Caesalpinioideae) em área de transição Cerrado-Caatinga no Brasil. Ecología Austral 19, 197-206.

Silva, J.O., Neves, F.S. 2014. Insect herbivores associated with an evergreen tree Goniorrhachis marginata Taub. (Leguminosae: Caesalpinioideae) in a tropical dry forest. Brazilian Journal of Biology 74, 623-631.

Silva, M.H.M., Costa Filho, L.O., Oliveira, A.F.M., Almeida-Cortez, J.S. 2018. Relação entre a composição química de cera epicuticular foliar e a interação com insetos galhadores em espécies de Croton L. (Euphorbiaceae). Journal of Environmental Analysis and Progress 3, 287 295.

Silva, M.H.M., Costa Filho, L.O., Oliveira, A.F.M., Almeida-Cortez, J.S. 2018. Relação entre a composição química de cera epicuticular foliar e a interação com insetos galhadores em espécies de Croton L. (Euphorbiaceae). Journal of Environmental Analysis and Progress 3, 287 295.
Silva, S.J.A. 2009. Padrão de distribuição e estrutura diamétrica de Croton sonderianus Muell. Arg. (Marmeleiro) na caatinga da Estação Ecológica do Seridó. Revista Verde de Agroecologia e Desenvolvimento Sustentável 4, 85-90.

Silveira, F.A., Melo, G.A., Almeida, E.A. 2002. Abelhas brasileiras. Sistemática e Identificação. Fundação Araucária, Belo Horizonte.

Simpson, B.B., Neff, J.L. 1987. Pollination ecology in the Southwest. Aliso: A Journal of Systematic and Evolutionary Botany 11, 417440.

Smilanich, A.M., Fincher, R.M., Dyer, L.A. 2016. Does plant apparency matter? Thirty years of data provide limited support but reveal clear patterns of the effects of plant chemistry on herbivores. New Phytologist 210, 1044-1057.

Soler, R., Harvey, J.A., Kamp, A.F., Vet, L.E., Van der Putten, W.H., Van Dam, N.M., Martijn Bezemer, T. 2007. Root herbivores influence the behaviour of an aboveground parasitoid through changes in plant-volatile signals. Oikos 116, 367-376.

Soper Gorden, N.L., Adler, L.S. 2016. Florivory shapes both leaf and floral interactions. Ecosphere 7, e01326.

Sousa-Souto, L., Santos, E.D.S., Figueiredo, P.M.F.G., Santos, A.J., Neves, F.S. 2014. Is there a bottom-up cascade on the assemblages of trees, arboreal insects and spiders in a semiarid Caatinga? Arthropod-Plant Interactions 8, 581-591.

Southwell, I.A., Bourke, C.A. 2001. Seasonal variation in hypericin content of Hypericum perforatum L. (St. John's wort). Phytochemistry 56, 437-441.

Souza, B.F.G., Carvalho, M.E.K., Peche Filho, A., Machado, F.H., Carlos, V.M., Pompêo, M., Medeiros, G.A. 2015. Uso do índice de estado trófico e análise rápida da comunidade de macroinvertebrados como indicadores da qualidade ambiental das águas na Bacia do Rio Jundiaí-Mirim-SP-BR. Brazilian Journal of Aquatic Science and Technology 19, 13-22.

Souza, B.I.D., Artigas, R.C., Lima, E.R.V.D. 2015. Caatinga e desertificação. Mercator (Fortaleza) 14, 131-150.

Spichiger, R., Calenge, C., Bise, B. 2004. Geographical zonation in the Neotropics of tree species characteristic of the Paraguay-Paraná Basin. Journal of Biogeography 31, 1489-1501.

Stamp, N. 2003. Out of the quagmire of plant defense hypotheses. The Quarterly Review of Biology 78, 23-55. 
Stanton, M.L. 1979. The role of chemotactile stimuli in the oviposition preferences of Colias butterflies. Oecologia, 39, 79-91.

Stebbins, G.L. 1970. Adaptive radiation of reproductive characteristics in angiosperms, I: pollination mechanisms. Annual Review of Ecology and Systematics 1, 307-326.

Stebbins, G.L. 1980. Rarity of plant species: a synthetic viewpoint. Rhodora 82, 77-86.

Stiling, P., Moon, D.C. 2005. Quality or quantity: the direct and indirect effects of host plants on herbivores and their natural enemies. Oecologia 142, 413-420.

Stoks, R., McPeek, M.A. 2003. Antipredator behavior and physiology determine Lestes species turnover along the pond-permanence gradient. Ecology 84, 3327-3338.

Strauss, S. Y., Irwin, R. E., Lambrix, V. M. 2004. Optimal defence theory and flower petal colour predict variation in the secondary chemistry of wild radish. Journal of Ecology 92, 132-141.

Strauss, S.Y. 1997. Floral characters link herbivores, pollinators, and plant fitness. Ecology 78, 1640-1645.

Strauss, S.Y., Conner, J.K., Rush, S.L. 1996. Foliar herbivory affects floral characters and plant attractiveness to pollinators: implications for male and female plant fitness. The American Naturalist 147, 1098-1107.

Strong, D.R. 1992. Are trophic cascades all wet? differentiation and donor-control in speciose ecosystems. Ecology 73, 747-754.

Strong, D.R., Larsson, S., Gullberg, U. 1993. Heritability of host plant resistance to herbivory changes with gallmidge density during an outbreak on willow. Evolution 47, 291-300.

Sunell, L.A., Healey, P. L. 1985. Distribution of calcium oxalate crystal idioblasts in leaves of taro (Colocasia esculenta). American Journal of Botany 72, 1854-1860.

Sunell, L.A., Healey, P.L. 1979. Distribution of calcium oxalate crystal idioblasts in corms of taro (Colocasia esculenta). American Journal of Botany 66, 1029-1032.

Suttle, K.B. 2003. Pollinators as mediators of topdown effects on plants. Ecology Letters 6, 688694.

Tannus, J.L., Assis, M.A., Morellato, L.P.C. 2006. Fenologia reprodutiva em campo sujo e campo úmido numa área de cerrado no sudeste do Brasil, Itirapina-SP. Biota Neotropica 6, 0-0.

Tavares, F.M., Schulz, K., Pereira, R. C. A. Cierjacks, A., Almeida-Cortez, J. S. 2016. Floristic survey of the caatinga in areas with different grazing intensities, Pernambuco,
Northeast Brazil. Journal of Environmental Analysis and Progress 1, 43-51.

Taylor, R.M., Pfannenstiel, R.S. 2008. Nectar feeding by wandering spiders on cotton plants. Environmental Entomology 37, 996-1002.

Terborgh, J.W. 2015. Toward a trophic theory of species diversity. Proceedings of the National Academy of Sciences 112, 11415-11422.

Theis, N., Kesler, K., Adler, L.S. 2009. Leaf herbivory increases floral fragrance in male but not female Cucurbita pepo subsp. texana (Cucurbitaceae) flowers. American journal of botany 96, 897-903.

Thompson J.N. 1997 Conserving Interaction Biodiversity. In: Pickett S.T.A., Ostfeld R.S., Shachak M., Likens G.E. (eds), The Ecological Basis of Conservation. Springer, Boston, pp. 285-293.

Thompson, J.N. 1999. The evolution of species interactions. Science 284, 2116-2118.

Thompson, K., Askew, A.P., Grime, J.P., Dunnett, N.P., Willis, A.J. 2005. Biodiversity, ecosystem function and plant traits in mature and immature plant communities. Functional Ecology 19, 355-358.

Throop, H.L., Lerdau, M.T. 2004. Effects of nitrogen deposition on insect herbivory: implications for community and ecosystem processes. Ecosystems 7, 109-133.

Toby Pennington, R., Prado, D.E., Pendry, C.A. 2000. Neotropical seasonally dry forests and Quaternary vegetation changes. Journal of Biogeography 27, 261-273.

Torezan-Silingardi, H.M., Oliveira, P.E.A.M. 2004. Phenology and reproductive ecology of Myrcia rostrata and M. tomentosa (Myrtaceae) in Central Brazil. Phyton, 44, 23-43.

Trovão, D.M.D., Fernandes, P.D., Andrade, L.A.D., Dantas Neto, J. 2007. Variações sazonais de aspectos fisiológicos de espécies da Caatinga. Revista Brasileira de Engenharia Agrícola e Ambiental 11, 307-311.

Turchetto-Zolet, A.C., Pinheiro, F., Salgueiro, F., Palma-Silva, C. 2013. Phylogeographical patterns shed light on evolutionary process in S outh A merica. Molecular Ecology 22, 11931213.

Tylianakis, J.M., Morris, R.J. 2017. Ecological networks across environmental gradients. Annual Review of Ecology, Evolution, and Systematics 48, 25-48.

Van Schaik, C. P., Terborgh, J. W., Wright, S. J. 1993. The phenology of tropical forests: adaptive significance and consequences for 
primary consumers. Annual Review of Ecology and Systematics 24, 353-377.

Velloso, A. L. 2002. Ecorregioes propostos para o bioma da caatinga. Instituto de Conservacao Ambiental The Nature Conservancy do Brasil, Recife, associação Plantas do Nordeste.

Vico, G., Thompson, S.E., Manzoni, S., Molini, A., Albertson, J.D., Almeida-Cortez, J.S., Fay, P.A., Feng, X., Guswa, A.J., Liu, H., Wilson, T.G., Porporato, A. 2015. Climatic, ecophysiological and phenological controls on plant ecohydrological strategies in seasonally dry ecosystems. Ecohydrology 8(4) 660-681,

Vilhena-Potiguara, R. C., Aguiar-Dias, A. C. A. D., Kikuchi, T. Y. S., Santos, A. C. F. D., Silva, R. J. F. 2012. Estruturas secretoras em cipó-d'alho (Mansoa standleyi (Steyerm.) AH Gentry, Bignoniaceae): ocorrência e morfologia. Acta Amazonica, 42, 321-328.

Vogel, S. 1974. Ölblumen und Ölsammelnde Bienen. Tropische und Subtropische Pflanzenwelt 7, 285-547.

Volf, M, Pyszko, P., Abe, T., Libra, M, Kotaskov, N, Sigut, M., Kumar, R, Kaman, O., Butterill, P.T., Sipo, J., Abe, H., Fukushima, H, Drozd, P, Kamata, N., Murakami, M., Novotny. V. 2017. Phylogenetic composition of host plant communities drives plant-herbivore food web structure.Journal of Animal Ecology, 86(3), 556-565.

Wäckers, F. L. 2005. Suitability of (extra-) floral nectar, pollen, and honeydew as insect food sources. Plant-provided food for carnivorous insects: A protective mutualism and its applications, 17-74.

Wagner, D., Kay, A. 2002. Do extrafloral nectaries distract ants from visiting flowers? An experimental test of an overlooked hypothesis. Evolutionary Ecology Research 4, 293-305.

Wardhaugh, C.W. 2014. The spatial and temporal distributions of arthropods in forest canopies: uniting disparate patterns with hypotheses for specialisation. Biological Reviews 89, 10211041.

Weis, A. E., Berenbaum, M. R. (1989). Herbivorous insects and green plants. Plantanimal interactions, 123-162.

Werner, E.E., Peacor, S.D. 2003. A review of traitmediated indirect interactions in ecological communities. Ecology 84, 1083-1100.

West, N. M., Louda, S. M. 2018. Cumulative herbivory outpaces compensation for early floral damage on a monocarpic perennial thistle. Oecologia 186, 495-506.
White T.C.R. 1969. An index to measure weatherinduced stress of trees associated with outbreaks of psyllids in Australia. Ecology 50, 905-909

White, T.C.R. 1984. The abundance of invertebrate herbivores in relation to the availability of nitrogen in stressed food plants. Oecologia 63, 90-105.

Williams, K.S. 1983. The coevolution of Euphydryas chalcedona butterflies and their larval host plants. Oecologia 56, 336-340

Wnson, S.B., Williams, H.J., Frankie, G.W., Shrum, G. 1997. Floral lipid chemistry of Byrsonima crassifolia (Malpigheaceae) and a use of floral lipids by Centris bees (Hymenoptera: Apidae). Biotropica 29, 76-83.

Wolda, H. 1988. Insect seasonality: why? Annual review of ecology and systematics 19, 1-18.

Wolfe, L.M. 2002. Why alien invaders succeed: support for the escape-from-enemy hypothesis. The American Naturalist 160, 705-711.

Wootton, J. T. 1994. The nature and consequences of indirect effects in ecological communities. Annual review of ecology and systematics 25, 443-466.

Wright, G. A. et al. Intensity and the ratios of compounds in the scent of snapdragon flowers affect scent discrimination by honeybees (Apis mellifera). Journal of Comparative Physiology A, v. 191, n. 2, p. 105-114, 2005.

Wright, I.J., Cannon, K. 2001. Relationships between leaf lifespan and structural defences in a low-nutrient, sclerophyll flora. Functional ecology 15, 351-359.

Wright, J.T., De Nys, R., Poore, A.G.B., Steinberg, P.D. 2004. Chemical defense in a marine alga: heritability and the potential for selection by herbivores. Ecology 85, 2946-2959.

Wright, S.J., Calderón, O., Muller-Landau, H.C. 2019. A phenology model for tropical species that flower multiple times each year. Ecological Research 34, 20-29.

Ye, Z.M., Jin, X.F., Wang, Q.F., Yang, C.F., Inouye, D.W. 2017. Pollinators shift to nectar robbers when florivory occurs, with effects on reproductive success in Iris bulleyana (Iridaceae). Plant Biology 19, 760-766.

Yves, B., Lukas, C., Philippe, C., Raphael, K., Didham, F. G., Olivier, M., Vojtech, N., Frode, O., Tomas, R., Jürgen, S., Alexey, K.T., Neville, N. W., David, W.R., Henri-Pierre, A., Johannes, B., Héctor, B., Jon, R. B., CastañoMeneses, G., Bruno, C., Gianfranco, C., Wesley, D.R., Domir, B., Jacques, H.C.D., Alain, D., Laura, L.F., Andreas, F., Roger, L.K., 
Medianero, E., Scott, E.M., Evandro, G.O., Jérôme, O., Marc, P., Mathieu, R., Sérvio, P.R., Yves, R., Schmidt,J.B., Sorensen, L., Leponce, M. 2012. Arthropod diversity in a tropical forest. Science, 338, 1481-1484.

Zanella, F.C. 2000. The bees of the Caatinga (Hymenoptera, Apoidea, Apiformes): a species list and comparative notes regarding their distribution. Apidologie 31, 579-592.

Zanella, F.C.V., Martins, C.F. 2003. Abelhas da Caatinga: biogeografia, ecologia e conservação.
Ecologia e conservação da Caatinga, 75-134.

Zappi, D.C., Filardi, F.L.R., Leitman, P., Souza, V.C., Walter, B. M., Pirani, J.R., Forzza, R.C. 2015. Growing knowledge: an overview of seed plant diversity in Brazil. Rodriguésia 66, 10851113.

Zvereva, E.L., Kozlov, M.V. 2001. Effects of pollution-induced habitat disturbance on the response of willows to simulated herbivory. Journal of Ecology 89, 21-30. 